\title{
A CHEMICAL KINETICS NETWORK FOR LIGHTNING AND LIFE IN PLANETARY ATMOSPHERES
}

\author{
P. B. Rimmer and Ch Helling \\ School of Physics and Astronomy, University of St Andrews, St Andrews, KY16 9SS, UK; pr33@st-andrews.ac.uk \\ Received 2015 June 3; accepted 2015 October 22; published 2016 May 23
}

\begin{abstract}
There are many open questions about prebiotic chemistry in both planetary and exoplanetary environments. The increasing number of known exoplanets and other ultra-cool, substellar objects has propelled the desire to detect life and prebiotic chemistry outside the solar system. We present an ion-neutral chemical network constructed from scratch, STAND2015, that treats hydrogen, nitrogen, carbon, and oxygen chemistry accurately within a temperature range between 100 and 30,000 K. Formation pathways for glycine and other organic molecules are included. The network is complete up to H6C2N2O3. STAND2015 is successfully tested against atmospheric chemistry models for HD 209458b, Jupiter, and the present-day Earth using a simple onedimensional photochemistry/diffusion code. Our results for the early Earth agree with those of Kasting for $\mathrm{CO}_{2}, \mathrm{H}_{2}, \mathrm{CO}$, and $\mathrm{O}_{2}$, but do not agree for water and atomic oxygen. We use the network to simulate an experiment where varied chemical initial conditions are irradiated by UV light. The result from our simulation is that more glycine is produced when more ammonia and methane is present. Very little glycine is produced in the absence of any molecular nitrogen and oxygen. This suggests that the production of glycine is inhibited if a gas is too strongly reducing. Possible applications and limitations of the chemical kinetics network are also discussed.
\end{abstract}

Key words: astrobiology - atmospheric effects - molecular processes - planetary systems

Supporting material: machine-readable tables

\section{INTRODUCTION}

The potential connection between a focused source of energy and life was first made apparent in the Miller-Urey experiment (Miller 1953), set to test a hypothesis proposed by Haldane (1928). In this experiment, a gas composed of water vapor, ammonia, methane, and molecular hydrogen was circulated past an electric discharge. After a week's time, various biologically relevant chemicals had developed, including glycine and alanine, identified with a paper chromatrogram. A follow-up study of Miller's samples, carried out approximately 50 years later, discovered a much richer variety of prebiotic compounds than originally thought (Johnson et al. 2008). Since then, numerous related experiments have been carried out under a variety of conditions (see Miller \& Urey 1959; Cleaves et al. 2008, and references therein).

The input energy source and the initial chemistry have been varied across these different experiments. An energy source may have been important for the production of prebiotic species on Earth, because the pathways to formation have considerable activation barriers, often on the order of $0.1-1 \mathrm{eV}$. Patel et al. (2015) generated prebiotic species by exposing $\mathrm{HCN}$ and $\mathrm{H}_{2} \mathrm{~S}$ to ultraviolet light. The experimental results from Powner et al. (2009) suggest that the aqueous synthesis of amino acids, nucleobases, and ribose is predisposed, starting from glyceraldehyde and glycoaldehyde, which they suggest would most likely form through heating and UV irradiation. Shock synthesis of amino acids due to the atmospheric entry of cometary meteors and micrometeorites or thunder is also sufficient to overcome these barriers and produce amino acids (Bar-Nun et al. 1970).

The initial chemical conditions are naturally significant to the formation of prebiotic chemistry. Of course, in an environment where hydrogen or carbon were lacking, there would be no complex hydrocarbons. Nitrogen and phosphorus are also essential to the origins of terrestrial life, although some scientists, such as Benner et al. (2004), have speculated that life could occur under very different chemistries; presently, we lack the ability to explore this possibility. The initial chemical composition also has an effect on the production of prebiotic chemical species. For example, hydrogen can be bound in a reducing species, $\mathrm{CH}_{4}$, in an oxidizing species, $\mathrm{H}_{2} \mathrm{SO}_{4}$, or into the neutral species of water $\left(\mathrm{H}_{2} \mathrm{O}\right)$. Both Schlesinger \& Miller (1983) and Miyakawa et al. (2002) have found that performing a Miller-Urey-like experiment in an oxidizing environment produces only trace amounts of prebiotic materials, whereas performing the experiment in a reducing environment produces a great number of prebiotic materials.

The atmosphere of Earth in its present state is oxidizing $\left(\approx 21 \% \mathrm{O}_{2}, 78 \% \mathrm{~N}_{2}\right)$. The atmosphere of the Earth during its first billion years (first $1 \mathrm{Gyr}$ ) would have had a very different composition, probably oxidizing or at least only weakly reducing (Kasting 1993), although Tian et al. (2005) suggest that the Earth's atmosphere was once highly reducing. Even if the Earth never possessed a strongly reducing atmosphere, other planets and moons are known to have both reducing atmospheres and active lighting and UV photochemistry, such as Jupiter, for example. Extrasolar planets may not simply have diverse compositions, but also widely varied gas-phase $\mathrm{C} / \mathrm{O}$ ratios, either intrinsically at formation, as may be the case with Wasp-12b, XO-1b, and CoRoT-2b (Madhusudhan et al. 2011; Moses et al. 2013), and possibly the interior of 55 Cancri e (Madhusudhan et al. 2012; but see also Nissen 2013); or alternatively due to oxygen depletion into the cloud particles (Bilger et al. 2013; Helling et al. 2014). The question of the $\mathrm{C} / \mathrm{O}$ ratio is not a settled matter (Benneke 2015).

These diverse planetary and exoplanetary environments provide unique "laboratories" within which to explore prebiotic chemistry. There are many potential drivers for prebiotic chemistry in planets and exoplanets, from the steep thermal gradients in hot Jupiters and close-in super-Earths to the thermal production of organics and complex hydrocarbons in 
Saturn's storms (Moses et al. 2015) and photochemical production of complex organics in Titan (Yung et al. 1984; Loison et al. 2015). There is some evidence that cosmic rays drive the formation of hydrogen cyanide in Neptune (Lellouch et al. 1994). Molina-Cuberos et al. (1999) have proposed pathways to formation of a rich variety of nitriles via cosmic rays in Titan's atmosphere.

As mentioned above, electric discharges may also be an important source of energy driving the production of prebiotic species, and are ubiquitous throughout the gas giants. Discharges in the form of lightning are known to occur within our solar system, on Earth, Jupiter (Little et al. 1999), Saturn (Dyudina et al. 2007), Uranus (Zarka \& Pedersen 1986), and Neptune (Gurnett et al. 1990). There are some indications of lightning discharges on Venus (Taylor et al. 1979), and possibly also in Titan's nitrogen chemistry (Borucki et al. 1984), although these traces are still tentative. Lightning is hypothesized to occur on exoplanets (Aplin 2013; Helling et al. 2013) and brown dwarfs (Helling et al. 2013; Bailey et al. 2014). Simulated plasma discharges initiated within Jupiterlike gas compositions suggest that lightning on Jupiter may produce a significant amount of trace gases (Borucki et al. 1985). The comparison between experimental rates of the production of organic compounds in high-temperature plasmas to chemical equilibrium models is unsurprisingly poor (Scattergood et al. 1989), and indicates that a chemical kinetics approach will be important in explaining the results of these experiments. Chemical kinetics seems to be necessary for exploring any of these pathways to the formation of prebiotic species.

Chemical kinetics models have been applied to planetary and exoplanetary atmospheric conditions in such a diverse range that it is impractical to provide complete references, so a brief summary of the work will instead be provided. Photochemical models of the modern Earth have been applied in the context of one-dimensional (1D) models (Owens et al. 1985), up to fully coupled three-dimensional (3D) general circulation models (Roble \& Ridley 1994), and even within a flexible modular framework that can be included as a module within other codes (Sander et al. 2005). The Earth's atmosphere during its first billion years has been extensively modeled (Zahnle 1986; Kasting 1993). Chemical kinetics models have also been applied to Jupiter's atmosphere, from the deep atmosphere (Fegley \& Lodders 1994; Visscher et al. 2010) through the stratosphere (Zahnle et al. 1995; Moses et al. 2005). The atmosphere of the moon Titan has also been analyzed using ion-neutral chemical kinetics to better explain the abundance of rich hydrocarbons in its atmosphere and its stratospheric haze (Yung et al. 1984; Keller et al. 1998; Lavvas et al. 2008a, 2008b).

Chemical kinetics models for exoplanetary atmospheres have typically been developed for hot Jupiters, especially HD 189733b and HD 209458b (Zahnle et al. 2009; Moses et al. 2011; Venot et al. 2012). Almost all of the models for hot Jupiters have been applied only in two dimensions, and so have not taken a more complete account of the atmospheric dynamics, instead relying on a parameterization of vertical mixing using the eddy diffusion coefficient, $K_{z z}\left[\mathrm{~cm}^{2} \mathrm{~s}^{-1}\right]$ (see Lee et al. 2015, their Section 4.2). Agúndez et al. (2014) have taken on the ambitious task of coupling a chemical kinetics model to two-dimensional (2D) dynamics for both HD $189733 \mathrm{~b}$ and HD 209458b. Ion-neutral models have been applied to exoplanets, taking into account photochemistry (Lavvas et al. 2014) and additionally cosmic-ray ionization (Walsh \& Millar 2011; Rimmer et al. 2014). Chemical kinetics models have also been applied to the extrasolar super-Earths (Hu et al. 2012, 2013; Hu \& Seager 2014), and have been used to explore possible biosignatures on rocky planets (Seager et al. 2013a, 2013b). There has also been some recent investigation into chemistry on helium-dominated exoplanets $(\mathrm{Hu}$ et al. 2015).

Lightning chemistry has been explored with some basic chemical kinetics models, e.g., within Earth's mesosphere (Luque \& Ebert 2009 and Parra-Rojas et al. 2013) and Saturn's lower ionosphere (Dubrovin et al. 2014). Dubrovin et al. (2014) present interesting results for Saturn's lower ionosphere, predicting that TLEs within this region would produce mostly $\mathrm{H}_{3}^{+}$, what they identify as the primary positive charge carrier during the duration of the TLE and for sometime after. This would mimic the effect of cosmic-ray ionization. Parra-Rojas et al. (2013) presented similar results involving terrestrial nitrogen chemistry. The products of discharge chemistry in the upper part of both hydrogen-rich and nitrogen-rich atmospheres seem to be similar to the products of cosmic-ray chemistry in these same atmospheres.

There are many open questions about prebiotic chemistry in diverse planetary and exoplanetary environments, as well as in the lab. In this paper, we present a candidate network for exploring UV photochemistry, cosmic-ray chemistry, and lightning-driven chemistry, constructed from scratch. We will mostly explore the photochemistry and thermochemistry within this paper, leaving the exploration of lightning-driven chemistry and cosmic-ray chemistry to future work.

The largest task in developing this network has been the collation of a full set of chemical reactions that treat both reducing and oxidizing chemistries at temperatures ranging from $100 \mathrm{~K}$ through $30,000 \mathrm{~K}$ (the approximate peak temperature of lightning, see Orville 1968; Price et al. 1997) and the selection of rate constants when more than one is published. Since one interest is the investigation of the formation rate of prebiotic species in diverse environments, the network is made extensive enough to include the simplest amino acid, glycine. In this paper, we present this chemical network (STAND2015), and test in a diversity of environments. For these tests, we developed a simple 1D photochemistry/diffusion code (ARGO). Argo was developed based on NAHOON (Wakelam et al. 2012) by including wavelength-dependent photochemistry, cosmicray transport, water condensation, and chemical mixing.

The STAND2015 network is presented in Section 2. We compare the predictions of our network using a simplified 1D photochemistry/diffusion code called ARGo (Section 3). The model and network are then combined and tested against other model results for HD 209458b and the early Earth, and compared to observation for Jupiter and the present-day Earth in Section 4. Finally, in Section 5 we simulate a Miller-Ureytype experiment and explore the formation of glycine under various chemical conditions. Section 6 contains a short discussion of the results and possible future applications of this model.

\section{THE CHEMICAL NETWORK}

The STAND2015 Atmospheric Chemical Network is an $\mathrm{H} / \mathrm{C} /$ $\mathrm{N} / \mathrm{O}$ network with reactions involving $\mathrm{He}, \mathrm{Na}, \mathrm{Mg}, \mathrm{Si}, \mathrm{Cl}, \mathrm{Ar}$, $\mathrm{K}$, $\mathrm{Ti}$, and $\mathrm{Fe}$, developed from scratch. It contains all known 
reactions for species of up to six hydrogen, two carbon, two nitrogen, and three oxygen atoms, for which a rate constant has been published, as well as a less complete network involving species with three or more carbon atoms, three nitrogen atoms, and/or four oxygen atoms. A chemical network is effectively a list of chemical reactions and reaction rate constants. Rate constants are used to calculate the rates of production and loss of a particular molecular or ionic species, $P_{i} \quad\left[\mathrm{~cm}^{-3} \mathrm{~s}^{-1}\right]$ and $L_{i}\left[\mathrm{~cm}^{-3} \mathrm{~s}^{-1}\right]$, respectively, and $i$ is enumerated over the list of species. Rate constants are of zeroth order (e.g., source terms, $S_{i}\left[\mathrm{~cm}^{-3} \mathrm{~s}^{-1}\right]$ ), first order (involving interactions with particles not accounted in the network, such as photons or cosmic rays, $k_{1}\left[\mathrm{~s}^{-1}\right]$ ), second order (collisions between particle $i$ and other particles within the network, $k_{2}\left[\mathrm{~cm}^{3} \mathrm{~s}^{-1}\right]$ ), or third order (collisions between particle $i$ and other particles, as well as a third body, denoted here as $\left.k_{3}\left[\mathrm{~cm}^{6} \mathrm{~s}^{-1}\right]\right)$. The rates of production and loss for a given species, $i$, in terms of rate constants, are generally:

$$
\begin{gathered}
P_{i}=S_{i}+\sum k_{1} n_{j}+\sum k_{2} n_{j} n_{k}+\sum k_{3} n_{\mathrm{gas}} n_{j} n_{k}, \\
L_{i}=\sum k_{1} n_{i}+\sum k_{2} n_{j} n_{i}+\sum k_{3} n_{\mathrm{gas}} n_{j} n_{i} .
\end{gathered}
$$

Summation is over all the relevant reactions, some involving species $j$ and/or $k$, that result in the production (Equation (1)) or loss (Equation (2)) of species $i$. The symbol $n_{i}\left[\mathrm{~cm}^{-3}\right]$ denotes the number density of species $i$ and $n_{\text {gas }}\left[\mathrm{cm}^{-3}\right]$ denotes the total gas number density.

The reaction rate constants have been assembled from various databases. With only a couple hundred exceptions, the rate constants for two-body and three-body neutral reactions have been assembled from the NIST Chemical Kinetics Database (Manion et al. 2013). Virtually all of the ion-neutral reactions were taken from Ikezoe et al. (1987). Several rate constants that we have used, relevant for terrestrial atmospheric chemistry, are taken from Sander et al. (2011). The KIDA database provided the rate constants for several dissociative recombination reactions (Wakelam et al. 2012). Coefficients for the cosmic-ray ionization rate constant were taken from the OSU chemical network (Harada et al. 2010).

Rate constants were compared to the publicly available networks of Moses et al. (2011) and Venot et al. (2012), and ion-neutral rate coefficients were checked against the KIDA database (Wakelam et al. 2012) ${ }^{1}$, as well as the OSU 092010 high-temperature network (Harada et al. 2010). ${ }^{2}$ Some further ion-neutral reactions involving the alkali ion chemistry were appropriated from Lavvas et al. (2014). Finally, 20 more reactions for suspected formation pathways for glycine have been added to the network, from Blagojevic et al. (2003) and Patel et al. (2015). The full network and references are provided in Appendix A. The following subsections contain brief discussions about the different classes of reactions, their rate coefficients and whether reverse reactions have been included.

\subsection{Two-body Neutral-Neutral and Ion-Neutral Reactions}

Two-body neutral-neutral and ion-neutral reactions follow the basic scheme:

$$
\mathrm{A}+\mathrm{B} \rightarrow \mathrm{Y}+\mathrm{Z} \text {, and }
$$

\footnotetext{
http://kida.obs.u-bordeaux1.fr/

2 http://faculty.virginia.edu/ericherb/research.html
}

$$
\mathrm{A}^{+}+\mathrm{B} \rightarrow \mathrm{Y}^{+}+\mathrm{Z}
$$

The rate constants for these reactions are approximated by the Kooij equation (Kooij 1893):

$$
k_{2}=\alpha\left(\frac{T}{300 \mathrm{~K}}\right)^{\beta} e^{-\gamma / T},
$$

where $T[\mathrm{~K}]$ is the gas temperature ${ }^{3}, k_{2}\left[\mathrm{~cm}^{3} \mathrm{~s}^{-1}\right]$ is the rate constant, and $\alpha\left[\mathrm{cm}^{3} \mathrm{~s}^{-1}\right], \beta$, and $\gamma$ are constants characterizing the reaction. All of these reactions are reversed in our network and we use the rate coefficients for the best characterized direction for each reaction, which is typically the exothermic direction. For neutral-neutral reactions, even when exothermic, there is often a sizable barrier to reaction, allowing certain elements to be locked into non-equilibrium configurations at low temperatures effectively for eternity, because the barrier to the lower energy state is too large to be overcome in the current environment.

Ion-neutral reactions do not typically have barriers in the exothermic direction, and in many cases the rate constants are altogether temperature-independent, closely approximating the Langevin approximation. A notable exception are chargeexchange reactions,

$$
\mathrm{A}^{+}+\mathrm{B} \rightarrow \mathrm{B}^{+}+\mathrm{A}
$$

which, due to the differences in energy between ionic and neutral ground states, often contains barriers on the order of a few $\times 100 \mathrm{~K}$.

The rate constants for the forward reactions are given in Appendix A with the label "2n," reactions 577-1352. These reactions are reversed following the scheme described in Appendix B. The ion-neutral reactions are also reversed, and are listed in Appendix A with "2i," reactions 1353-2569.

\subsection{Three-body Neutral Reactions, Dissociation Reactions, and Radiative Association Reactions}

Reactions that involve a third body occur primarily in the two forms:

$$
\begin{aligned}
& \mathrm{A}+\mathrm{M} \rightarrow \mathrm{Y}+\mathrm{Z}+\mathrm{M}, \\
& \mathrm{A}+\mathrm{B}+\mathrm{M} \rightarrow \mathrm{Z}+\mathrm{M},
\end{aligned}
$$

where $\mathrm{M}$ represents any third body. Decomposition reactions are well studied at high temperatures, being important for various combustion processes. Just as in Section 2.1, we choose the reactions best characterized, which in this case often involve endothermic reactions. The rate coefficients for the majority of these reactions follow the Lindemann form (Lindemann et al. 1922). In this form, we first determine the rate constants in the low-pressure $\left(k_{0}\left[\mathrm{~cm}^{6} \mathrm{~s}^{-1}\right]\right)$ and highpressure $\left(k_{\infty}\left[\mathrm{cm}^{3} \mathrm{~s}^{-1}\right]\right)$ limits:

$$
\begin{gathered}
k_{0}=\alpha_{0}\left(\frac{T}{300 \mathrm{~K}}\right)^{\beta_{0}} e^{-\gamma_{0} / T}, \\
k_{\infty}=\alpha_{\infty}\left(\frac{T}{300 \mathrm{~K}}\right)^{\beta_{\infty}} e^{-\gamma_{\infty} / T} .
\end{gathered}
$$

\footnotetext{
3 Surface chemistry is not considered in this paper, and the temperature of all chemical species including electrons is set equal to the gas-phase temperature.
} 
These are combined with the number density of the neutral third species, $[\mathrm{M}]\left[\mathrm{cm}^{-3}\right]$ to determine the reduced pressure, $p_{r}=k_{0}[\mathrm{M}] / k_{\infty}$, and this can then be utilized to set the pressure-dependent effective "two-body" rate:

$$
k_{2}=\frac{k_{\infty} p_{r}}{1+p_{r}} .
$$

Sometimes this expression is multiplied by a dimensionless function $F(p, T)$ to more accurately approximate the transition between the low-pressure and high-pressure limits, and this provides the Troe form (Troe 1983). The coefficients for the Troe form are not explicitly given.

We favor using the rate constants for three-body combination reactions, and reversing these reactions to determine the rate of thermal decomposition. In many cases, however, the rate constants are unavailable. When we have only the rate coefficients for the decomposition reactions, we add an additional $500 \mathrm{~K}$ barrier to both the decomposition and threebody combination rate constants. This barrier is added in order to limit runaway three-body reactions that can result from reversing decomposition reactions at low temperatures.

Additionally, we incorporate a small number of radiative association reactions, of the form:

$$
\mathrm{A}+\mathrm{B} \rightarrow \mathrm{Z}+\gamma,
$$

where $\gamma$ is the radiated photon that carries the excess energy from the association. We appropriate the Kooij form for this reaction, as with two-body neutral-neutral reactions, in order to determine the rate constant $k_{\mathrm{ra}}\left[\mathrm{cm}^{3} \mathrm{~s}^{-1}\right]$. We then apply this rate constant, along with the rate constant for the corresponding three-body reaction, to the adduct form of the overall rate constant (Hébrard et al. 2013, their Equation (B.2)):

$$
k=\frac{\left(k_{0}[\mathrm{M}] F+k_{r}\right) k_{\infty}}{k_{0}[\mathrm{M}]+k_{\infty}}
$$

where the function $F$ is from the Troe form of the transition from high to low pressure.

The rate constants for the forward reactions are given in Appendix A with the labels " $2 \mathrm{~d}$ " for the neutral species and " $3 \mathrm{i}$ " for ion-neutral species. These reactions are reversed in the manner described by Appendix B. Reactions 1-420 are reactions of this type, for which each odd number reaction gives the low-pressure rate constant $k_{0}\left[\mathrm{~cm}^{6} \mathrm{~s}^{-1}\right]$ and each even number reaction gives the high-pressure rate constant $k_{\infty}$ $\left[\mathrm{cm}^{3} \mathrm{~s}^{-1}\right]$. Reactions labeled "ra" are radiative association reactions, numbered 2974-2980.

\subsection{Thermal Ionization and Recombination Reactions}

A special set of three-body reactions are thermal ionization and three-body recombination reactions, which proceed by the pair of equations (analogous to Equations (7) and (8)):

$$
\begin{aligned}
& \mathrm{A}+\mathrm{M} \rightarrow \mathrm{Z}^{+}+e^{-}+\mathrm{M}, \\
& \mathrm{A}^{+}+e^{-}+\mathrm{M} \rightarrow \mathrm{Z}+\mathrm{M} .
\end{aligned}
$$

For which we again use published rates wherever possible for the ionization reactions, (Equation (14)), but in many cases here use the simple approximation:

$$
k_{0}=\left(\frac{8 \pi e^{8}}{m_{e} k_{B} T}\right)^{1 / 2} e^{-I / k_{B} T},
$$

where $e=4.9032 \times 10^{-10}$ esu is the elementary charge, $k_{B}=1.38065 \times 10^{-16} \mathrm{erg} \mathrm{K}^{-1}$ is the Boltzmann constant, $m_{e}=9.1084 \times 10^{-28} \mathrm{~g}$ is the mass of the electron, and $I$ is the ionization energy (here in units of erg) which we determine from the change in the Gibbs free energy for the reaction. $k_{\infty}$ is then estimated from $k_{0}$.

Three-body recombination and ionization reactions have been well studied, and in many cases have well characterized rate constants. Here we treat the three-body recombinations as the reverse reactions for the collisional ionization reactions, but the studied rate coefficients for these reactions generally have a temperature dependence of $T^{-4.5}$, at least for $T>1 \mathrm{~K}$ (Hahn 1997). This creates a problem for reversibility. Using these rates will not allow us to reproduce chemical equilibrium for plasmas and this is largely because we are not properly treating the time-dependent plasma conditions in which these rates are often measured. Many of these rate constants may accurately describe the time to achieve an equilibrium electron density in a regime where a strong ionizing source has recently been removed from the environment.

With this in mind, we instead set the recombination rate constants such that, when dissociative recombination reactions are disabled, the Saha equation is upheld.

These reactions and rate coefficients are also given in Appendix A. The ionization reactions are labeled "ti" and numbered 421-576. As with Section 2.2, the odd reactions are $k_{0}\left[\mathrm{~cm}^{6} \mathrm{~s}^{-1}\right]$ and the even numbers are $k_{\infty}\left[\mathrm{cm}^{3} \mathrm{~s}^{-1}\right]$.

Finally, we include a series of dissociative recombination reactions, which take the form:

$$
\mathrm{A}^{+}+e^{-} \rightarrow \mathrm{Y}+\mathrm{Z} \text {. }
$$

These have rate constants parameterized in the form of Equation (5). The reverse reactions can in principle be calculated, and their rate constants could be calculated straightforwardly using the same principles used for the three-body reactions. This would effectively be analogous to the rates of three-body recombination for any third body, and we do not find that reversing these reactions changes the results much. When we compare with chemical equilibrium, however, we disable these reactions. The dissociative recombination reactions are taken only from the OSU 092010 hightemperature network (Harada et al. 2010), and shown in Appendix A, numbered 2777-2973, and labeled "dr."

\subsection{Photochemistry and Cosmic-ray Chemistry}

Photochemistry is considered for the species $\mathrm{H}, \mathrm{H}^{-}, \mathrm{He}, \mathrm{C}$, $\mathrm{C}\left({ }^{1} \mathrm{D}\right), \mathrm{C}\left({ }^{1} \mathrm{~S}\right), \mathrm{N}, \mathrm{O}, \mathrm{O}\left({ }^{1} \mathrm{D}\right), \mathrm{O}\left({ }^{1} \mathrm{~S}\right), \mathrm{H}^{-}, \mathrm{C}_{2}, \mathrm{CH}, \mathrm{CN}, \mathrm{CO}, \mathrm{H}_{2}$, $\mathrm{N}_{2}, \mathrm{NO}, \mathrm{O}_{2}, \mathrm{OH}, \mathrm{CO}_{2}, \mathrm{H}_{2} \mathrm{O}, \mathrm{HO}_{2}, \mathrm{HCN}, \mathrm{NH}_{2}, \mathrm{NO}_{2}, \mathrm{O}_{3}, \mathrm{C}_{2} \mathrm{H}_{2}$, $\mathrm{H}_{2} \mathrm{CO}, \mathrm{H}_{2} \mathrm{O}_{2}, \mathrm{NH}_{3}, \mathrm{NO}_{3}, \mathrm{CH}_{4}, \mathrm{HCOOH}, \mathrm{HNO}_{3}, \mathrm{~N}_{2} \mathrm{O}_{3}, \mathrm{C}_{2} \mathrm{H}_{4}$, $\mathrm{C}_{2} \mathrm{H}_{6}, \mathrm{CH}_{3} \mathrm{CHO}, \mathrm{C}_{4} \mathrm{H}_{2}, \mathrm{C}_{4} \mathrm{H}_{4}, \mathrm{Na}, \mathrm{K}$, and $\mathrm{HCl}$. The photoionization and photodissociation cross sections are taken almost entirely from PhIDRATES ${ }^{4}$ (Huebner \& Carpenter 1979; Huebner et al. 1992; Huebner \& Mukherjee 2015), with the exception of $\mathrm{C}_{4} \mathrm{H}_{2}, \mathrm{C}_{4} \mathrm{H}_{4}$, and $\mathrm{N}_{2} \mathrm{O}_{3}$, the cross sections of

\footnotetext{
phidrates.space.swri.edu
} 


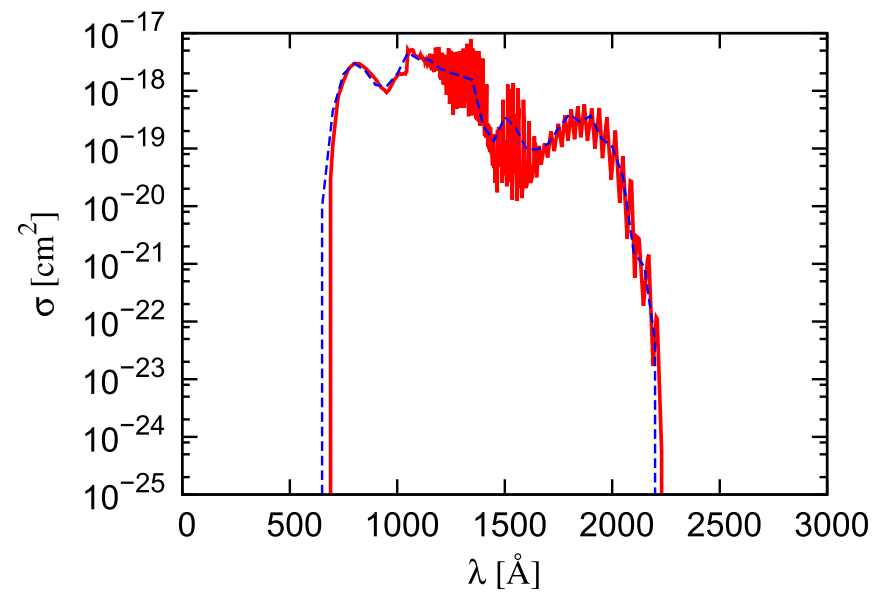

Figure 1. Photodissociation cross sections of $\mathrm{NH}_{3} \rightarrow{ }^{1} \mathrm{NH}+\mathrm{H}_{2}, \sigma\left[\mathrm{cm}^{2}\right]$, as a function of wavelength, $\lambda(\AA)$, from PHIDRATES (original data from McNesby et al. 1962; Schurath et al. 1969, red line). The data is compared to our binned fit (blue line).

which are taken from the MPI-Mainz UV/VIS Spectral Atlas ${ }^{5}$ (Keller-Rudek et al. 2013).

We divide the cross sections between 200 bins each $\approx 50 \AA$ wide. A comparison between our binned cross sections and the raw cross sections from PHIDRATES is plotted for an example reaction (Figure 1). The cross sections, both in the database and here are of the form $\sigma(\lambda)$ with $\sigma$ in units $\mathrm{cm}^{2}$ and wavelength in units of $\AA$. The resolution for the UV cross sections is fairly low, and cannot encapsulate the fine structure of the UV emission lines or the UV cross sections. This is especially important when treating ionospheres of gas giants, since, e.g., the fine structure in the $\mathrm{H}_{2}$ bands leave small spectral windows through which photons can penetrate and effectively ionize deeper in the atmosphere. Such a low-resolution spectrum will effectively close these windows and underestimate the ion production in the ionosphere (Kim \& Fox 1994; Kim et al. 2014). High resolution is also a important for capturing where the UV flux and cross sections both peak; a low-resolution cross section can, in this case, underestimate the destruction rate of the species with this resonant photochemical cross section. As can be seen below, these issues do not significantly affect the comparisons of this model for HD 209458b, Jupiter, or Earth. For photoionization deep in the atmosphere, where high resolution is essential, the network itself need not be modified. The transport of UV photons line by line would need to be calculated.

The tabulated chemical cross sections are combined with $F(\lambda, z)$ [photons $\mathrm{cm}^{-2} \mathrm{~s}^{-1} \AA^{-1}$ ], the radiant flux density onto a unit sphere (hereafter called the actinic flux) located at atmospheric height, $z[\mathrm{~cm}]$, to determine the photochemical rate constants,

$$
k_{\mathrm{ph}, i}(z)=\tau_{f} \int_{1 \AA}^{10^{4} \AA} \sigma_{i} F(\lambda, z) d \lambda,
$$

where $i$ is indexed over the molecules listed above, for which photochemistry is considered. $\tau_{f}$ is a dimensionless parameter representing the fraction of time (over a period much longer than the longest characteristic timescale for the atmosphere) the particular atmospheric region is irradiated; for tidally locked

\footnotetext{
5 http://satellite.mpic.de/spectral_atlas/index.html
}

planets, $\tau_{f}=1$ (dayside) or 0 (nightside), the diurnal average for a rotating planet is $\tau_{f}=1 / 2$. The photoionization and photodissociation reactions are listed in Appendix A, reactions numbered 2570-2693, and labeled "pi" for photoionization reactions and "pd" for photodissociation reactions.

Cosmic-ray ionization and dissociation is parameterized by $\zeta$ (Rimmer \& Helling 2013), to treat both direct ionization by galactic cosmic rays and ionization by secondary particles produced in air showers. The cosmic-ray ionization rate depends on the chemical species in question, since different species will have different chemical cross sections for the photons produced by cosmic rays, and this is accounted for by multiplying $\zeta(z)$ by a constant $\kappa_{\mathrm{CR}, i}$ such that:

$$
k_{\mathrm{CR}, i}(z)=\kappa_{\mathrm{CR}, i} \zeta(z) \text {. }
$$

We treat low-energy cosmic rays $(E<1 \mathrm{GeV})$ for these objects as though they have been significantly shielded by the astrospheres of the host stars, and therefore set the fitting parameters for the incident cosmic-ray flux to $\alpha=0.1$ and $\gamma=-1.3$ in the equation for the flux of cosmic-ray particles:

$$
j(E)= \begin{cases}j\left(E_{1}\right)\left(\frac{p(E)}{p\left(E_{1}\right)}\right)^{\gamma}, & \text { if } E>E_{2} \\ j\left(E_{1}\right)\left(\frac{p\left(E_{2}\right)}{p\left(E_{1}\right)}\right)^{\gamma}\left(\frac{p(E)}{p\left(E_{2}\right)}\right)^{\alpha}, & \text { if } E_{\text {cut }}<E<E_{2} \\ 0, & \text { if } E<E_{\text {cut }}\end{cases}
$$

where $\quad p(E)=\frac{1}{c} \sqrt{E^{2}+2 E E_{0}}, \quad E_{0}=9.38 \times 10^{8} \mathrm{eV}$, $E_{1}=10^{9} \mathrm{eV}$, and $E_{2}=2 \times 10^{8} \mathrm{eV}$, and the flux at $E_{1}$ is set to $j\left(E_{1}\right)=0.22 \mathrm{~cm}^{-2} \mathrm{~s}^{-1} \mathrm{sr}^{-1}(\mathrm{GeV} / \text { nucleon })^{-1}$. All of these parameters except $\alpha$ are observationally well constrained (Indriolo et al. 2009). For a demonstration of how $\alpha$ affects the cosmic-ray spectrum, and a discussion of the Monte Carlo transport we use for cosmic rays of energy $<1 \mathrm{GeV}$, see Rimmer et al. (2012) and Rimmer \& Helling (2013). For ionization rate by cosmic rays of energy $>1 \mathrm{GeV}, Q_{\mathrm{HECR}}$ $\left[\mathrm{cm}^{-3} \mathrm{~s}^{-1}\right]$, we use the analytical method of Velinov \& Mateev (2008).

Cosmic-ray reactions are listed in Appendix A, numbered 2694-2776, and labeled "cr."

\subsection{Test for Chemical Equilibrium}

At sufficiently high temperatures and pressures, a gas should rapidly settle into chemical equilibrium. An important test for a chemical network is that its steady state solution converges to the chemical equilibrium solution. To perform this test of our network, we solve the chemical kinetics at a single $(T, p)$ point, using the rate constants from the STAND2015 network, disabling the cosmic-ray reactions, photochemistry, and dissociative recombination. We compute a time-dependent solution of the equation

$$
\frac{d n_{i}}{d t}=P_{i}-L_{i}
$$

We solve this equation for $T=1000 \mathrm{~K}$ and $p=1 \mathrm{bar}$, with solar abundances from Asplund et al. (2009). We compare our results to chemical equilibrium calculations using the Burcat polynomials (Burcat \& Ruscic 2005), and plot our comparisons in Figure 2 and find excellent agreement. This agreement is not 

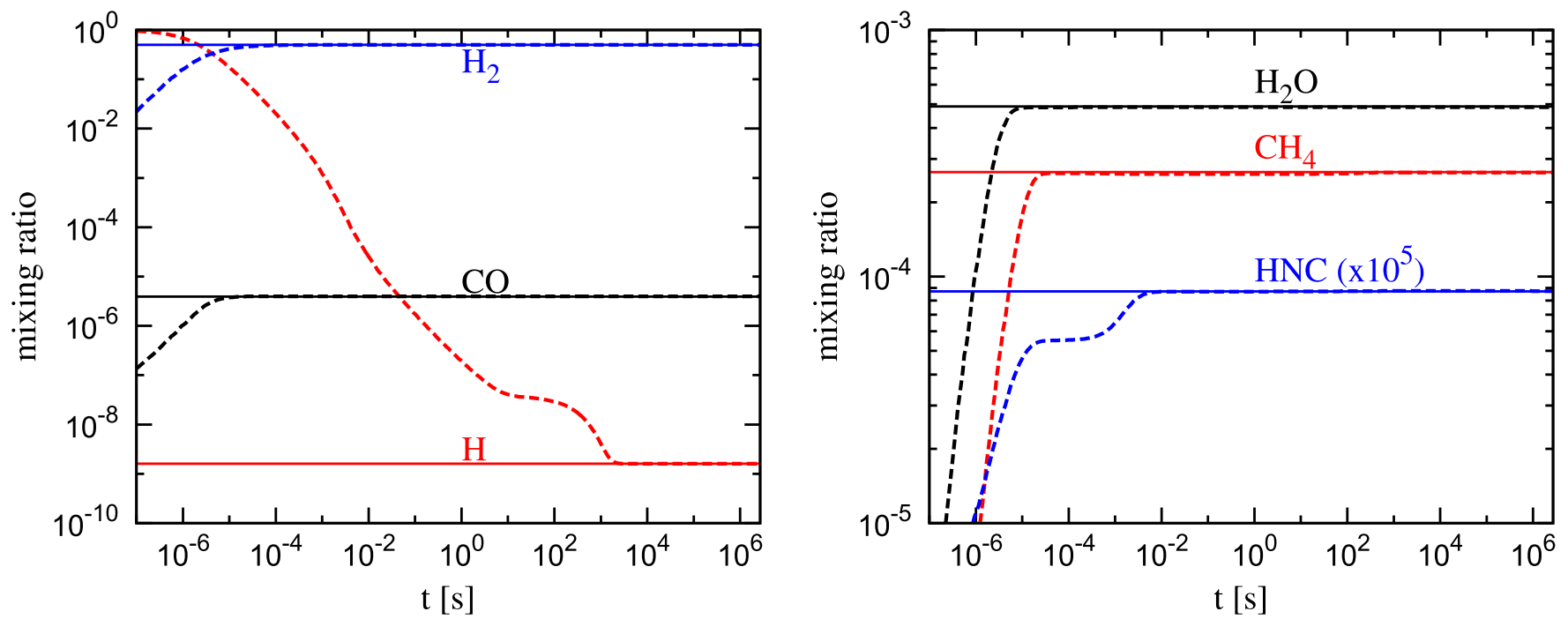

Figure 2. Mixing ratios as a function of time [s] at 1 bar and $1000 \mathrm{~K}$ (dashed lines) compared to chemical equilibrium (solid lines) for $\mathrm{H}_{2}, \mathrm{H}, \mathrm{CO}, \mathrm{CH}_{4}$, and $\mathrm{H}_{2} \mathrm{O}$.

surprising; we have used the same thermochemical data to reverse our reactions, and only include reversed reactions in this test, so once the system achieves steady state, computationally achievable at this pressure and temperature, the chemistry has effectively settled into equilibrium.

We also compare our electron number density to the electron number density achieved using the Saha equation, this time at a pressure of $10^{-4}$ bar and over a range of temperatures from 1000 to $10,000 \mathrm{~K}$. This comparison is plotted in Figure 3. The comparison is virtually perfect when $T \gtrsim 2000 \mathrm{~K}$, unsurprising given the way the three-body recombination reactions are calculated (see Section 2.3). At $\sim 1000 \mathrm{~K}$, our results diverge from the Saha equation. This is because the integrator does not reliably calculate mixing ratios below $\sim 10^{-30}$. Indeed, at this stage, the electron number density achieves $\sim 10^{-300} \mathrm{~cm}^{-3}$ while the $\mathrm{H}^{+}$number density rests at $\sim 10^{-60} \mathrm{~cm}^{-3}$, producing significant charge balance errors. These large errors in the charge balance fluctuate, and only appear when the ionization fraction is $\lesssim 10^{-30}$, at which point ion-neutral chemistry is inconsequential.

\section{1D PHOTOCHEMISTRY/DIFFUSION CODE}

We have developed a simple 1D photochemistry/diffusion code (ARGO) for the purposes of testing the STAND2015 network. The required inputs for ARGO are as follows.

1. $(p, T)$ profile of the atmosphere.

2. Vertical eddy diffusion $\left(K_{z z}\left[\mathrm{~cm}^{2} \mathrm{~s}^{-1}\right]\right)$ profile of the atmosphere (see discussion in Lee et al. 2015).

3. Atmospheric elemental abundances.

4. Boundary conditions at top and bottom of the $p, T$ profile.

5. Actinic flux ${ }^{6}$ at the top of the atmosphere.

6. Chemical Network (in our case, STAND2015).

7. Initial chemical composition.

All of these inputs except the chemical composition are fixed.

\footnotetext{
6 The actinic flux is the radiance integrated over all angles, expressing flow of energy through a unit sphere. There are subtle differences between the actinic flux and the spectral irradiance; see Madronich (1987).
}

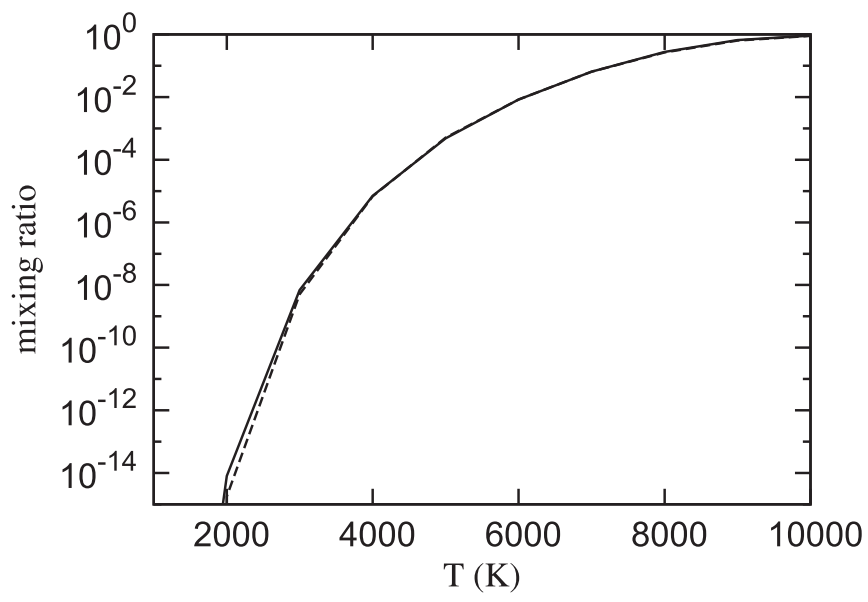

Figure 3. Mixing ratio as a function of temperature. The solid line is from the Saha equation and the dashed line is the result from our model calculation.

With these inputs, ARGo solves molecular transport in a fully Lagrangian manner, similar to Alam \& Lin (2008) and Zahnle et al. (1995). The model consists of two parts: (1) A chemical transport model (Section 3.1), and (2) calculation of the photochemical and cosmic-ray chemical rate constants from cross sections and a depth-dependent actinic flux (Section 3.2). A conceptual illustration is shown in Figure 4.

\subsection{The Continuity Equations for Chemical Species}

The coupled 1D continuity equations describing the timedependent vertical atmospheric chemistry are

$$
\frac{\partial n_{i}}{\partial t}=P_{i}-L_{i}-\frac{\partial \Phi_{i}}{\partial z}
$$

where $n_{i}\left[\mathrm{~cm}^{-3}\right]$ is the number density of species $i$, and $i=1, \ldots, N_{s}$, and $N_{s}$ is the total number of species. $P_{i}$ $\left[\mathrm{cm}^{-3} \mathrm{~s}^{-1}\right]$ is the rate of production and $L_{i}\left[\mathrm{~cm}^{-3} \mathrm{~s}^{-1}\right]$ is the rate of loss of species $i$. The rightmost term is the vertical change in flux $\Phi_{i}\left[\mathrm{~cm}^{-2} \mathrm{~s}^{-1}\right]$ and represents the flux due to both eddy $\left(K\left[\mathrm{~cm}^{2} \mathrm{~s}^{-1}\right]\right)$ and molecular diffusion $\left(D\left[\mathrm{~cm}^{2} \mathrm{~s}^{-1}\right]\right)$, respectively, related as (Banks \& Kockarts 1973, their Equation 


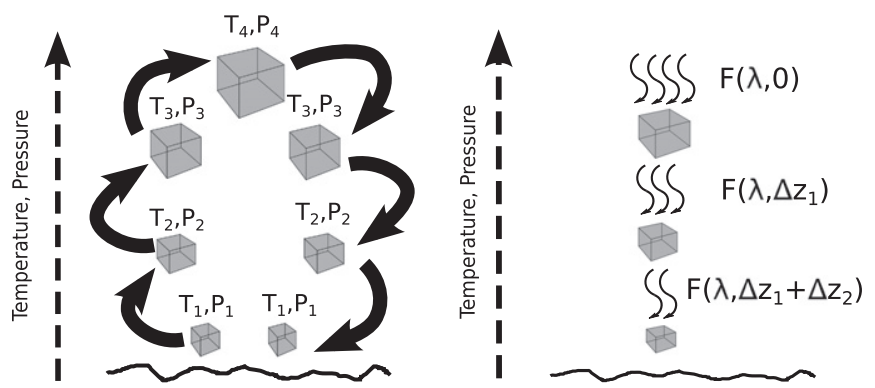

Figure 4. Illustration representation of the model. The illustration on the left represents the motion of the single parcel from the bottom of the atmosphere, $T_{1}, P_{1}$, up to the top of the atmosphere, $T_{4}, P_{4}$, and then back down; see Section 3.1. Once this journey is completed, we irradiate the atmosphere by stacking up the parcel at different times, when it was located at different parts of the atmosphere. The illustration on the right represents the calculation of the depth-dependent actinic flux discussed in Section 3.2. Only photons of wavelength between 1 and $10000 \AA$ are considered. Figure 5 gives a flow chart for the calculation.

(15.14)),

$$
\begin{aligned}
\Phi_{i}= & -K\left[\frac{\partial n_{i}}{\partial z}+n_{i}\left(\frac{1}{H_{0}}+\frac{1}{T} \frac{d T}{d z}\right)\right] \\
& -D\left[\frac{\partial n_{i}}{\partial z}+n_{i}\left(\frac{1}{H_{i}}+\frac{1+\alpha_{T}}{T} \frac{d T}{d z}\right)\right],
\end{aligned}
$$

where $H_{0}[\mathrm{~cm}]$ is the pressure scale height of the atmosphere at $z[\mathrm{~cm}], H_{i}[\mathrm{~cm}]$ is the molecular scale height of the atmosphere for species $i$, and $\alpha_{T}$ is the thermal diffusion factor (Banks \& Kockarts 1973; Yung \& Demore 1999; Zahnle et al. 2006; Hu et al. 2012). For molecular diffusion coefficients, we adopt the Chapman-Enskog theory (Enskog 1917; Chapman \& Cowling 1991). Eddy diffusion coefficients are either determined empirically, as with Earth and Jupiter, or are derived from global circulation models, as is the case for HD 209458b.

In Equation (23), the terms dealing with eddy diffusion and molecular diffusion are separated out, clarifying the four regions that Equations (22) and (23) describe. (1) Deep within the atmosphere, where pressures and temperatures are sufficiently large, the thermochemistry dominates, and the equation simplifies to Equation (21). The atmospheric chemical composition converges to chemical equilibrium or at least to some stable quasi-equilibrium. (2) Higher in the atmosphere, the eddy diffusion may dominate, and the species are quenched. Their abundance is mixed evenly over a wide range of the atmosphere at timescales shorter than the chemical timescales. (3) Above this region, molecular diffusion may dominate, and at that point, species lighter than the mean molecular mass of the atmospheric gas will rise up, and species heaver than the mean molecular mass will settle down, and the chemistry will largely be determined by the individual scale heights of the atmospheric constituents. (4) Non-equilibrium processes, such as photochemistry or cosmic-ray chemistry, may create a fourth region, the composition of which is determined by irreversible chemical reactions.

Since the purpose of this paper is to introduce a new chemical kinetics network for lightning and prebiotic processes, our focus is not on the atmospheric dynamics (for this, see Lee et al. 2015). We therefore apply a simple approximation to Equation (22), inspired by Alam \& Lin (2008). We first cast Equation (22) in a Lagrangian formulation, and consider
Eddy diffusion to be moving small parcels of the gas vertically. We follow a single parcel as it moves up from the lower boundary of the temperature profile, and then returns down again. In reality, the parcel would be jostled in all three dimensions as it makes a complex journey up to the top of the atmosphere, but 1D transport models are unable to capture this effect in full.

The differential diffusion of molecules into and out of the parcel requires a different approach. The discrete formulas used by $\mathrm{Hu}$ et al. (2012, their Equation (9)) in the Lagrangian frame are

$$
\begin{aligned}
\frac{\partial n_{i, j}}{\partial t}= & P_{i, j}-L_{i, j} n_{i, j}-d_{j+1 / 2} \frac{n_{\mathrm{gas}, j+1 / 2}}{n_{\mathrm{gas}, j+1}} n_{i, j+1} \\
& -\left(d_{j+1 / 2} \frac{n_{\mathrm{gas}, j+1 / 2}}{n_{\mathrm{gas}, j}}-d_{j-1 / 2} \frac{n_{\mathrm{gas}, j-1 / 2}}{n_{\mathrm{gas}, j}}\right) n_{i, j} \\
& +d_{j-1 / 2} \frac{n_{\mathrm{gas}, j-1 / 2}}{n_{\mathrm{gas}, j-1}} n_{i, j-1} .
\end{aligned}
$$

Here, $j$ represents the parcel being followed, $j-1$ the parcel directly beneath $j, j+1$ the parcel above $j$, and $j \pm 1 / 2$ an arithmetic average between $j$ and $j \pm 1$. $n$ without any $i$ subscript represents $n_{\text {gas }}$ at the relevant parcel, and

$$
d_{j \pm 1 / 2}=\frac{D_{j \pm 1 / 2}}{2(\Delta z)^{2}}\left[\frac{\left(\bar{m}-m_{i}\right) g \Delta z}{k_{B} T_{j \pm 1 / 2}}-\frac{\alpha_{T}}{T_{j \pm 1 / 2}}\left(T_{j \pm 1}-T_{j}\right)\right] .
$$

$\bar{m}$ [g] denotes the mean molecular mass of the atmosphere at $z$ and $m_{i}[\mathrm{~g}]$ the mass of species $i$.

Both the third and last terms on the right-hand side of Equation (24) do not depend on $n_{i}$ and can therefore be treated as source terms, $P_{i}$. The fourth term can be treated as a term in $L_{i}$, such that molecules "destroyed" by this reaction are "banked," A $\rightarrow$ BA. The "banked" molecules re-enter the parcel at a rate determined by the third and last terms on the right-hand side of the equation, thus conserving mass throughout the parcel's travels. Violations of this conservation do not appear here, but can be accounted for via further reactions, settling, condensation and evaporation, outgassing and escape, discussed in Appendix C. Although it is straightforward to handle atmospheric escape with this method, we do not do so for any of the test cases in this paper.

Equation (24) is solved within ARGO in the same numerical manner as NAHOON (Wakelam et al. 2012) by the implicit timedependent Gear method as incorporated by the Livermore Solver for Ordinary Differential Equations (DLSODE; Gear 1971; Brown \& Hindmarsh 1989).

\subsection{Calculating the $X U V$ and Cosmic-ray Flux}

Once the fluid parcel has completed the atmospheric profile, the solar XUV actinic flux from 1 to $10000 \AA$ as a function of depth, $z[\mathrm{~cm}]{ }^{7}$ and wavelength $\lambda[\AA]$ is calculated. We consider both the direct and approximate diffusive actinic flux. The local height-dependent actinic flux is calculated without any iteration on the local temperature. The cross sections for various photochemical reactions (Section 2.4) are multiplied by each vertical step $(\Delta z)_{j}[\mathrm{~cm}]$, where $(\Delta z)_{j}$ is the size of the step

\footnotetext{
7 The depth for this model extends from $z=0$, the bottom of the temperature profile for the planet in question, to $z=z_{\text {top }}$, the top of the profile.
} 
at height $z_{j}$. The total optical depth as a function of the wavelength takes the form

$$
\tau(\lambda, z)=\Sigma_{j}\left[(\Delta z)_{j} \Sigma_{i} \sigma_{i} n_{i j}\right]+\tau_{s},
$$

where $i$ is summed over all species for which photoabsorption is considered (see Section 2.4 for a list of these species). $\tau_{s}$ is the optical depth due to Rayleigh scattering, and the actinic flux as a function of depth is defined as (Hu et al. 2012)

$$
F(\lambda, z)=F\left(\lambda, z_{\text {top }}\right) e^{-\tau(\lambda, z) / \mu_{0}}+F_{\text {diff }},
$$

where $\mu_{0}=\cos \theta$, where $\theta$ is the stellar zenith angle; we set $\mu_{0}=1 / 2$ for all calculations within this paper (see Hu et al. 2012 , their Figure 7). $F_{\text {diff }}$ denotes the actinic flux of the diffusive radiation, determined using the $\delta$-Eddington twostream method (Toon et al. 1989). Once the actinic flux is calculated, the photochemical rates are determined as in Section 2.4. Once the depth-dependent flux, $F(z, \lambda)$ $\left[\mathrm{cm}^{-2} \mathrm{~s}^{-1} \AA^{-1}\right]$, is determined for all layers, the parcel's path through the atmospheric profile is repeated, now accounting for the photochemistry. The cosmic-ray ionization rate, $\zeta(z)\left[\mathrm{s}^{-1}\right]$, is likewise calculated in a depth-dependent manner following Rimmer \& Helling (2013) and incorporated into the chemistry (Section 2.4).

A new depth-dependent composition is constructed, then applied to Equation (26) to solve again for $F(z, \lambda)$. The value of $\zeta(z)$ does not change significantly between iterations. This process is repeated until the results converge; i.e., until the profile from the previous global calculation (transport + depthdependent flux) agrees to within $1 \%$ the profile from the current global calculation. The number of repetitions depends on the parameters, but is typically between 5 and 12 global iterations. This iterative process is represented as a flow chart in Figure 5.

This method is both simple and functional, requiring relatively little computational resources. It is also straightforward to adapt to diverse chemical environments, since it does not require the selection of "fast" and "slow" chemistry to ease computational speed. These strengths do not come without a cost: the simplistic dynamics does not transition as smoothly from the eddy diffusion regime to the molecular diffusion regime as the Eulerian formulation, and can result in steep changes over a handful of height steps.

\subsection{Testing the Atmospheric Transport Model for Molecular Diffusion}

In order to benchmark the STAND2015 chemical network in different planetary atmospheres, we test the molecular diffusion within ARGO. We consider a 1D isothermal gas under a constant surface gravity, $g=10^{3} \mathrm{~cm} \mathrm{~s}^{-2}$, with temperature $T=300 \mathrm{~K}$, at hydrostatic equilibrium. The gas is initially composed of carbon and hydrogen atoms, each with a mixing ratio of $X_{0}(\mathrm{C})=n(\mathrm{C}) / n_{\mathrm{gas}}=0.5$ and $X_{0}(\mathrm{O})=0.5$ throughout. All chemistry is disabled. It is expected that the heavier species, carbon, will settle into the atmosphere, and the lighter species, hydrogen, will rise up, until they stratify. The analytic solution to this system is well known. The mixing ratio should be determined by the scale heights of the individual species such that, for the carbon abundance,

$$
X(\mathrm{C})=\frac{X_{0}(\mathrm{C}) e^{-z / H_{\mathrm{C}}}}{X_{0}(\mathrm{H}) e^{-z / H_{\mathrm{H}}}+X_{0}(\mathrm{C}) e^{-z / H_{\mathrm{C}}}},
$$

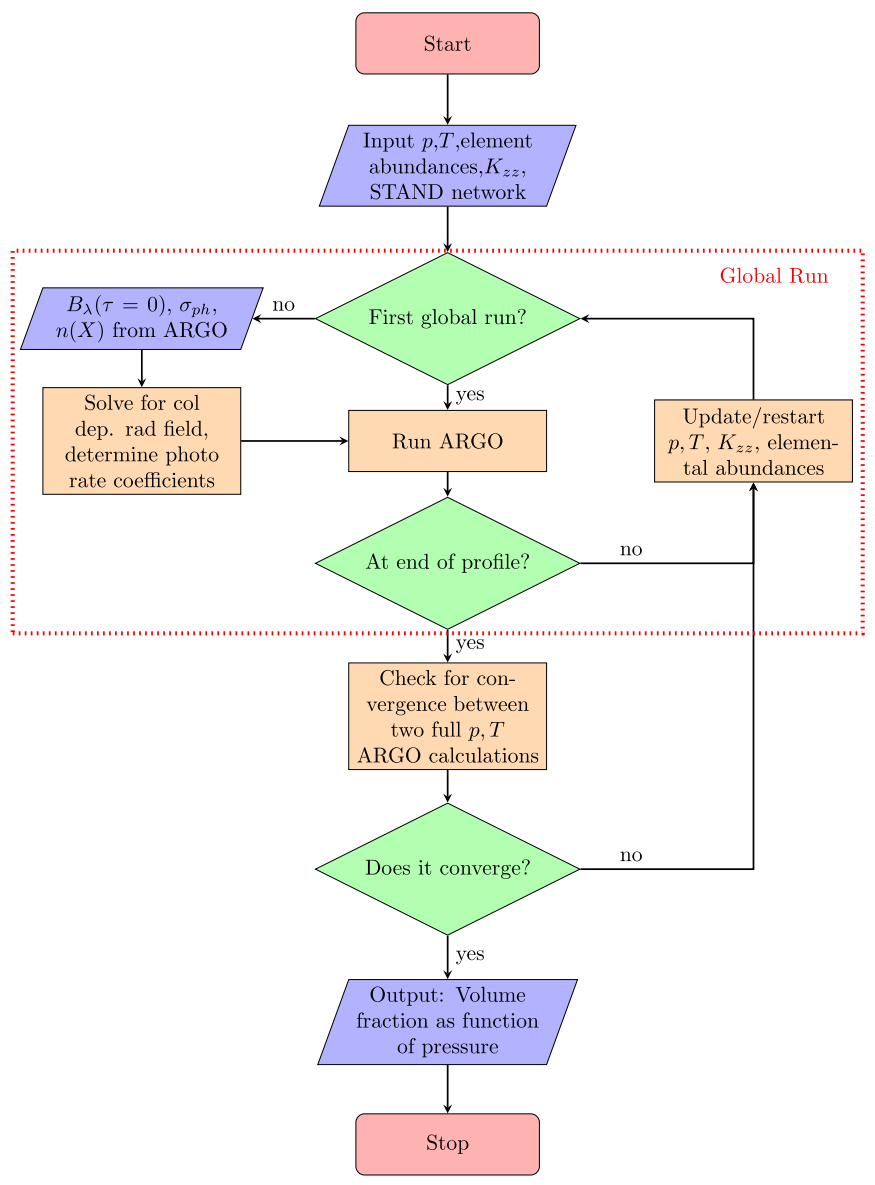

Figure 5. Flow chart representation for the program.

where $X(\mathrm{C})$ is the final steady state carbon mixing ratio, and $H_{\mathrm{H}}[\mathrm{cm}]$ and $H_{\mathrm{C}}[\mathrm{cm}]$ are the atmospheric scale heights for the hydrogen and carbon.

The code is run until steady state is achieved, when the carbon in the very upper atmosphere diffuses into the lower atmosphere. The steady state mixing ratio, as a function of height is compared the analytic mixing ratio, Equation (28), in Figure 6. The comparison is reasonable through the extent of the atmosphere.

\section{TESTING THE NETWORK FOR PLANETARY ENVIRONMENTS}

The STAND2015 network contains chemical reactions for an $\mathrm{H} / \mathrm{C} / \mathrm{N} / \mathrm{O}$ gas, and including both highly reducing to highly oxidizing atmospheres, and for a temperature range of $100-30,000 \mathrm{~K}$. The network should then be tested for a variety of planetary atmospheres with different chemical compositions, from the (probably) oxidizing atmosphere of the early Earth to the highly reducing atmosphere of Jupiter. The large range of temperatures is tested for the irradiated exoplanet HD $209458 \mathrm{~b}$. We also test our model against the height-dependent measurements of select trace species within the atmosphere of the present-day Earth. It would be interesting to apply our model to Titan, due to its rich nitrile and organic chemistry. Titan's atmosphere is a very rich and complex environment, and it is important to account for these complexities when modeling Titan. Titan has upper atmospheric hazes, temperatures low enough to condense several molecular species, and ionization 


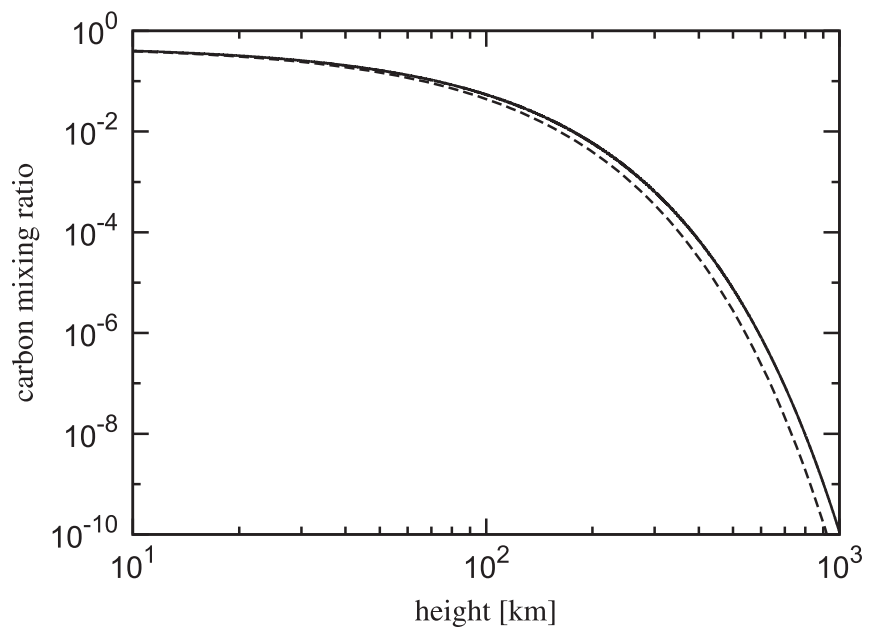

Figure 6. Carbon mixing ratio as a function of atmospheric height $[\mathrm{km}]$. We test for diffusion, with chemistry turned off, for carbon atoms and hydrogen atoms in a gas at hydrostatic equilibrium for an isothermal gas $\left(g=10^{3} \mathrm{~cm} \mathrm{~s}^{-2}, T=300 \mathrm{~K}\right)$. The solid line is the result from ARGo and the dashed line is the analytic result (Equation (28)).

and dissociation by energetic particles including cosmic rays, Saturn magnetospheric particles, solar wind protons, and interplanetary electrons. As useful as a study of the atmosphere of Titan would be for exploring Miller-Urey-like chemistry (Waite et al. 2007), though such a model is beyond the scope of this paper. The boundary conditions for these various objects are given in Section 4.1. We then compare our results to the results from other chemical kinetics models and, where possible, with observations, for HD 209458b (Section 4.2), Jupiter (Section 4.3), and the Earth (Section 4.4).

\subsection{Boundary Conditions for Three Test Cases: HD 209458b, Jupiter, and the Earth}

Below, we compare the results of our chemical kinetics to other results for HD 209458b and also for Jupiter and the Earth. Each of these objects has different boundary conditions and parameters. These conditions and parameters include the temperature profile of the object's atmosphere, the eddy diffusion profile, the elemental abundances, the initial composition at the lower boundary of the atmospheric profile, and the unattenuated UV flux. For HD 209458b, the conditions at the lower boundary of the atmospheric profile rapidly develop from the prescribed initial conditions toward chemical equilibrium. For Jupiter and the early Earth, the composition at the lower boundary is stable over the dynamical timescale $\left(d n_{i}(z=0) / d t \approx 0\right)$, and so the initial composition effectively acts as a lower boundary condition. The assumed elemental abundances and initial conditions at the lower boundary of the atmospheric profile are given in Table 1.

We take HD 209458b to have solar elemental abundances throughout its atmosphere, and set the initial conditions at the lower boundary of the atmosphere to be entirely atomic. The initial composition hardly matters here, since the composition quickly settles to chemical equilibrium at such a high temperature and pressure. The temperature profile and eddy diffusion profile for HD 209458b are both taken from Moses et al. (2011) so we can directly compare results.

Since HD 209458 is a G0 star, we use the solar UV flux. The unattenuated solar UV flux at 1 au is obtained from the SORCE data (Rottman et al. 2006) for 1-350 $\AA$ and 1150-10000 $\AA$ with
Table 1

Initial Conditions for the Chemistry at the Lower Boundary in Terms of $n(X) / n_{\text {gas }}$

\begin{tabular}{lcccc}
\hline \hline Species & HD 209458b & Earth $^{\mathrm{b}}$ & Early Earth $^{\mathrm{c}}$ & Jupiter $^{\mathrm{d}}$ \\
\hline $\mathrm{H}$ & $9.2092(-1)$ & $\ldots$ & $\ldots$ & $\ldots$ \\
$\mathrm{He}$ & $7.8383(-2)$ & $\ldots$ & $\ldots$ & $1.3600(-1)$ \\
$\mathrm{C}$ & $2.4787(-4)$ & $\ldots$ & $\ldots$ & $\ldots$ \\
$\mathrm{N}$ & $6.2262(-5)$ & $\ldots$ & $\ldots$ & $\ldots$ \\
$\mathrm{O}$ & $4.5105(-4)$ & $\ldots$ & $\ldots$ & $\ldots$ \\
$\mathrm{Ar}$ & $2.3133(-6)$ & $\ldots$ & $9.1150(-3)$ & $\ldots$ \\
$\mathrm{K}$ & $9.8766(-8)$ & $\ldots$ & $\ldots$ & $\ldots$ \\
$\mathrm{Cl}$ & $2.9122(-7)$ & $\ldots$ & $\ldots$ & $\ldots$ \\
$\mathrm{Fe}$ & $2.9122(-5)$ & $\ldots$ & $\ldots$ & $\ldots$ \\
$\mathrm{Mg}$ & $3.6663(-5)$ & $\ldots$ & $\ldots$ & $\ldots$ \\
$\mathrm{Na}$ & $1.6004(-6)$ & $\ldots$ & $\ldots$ & $\ldots$ \\
$\mathrm{Si}$ & $2.9800(-5)$ & $\ldots$ & $\ldots$ & $\ldots$ \\
$\mathrm{Ti}$ & $8.2077(-8)$ & $\ldots$ & $\ldots$ & $\ldots$ \\
$\mathrm{CO}$ & $\ldots$ & $1.1300(-7)$ & $4.9005(-5)$ & $8.0000(-10)$ \\
$\mathrm{H}_{2}$ & $\ldots$ & $1.0000(-6)$ & $9.8010(-4)$ & $8.6219(-1)$ \\
$\mathrm{N}_{2}$ & $\ldots$ & $7.9172(-1)$ & $7.8408(-1)$ & $\ldots$ \\
$\mathrm{NO}$ & $\ldots$ & $2.4000(-11)$ & $\ldots$ & $\ldots$ \\
$\mathrm{O}_{2}$ & $\ldots$ & $1.9793(-1)$ & $\ldots$ & $\ldots$ \\
$\mathrm{CO}$ & $\ldots$ & $3.5000(-4)$ & $1.9602(-1)$ & $\ldots$ \\
$\mathrm{H}_{2} \mathrm{O}$ & $\ldots$ & $1.0000(-2)$ & $9.8010(-3)$ & $\ldots$ \\
$\mathrm{N}_{2} \mathrm{O}$ & $\ldots$ & $3.0200(-7)$ & $\ldots$ & $\ldots$ \\
$\mathrm{NH}_{3}$ & $\ldots$ & $2.4000(-10)$ & $\ldots$ & $\ldots$ \\
$\mathrm{CH}_{4}$ & $\ldots$ & $1.9390(-6)$ & $\ldots$ & $1.8100(-3)$ \\
\hline
\end{tabular}

Notes.

a Solar metallicity from Asplund et al. (2009).

b Surface mixing ratios based on the US Standard Atmosphere 1976.

${ }^{c}$ Based on early Earth models (Kasting 1993).

${ }^{\mathrm{d}}$ Moses et al. (2005).

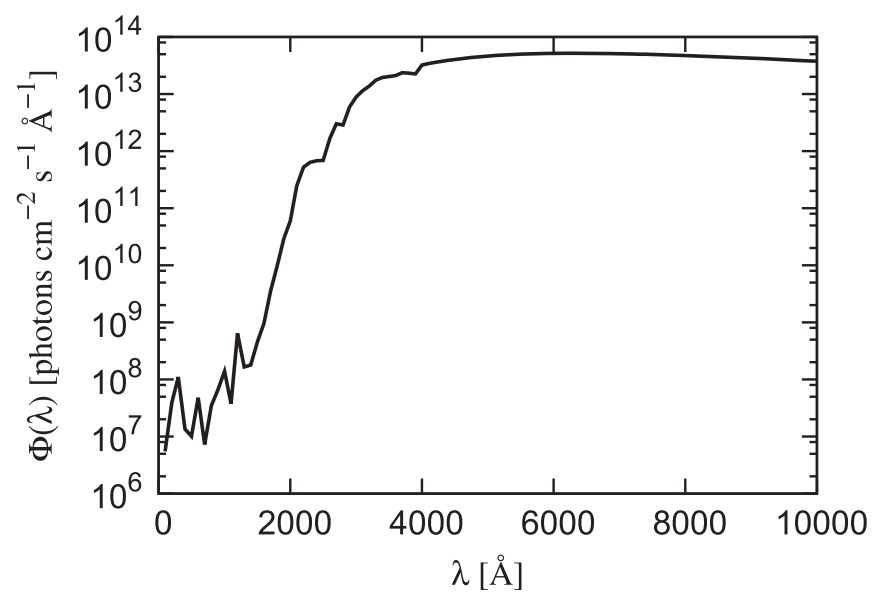

Figure 7. Solar flux used in our model [photons $\left.\mathrm{cm}^{-2} \mathrm{~s}^{-1} \AA^{-1}\right]$, as a function of wavelength, $\lambda[\AA]$, taken from Huebner \& Carpenter (1979), Huebner et al. (1992), and Huebner \& Mukherjee (2015). Weighted versions of this flux are used for HD 209458b and Jupiter. This flux is used, unadjusted, for the early Earth.

data from PhIDRATES for the 350-1150 ̊ range. The binned flux we use is plotted in Figure 7. This flux is adapted to HD 209458 b by multiplying the solar UV flux by a factor of $\left(d_{\oplus} / d_{p}\right)^{2}$, where $d_{\oplus}[\mathrm{au}]$ is the distance from the Earth to the Sun and $d_{p} \approx 0.047$ au is the approximate distance between HD 209458b and its host star. This may not be the most accurate approximation to the UV behavior of HD 209458, since it might have quite different activity from our Sun (Tu et al. 2015). 
For Jupiter, we use the temperature and eddy profiles from Moses et al. (2005). For consistency, we set the initial conditions at the lower boundary of Jupiter's atmosphere to be the same as Moses et al. (2005); see Table 1. The solar UV spectrum at 1 au is used for Jupiter, although multiplied by a factor of $\left(d_{\oplus} / d_{J}\right)^{-2}$, where $d_{J} \approx 4.5$ au is the square of the distance between the sun and Jupiter.

For the present-day Earth, we use the measured surface mixing ratios from the US Standard Atmosphere 1976 (see Table 1) and the temperature profile from Hedin (1987, 1991), Figure 13. We use the present-day solar flux at 1 au as our incident UV flux.

We use the same chemical lower boundary conditions as from Kasting (1993) for the atmosphere of the early Earth (Table 1). The temperature profile for the early Earth is assumed to be the same as that of the present Earth (Hedin 1987, 1991), Figure 13. The UV field used for this model is that of the young Sun calculated using the scaling relationships of Ribas et al. (2005) for wavelengths between 1 and $1200 \AA$ and the UV field of the solar analogue $\kappa^{1}$ Cet above $1200 \AA$ (Ribas et al. 2010).

\section{2. $H D 209458 b$}

HD 209458b was first observed by Henry et al. (2000), and is one of a growing number of Hot Jupiters to have a measured spectrum, via transit (e.g., Queloz et al. 2000), and also in emission (e.g., Knutson et al. 2008). Various molecular species have been tentatively identified in the spectrum, such as $\mathrm{TiO}$ (Désert et al. 2008), water (Madhusudhan \& Seager 2009; Swain et al. 2009; Beaulieu et al. 2010), CO, $\mathrm{CO}_{2}$, and methane features (Madhusudhan \& Seager 2009; Swain et al. 2009). HD 209458b has been extensively modeled with retrieval modeling (Madhusudhan \& Seager 2009) and with hydrodynamic global circulation models (Showman et al. 2008). This planet has also been a popular target for nonequilibrium chemistry models such as those of Liang et al. (2003), Zahnle et al. (2009), Moses et al. (2011), Venot et al. (2012), Agúndez et al. (2014), and Lavvas et al. (2014).

We have chosen the atmosphere of HD 209458b as one candidate for benchmarking our results because it is well characterized and has been the subject of several nonequilibrium chemistry models, and it has a very high temperature even among Hot Jupiters. An additional benefit to HD 209458b is its suspected temperature inversion (Knutson et al. 2008, although this is debated; see also Schwarz et al. 2015), which allows us to test our chemistry at very high temperatures both at both high and low pressures. The thermal profile of HD 209458b from Moses et al. (2011) is shown in Figure 8 . The local gas-phase temperature $T>2000 \mathrm{~K}$ both when $p>100$ bar and when the gas-phase pressure, $p<10^{-4}$ bar. This is a wide parameter space relevant for ion-neutral chemistry initiated via thermal ionization.

We compare our results to the predictions of two different chemical kinetics models. (1) We compare our results to the results of Moses et al. (2011) with the ion-neutral chemistry disabled. (2) We compare the ionic abundances for our most abundant ions to the results of Lavvas et al. (2014). Also in this case, we disable cosmic-ray chemistry in order to draw a better comparison to the ion-neutral chemistry.

We compare our network and transport model to Moses et al. (2011) by examining the volume mixing ratios of major neutral species: $\mathrm{H}, \mathrm{H}_{2}$, $\mathrm{He}$ (hydrogen/helium chemistry), $\mathrm{OH}, \mathrm{H}_{2} \mathrm{O}, \mathrm{O}$,

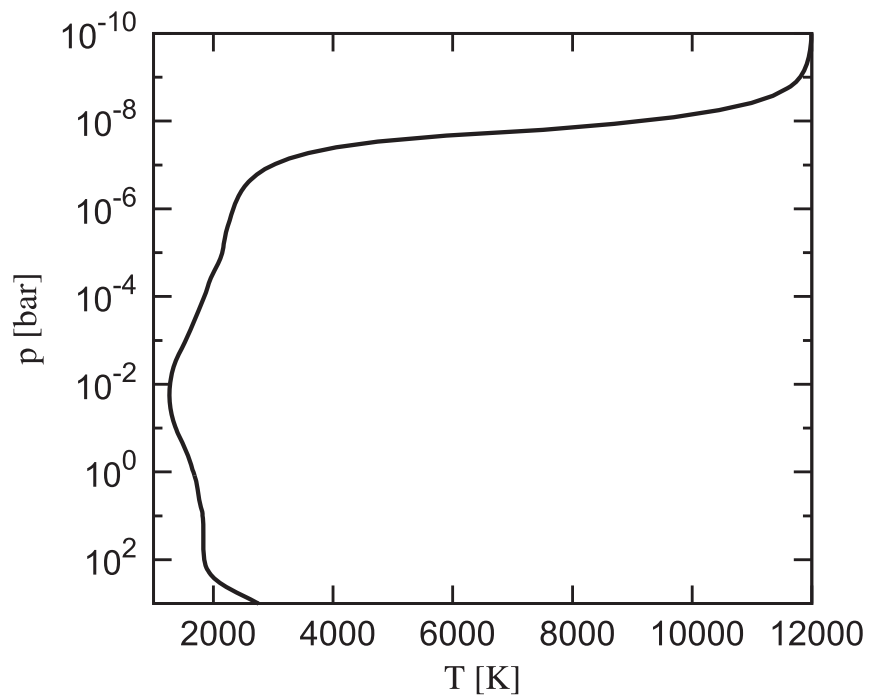

Figure 8. Temperature profile for HD 209458b, $T$ [K], as a function of $p$ [bar], as used by Moses et al. (2011).

and $\mathrm{O}_{2}$ (oxygen/water chemistry), $\mathrm{N}_{2}$ and $\mathrm{NH}_{3}$ (nitrogen chemistry), and $\mathrm{CO}, \mathrm{CH}_{4}$, and $\mathrm{CO}_{2}$ (carbon chemistry). See Figure 9. These species were chosen because they are abundant and, in the case of $\mathrm{H}_{2}$ and $\mathrm{N}_{2}$, play an important role in the nonequilibrium chemistry. $\mathrm{N}_{2}$ provides the reservoir for the transition between $\mathrm{N}_{2} \rightleftharpoons \mathrm{NH}_{3}$. Other species were chosen because they contribute to features observed in transit spectroscopy (e.g., $\mathrm{CO}_{2}$ ). The molecules $\mathrm{CO}$ and $\mathrm{H}_{2} \mathrm{O}$ do both. Helium was chosen because its mixing ratio is not significantly affected by the chemistry. It changes with pressure due to molecular diffusion, and so it provides a useful comparison between our dynamical calculations and those of Moses et al. (2011).

The transition of carbon between $\mathrm{CO}$ and $\mathrm{CH}_{4}$, and nitrogen between $\mathrm{N}_{2}$ and $\mathrm{NH}_{3}$ is very sensitive to non-equilibrium chemistry, as $\mathrm{CH}_{4} \approx \mathrm{CO}$ when $p \sim 100 \mathrm{bar}$ and $T \sim 2000 \mathrm{~K}$. As the pressure decreases rapidly while the temperature remains relatively high $(T>1000 \mathrm{~K})$, the thermochemical equilibrium ratio for $\mathrm{CH}_{4} / \mathrm{CO}$ plummets, approaching $10^{-7}$ at $0.1 \mathrm{bar}$ in the HD $209458 \mathrm{~b}$ atmosphere. The time it takes the carbon to meander from $\mathrm{CH}_{4}$ to $\mathrm{CO}$, however, becomes significantly longer than the relevant dynamical timescales (for HD 209458b, this timescale is prescribed by the eddy diffusion coefficient; see Bilger et al. 2013), and the $\mathrm{CH}_{4}$ and $\mathrm{CO}$ abundances are quenched. The same sort of process governs the transition of nitrogen from $\mathrm{N}_{2}$ to $\mathrm{NH}_{3}$.

The pathways for both $\mathrm{CH}_{4} \rightleftharpoons \mathrm{CO}$ and $\mathrm{N}_{2} \rightleftharpoons \mathrm{NH}_{3}$ interconversions are not well understood. In both cases, the paths competing with one another are often circuitous, and tend to be regulated by one of several reactions encountered along the journey, a slow rate-limiting step (Moses 2014). The timescale of the transition between species is almost entirely set by the rate by which that single reaction proceeds. As discussed in Section 2, rate coefficients can be frustratingly uncertain, with different estimations sometimes varying by more than an order of magnitude. For example, compare the rate experimental and theoretical rate constants for $\mathrm{C}_{2} \mathrm{H}_{6} \rightarrow \mathrm{CH}_{3}+\mathrm{CH}_{3}$ (Yang et al. 2009 and Kiefer et al. 2005, respectively). The path that one believes regulates these central transitions can be very different depending on what rate coefficients are used. 

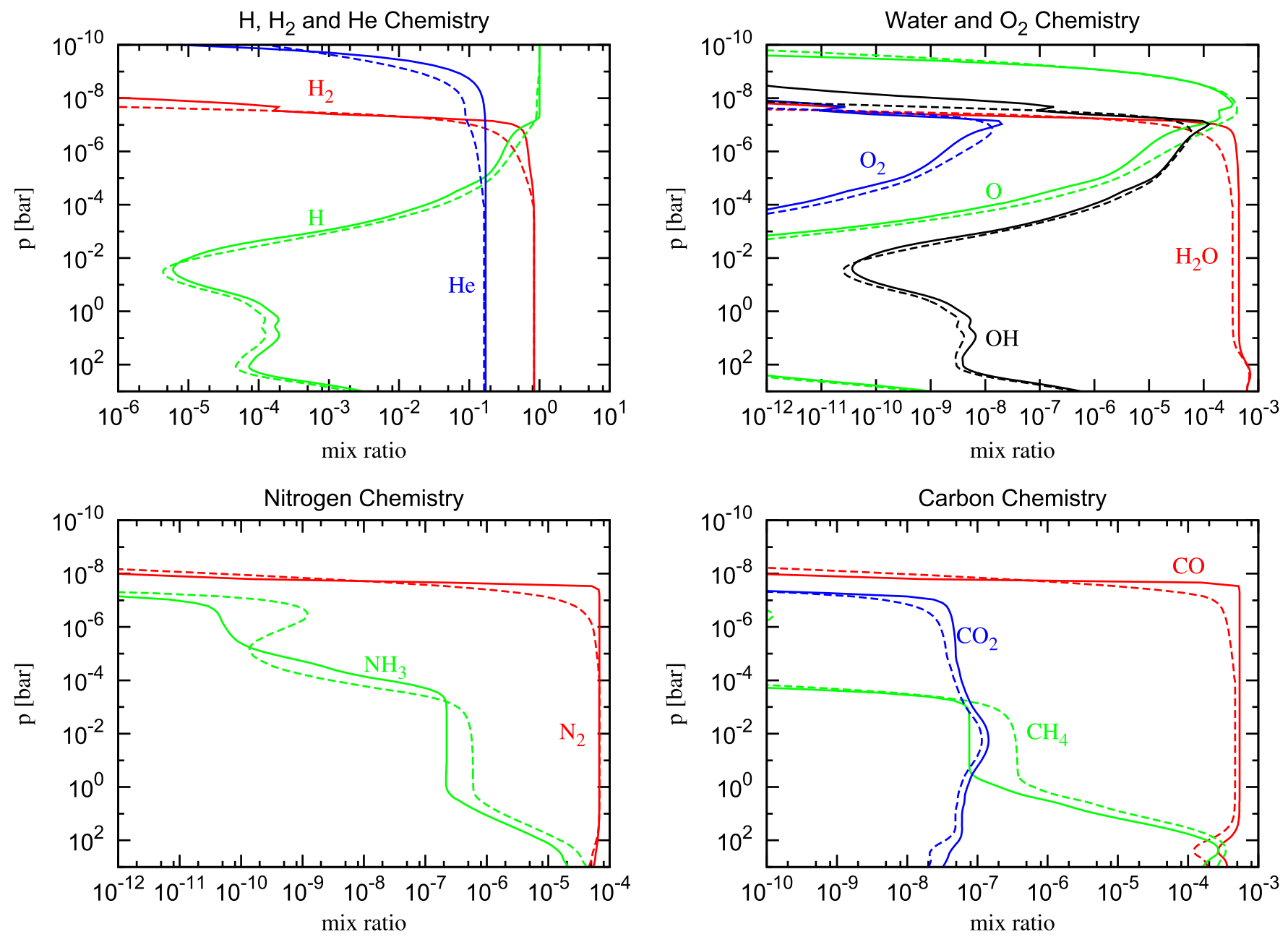

Figure 9. Mixing ratios for various chemical species as a function of pressure, $p$ [bar]. A comparison between our model (solid lines) and that of Moses et al. (2011, dashed lines) is shown for $\mathrm{H} / \mathrm{H}_{2}$ chemistry, water and $\mathrm{O}_{2}$ chemistry, nitrogen chemistry, and carbon chemistry in the atmosphere of $\mathrm{HD} 209458 \mathrm{~b}$.

An illustrative example is the reaction $\mathrm{CH}_{3}+\mathrm{H}_{2} \mathrm{O} \rightarrow \mathrm{CH}_{3} \mathrm{OH}+\mathrm{H}$. Hidaka et al. (1989) has determined the rate for $\mathrm{CH}_{3}+\mathrm{H}_{2} \mathrm{O} \rightarrow$ Products, Reaction (29), proceeds with a barrier of $\approx 2670 \mathrm{~K}$ (see Visscher et al. 2010 for a discussion on this reaction). With reasonable assumptions of the branching ratios for this reaction, namely that the branching ratios do not change much with temperature, one would set the same barrier to $\mathrm{CH}_{3}+\mathrm{H}_{2} \mathrm{O} \rightarrow \mathrm{CH}_{3} \mathrm{OH}+\mathrm{H}$, as done by Venot et al. (2012). However, Moses et al. (2011) carried out quantum chemical calculations for this reaction using MOLPRO and estimate a barrier for this particular branch of $\approx 10380 \mathrm{~K}$, much larger than the activation energies of the other branches. With the smaller barrier, the path carbon takes from $\mathrm{CH}_{4}$ to $\mathrm{CO}$ proceeds as

$$
\begin{aligned}
\mathrm{H}_{2}+\mathrm{M} & \rightarrow \mathrm{H}+\mathrm{H}+\mathrm{M} \\
\mathrm{CH}_{4}+\mathrm{H} & \rightarrow \mathrm{CH}_{3}+\mathrm{H}_{2} \\
\mathrm{CH}_{3}+\mathrm{H}_{2} \mathrm{O} & \rightarrow \mathrm{CH}_{3} \mathrm{OH}+\mathrm{H} \\
\mathrm{CH}_{3} \mathrm{OH}+\mathrm{H} & \rightarrow \mathrm{CH}_{2} \mathrm{OH}+\mathrm{H}_{2} \\
\mathrm{CH}_{2} \mathrm{OH}+\mathrm{M} & \rightarrow \mathrm{H}_{2} \mathrm{CO}+\mathrm{H}_{2}+\mathrm{M} \\
\mathrm{H}_{2} \mathrm{CO}+\mathrm{H} & \rightarrow \mathrm{HCO}+\mathrm{H}_{2} \\
\mathrm{HCO}+\mathrm{H} & \rightarrow \mathrm{CO}+\mathrm{H}_{2} \\
\mathrm{HCO}+\mathrm{M} & \rightarrow \mathrm{CO}+\mathrm{H}+\mathrm{M}
\end{aligned}
$$

$$
\overline{\mathrm{CH}_{4}+\mathrm{H}_{2} \mathrm{O} \rightarrow \mathrm{CO}+3 \mathrm{H}_{2} .}
$$

We adopt the rates of Moses et al. (2011) for this pathway, as well as the smaller rate coefficient for the three-body reaction $\mathrm{H}_{2} \mathrm{O}+\mathrm{CH}_{2}+\mathrm{M} \rightarrow \mathrm{CH}_{3} \mathrm{OH}$. An examination of our results would reveal that, as with Venot et al. (2012), the transition of carbon from $\mathrm{CH}_{4}$ to $\mathrm{CO}$ is much more efficient than with Moses et al. (2011). We have examined the rates at which reactions proceed in our network and find another formation pathway:

$$
\begin{aligned}
\mathrm{H}_{2}+\mathrm{OH} & \leftrightarrow \mathrm{H}_{2} \mathrm{O}+\mathrm{H} \\
\mathrm{OH}+\mathrm{O} & \rightarrow \mathrm{O}_{2}+\mathrm{H} \\
\mathrm{CH}_{4}+\mathrm{H} & \rightarrow \mathrm{CH}_{3}+\mathrm{H}_{2} \\
\mathrm{CH}_{3}+\mathrm{H} & \rightarrow \mathrm{CH}_{2}+\mathrm{H}_{2} \\
\mathrm{CH}_{2}+\mathrm{O}_{2} & \rightarrow \mathrm{COOH}+\mathrm{H} \\
\mathrm{COOH}+\mathrm{H}_{2} \mathrm{O} & \rightarrow \mathrm{CH}_{2} \mathrm{O}_{2}+\mathrm{OH} \\
\mathrm{CH}_{2} \mathrm{O}_{2}+\mathrm{M} & \rightarrow \mathrm{CO}_{2}+\mathrm{H}_{2}+\mathrm{M} \\
\mathrm{CO}_{2}+\mathrm{H} & \rightarrow \mathrm{CO}+\mathrm{OH} \\
\mathrm{CH}_{4}+\mathrm{O} & \rightarrow \mathrm{CO}+2 \mathrm{H}_{2},
\end{aligned}
$$

The atomic oxygen arises from thermal dissociation of $\mathrm{OH}$ or photodissociation of $\mathrm{H}_{2} \mathrm{O}$ followed by diffusion downward. This pathway is critically dependent on Reaction (31). To our knowledge, the three-body rate coefficient for this reaction has 
not been determined. This reaction has instead appeared in our network as the reverse reaction of $\mathrm{CH}_{2} \mathrm{O}_{2}+\mathrm{OH} \rightarrow \mathrm{COOH}+\mathrm{H}_{2} \mathrm{O}$, for which we use an estimate based on reaction energetics (Mansergas \& Anglada 2006). This pathway is highly uncertain, and removing it makes up the majority of the difference between our results and those of Moses et al. (2011) for methane between $1-10^{-4}$ bar. We suspect further differences owe to our different thermochemical constants and the use of slightly different solar abundances.

The path of nitrogen from $\mathrm{NH}_{3}$ to $\mathrm{N}_{2}$ is considerably more uncertain. The path is believed to roughly follow from $\mathrm{NH}_{3}$ to $\mathrm{NH}$ via hydrogen abstraction, which will in turn react with another $\mathrm{NH}_{X}$ species to form $\mathrm{N}_{2} \mathrm{H}_{Y}$. This species will be destroyed either by reacting with hydrogen or via thermal decomposition, to form $\mathrm{N}_{2}$. The reactions $\mathrm{N}_{2} \mathrm{H}_{X+2} \rightarrow \mathrm{NH}_{2}+$ $\mathrm{NH}_{X}$ involve large uncertainties, which result in variations of the $\mathrm{NH}_{3}$ quenched abundance by an order of magnitude. We find, similar to Moses et al. (2011), that

$$
\begin{aligned}
\mathrm{H}_{2}+\mathrm{M} & \rightarrow \mathrm{H}+\mathrm{H}+\mathrm{M} \\
\mathrm{NH}_{3}+\mathrm{H} & \rightarrow \mathrm{NH}_{2}+\mathrm{H}_{2} \\
\mathrm{NH}_{2}+\mathrm{H} & \rightarrow \mathrm{NH}+\mathrm{H}_{2} \\
\mathrm{NH}_{2}+\mathrm{NH} & \rightarrow \mathrm{N}_{2} \mathrm{H}_{2}+\mathrm{H} \\
\mathrm{N}_{2} \mathrm{H}_{2}+\mathrm{H} & \rightarrow \mathrm{NNH}+\mathrm{H}_{2} \\
\mathrm{NNH}+\mathrm{M} & \rightarrow \mathrm{N}_{2}+\mathrm{H}+\mathrm{M}
\end{aligned}
$$

$$
2 \mathrm{NH}_{3} \rightarrow \mathrm{N}_{2}+3 \mathrm{H}_{2}
$$

with Reaction (33) as the rate-limiting step. The profile we have for $\mathrm{NH}_{3}$ deviates considerably from the results of Moses et al. (2011), but this is in large part due to a difference in the nitrogen thermochemistry and initial abundances at high pressures propagating up through the atmosphere. Figure 9 shows that our quenching height is, in both cases, higher than for Moses et al. (2011), suggesting that the nitrogen in $\mathrm{NH}_{3}$ migrates to $\mathrm{N}_{2}$ more slowly in our network, even overtaking Moses et al. (2011) at $\sim 10^{-4}$ bar, but that we start with less $\mathrm{NH}_{3}$ than Moses et al. (2011). The increase in $\mathrm{NH}_{3}$ abundance at $\sim 5 \times 10^{-6}$ bar is due to a formation path for $\mathrm{NH}_{3}$ in Moses et al. (2011) that is less efficient in our network.

We conclude this section with a brief discussion of the most neutral ions, in comparison with Lavvas et al. (2014). We have plotted the most abundant ions in Figure 10. Note that for this paper, $n_{\text {gas }}$ is a sum of all neutral gas particles, cations, ions, and electrons, so the mixing ratio of ions cannot increase above unity. This plot allows a direct comparison to Lavvas et al. (2014, their Figures 5 and 6). In our model, $\mathrm{K}^{+}$is the most abundant ion deep within the atmosphere, followed by $\mathrm{Mg}^{+}$ and $\mathrm{Fe}^{+}$. Lavvas et al. (2014) does not consider these species, but they do not seem to have very much affect on the abundances of other ions deep within the atmosphere. When the pressure delves to $10^{-2}$ bar, $\mathrm{K}^{+}$deviates considerably between our results and those of Lavvas et al. (2014). This is likely due to the inclusion of several other ions in our model that become dominant charge carriers at this height, including several complex hydrocarbon ions, of the form $\mathrm{C}_{n} \mathrm{H}_{m}^{+}$. This indicates that ion-neutral chemistry can be significantly influenced by the variety of ions and neutral species under consideration. This will be especially true for the potassium chemistry. Our network contains a small number of potassium-

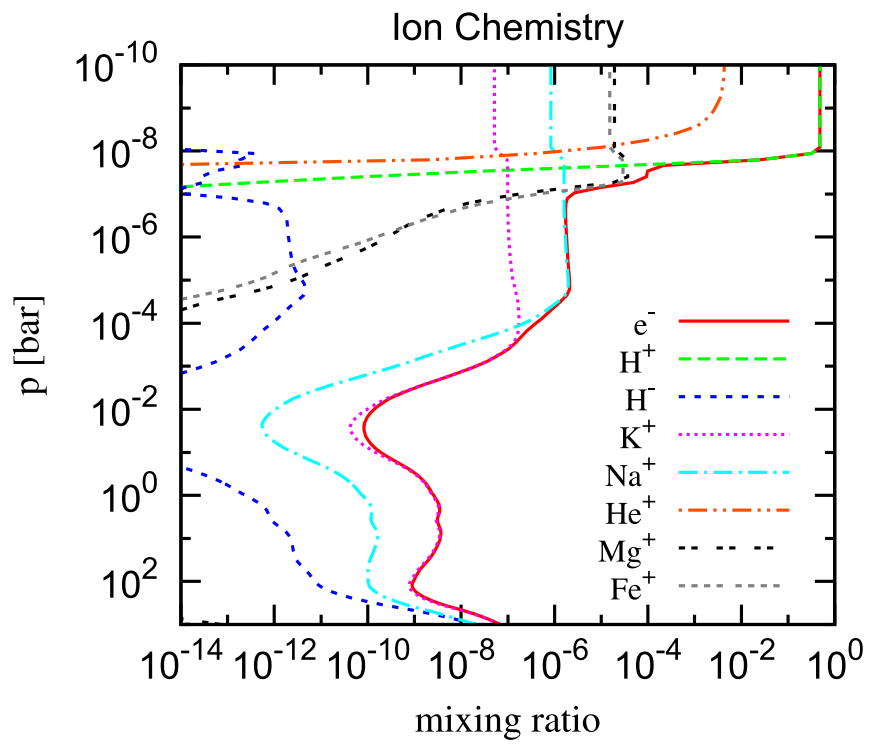

Figure 10. Mixing ratios for the dominant ionic species as a function of pressure, $p$ [bar], for the atmosphere of HD 209458b.

bearing species. Including new species and reactions could significantly affect the degree of ionization. It will be interesting to discover how an expanded potassium and sodium chemistry affects the overall ion-neutral chemistry and the resulting abundances of trace species.

Between $10^{-3}$ and $10^{-4}$ bar, $\mathrm{Na}^{+}$overtakes $\mathrm{K}^{+}$as the dominant positive charge carrier, and remains so until $\sim 10^{-7}$ bar. This transition, the ratios between the ions, and the abundances of the ions are nearly identical between our model and that of Lavvas et al. (2014). Within the thermosphere of HD 209458b, there are some small discrepancies between our model and Lavvas et al. (2014) for $\mathrm{He}^{+}$, and quite large discrepancies for $\mathrm{C}^{+}$which we suggest are owing to the nonAlkali photochemistry that Lavvas et al. (2014) include, but that we have not included here.

\subsection{Jupiter}

The atmosphere of Jupiter is divided into three regions: (1) the troposphere, where the gas-phase temperature $T$ decreases with atmospheric height, (2) the stratosphere, where $T$ is roughly constant with increasing height, and (3) the thermosphere, where $T$ increases with height. In this section, we consider the chemical composition of Jupiter's stratosphere. The stratosphere of Jupiter is rich in hydrocarbons, owing to its large gas-phase $\mathrm{C} / \mathrm{O}$ ratio, because the majority of the oxygen is locked in water ice and then gravitationally settles to below the tropopause. This is predicted to lead to a $\mathrm{C} / \mathrm{O} \sim 2 \times 10^{6}$ (Moses et al. 2005) in the absence of external sources of $\mathrm{H}_{2} \mathrm{O}$ and $\mathrm{CO}_{2}$ (Feuchtgruber et al. 1997; Moses et al. 2000a, 2000b), such as Shoemaker-Levy 9 (Cavalié et al. 2012). Jupiter's stratosphere provides an extreme example of how surface deposition can radically affect the $\mathrm{C} / \mathrm{O}$ ratio, an effect more recently predicted for exoplanets and brown dwarfs (Bilger et al. 2013; Helling et al. 2014). The high $\mathrm{C} / \mathrm{O}$ ratio, in combination with the large abundance of hydrogen $\left(\mathrm{H}_{2}\right.$ and $\mathrm{CH}_{4}$ are the two most abundant volatiles in the stratosphere and lower thermosphere), means that the stratosphere of Jupiter is strongly reducing (Strobel 1983). 


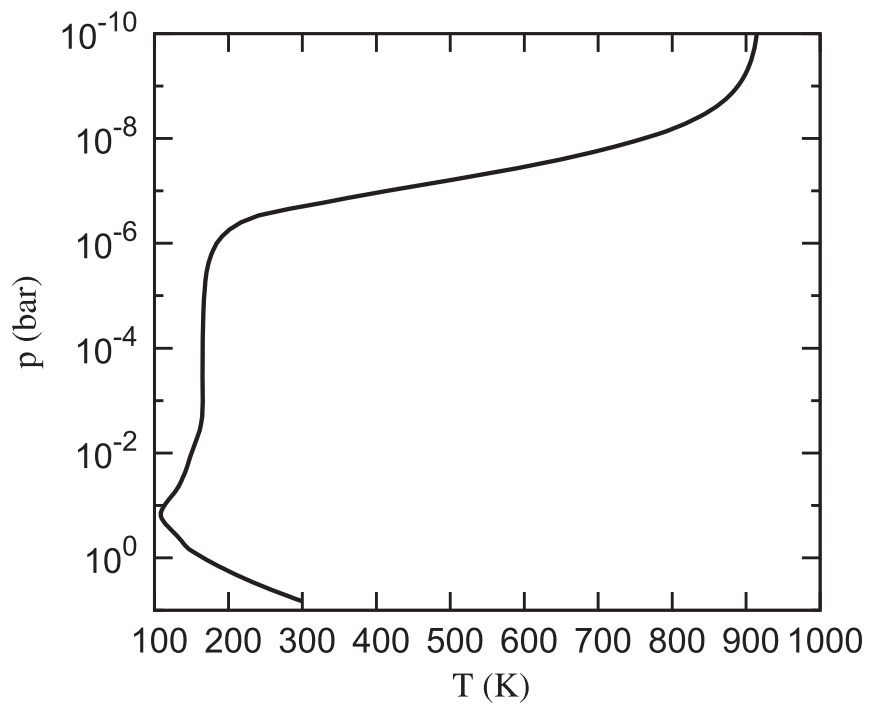

Figure 11. Temperature profile for Jupiter, $T[\mathrm{~K}]$, as a function of $p[\mathrm{bar}]$ (Moses et al. 2005).

Fouchet et al. (2000) have observed ethane and acetylene in Jupiter's stratosphere. Ethylene has also been observed by Bézard et al. (2001). The stratospheric chemistry of Jupiter has been modeled by several groups, including Gladstone et al. (1996) and Moses et al. (2005). We adopt the lower boundary conditions and temperature profile that Moses et al. (2005) used and model the carbon-oxygen chemistry in the stratosphere of Jupiter, ignoring the nitrogen chemistry (most of the nitrogen will be locked in $\mathrm{NH}_{3}$ ice). Boundary conditions are discussed in Section 4.1.

Our lower boundary is set to be identical to Moses et al. (2005). These boundary conditions are somewhat artificial; the carbon budget is controlled by the photochemistry and the dynamics. There is no effective destruction pathway for the stable hydrocarbons, but the timescale for their formation is often competing with the dynamical timescales. In the thermosphere, $\sim 10^{-7}-10^{-8}$ bar, these hydrocarbons are lost through photodissociation and photoionization as well as molecular diffusion. At the base, the chemistry is halted once the dynamical timescale is reached, effectively treating the bottom boundary as an open boundary through which the hydrocarbons would continue to diffuse. In reality, the complex hydrocarbons are carried into Jupiter's deep atmosphere, where the high temperatures and pressures dissociate these hydrocarbons, and force the carbon budget to return to chemical equilibrium values: $\mathrm{CH}_{4}$ with trace amounts of $\mathrm{CO}$ and other species. Visscher et al. (2010, their Figure 6) demonstrate how the carbon budget is set deep within Jupiter's atmosphere; we do not model this region.

With these reactions removed from the network, we ran the network using the temperature and $K_{z} z$ profiles from Moses et al. (2005), shown in Figure 11. Comparisons between our results and a representative set of observations for the depthdependent mixing ratios, for the species $\mathrm{CH}_{4}, \mathrm{C}_{2} \mathrm{H}_{2}, \mathrm{C}_{2} \mathrm{H}_{4}$, $\mathrm{C}_{2} \mathrm{H}_{6}$, and $\mathrm{C}_{4} \mathrm{H}_{2}$, are shown in Figure 12. The observations for $\mathrm{CH}_{4}$ are taken from Drossart et al. (1999) and Yelle et al. (1996), $\mathrm{C}_{2} \mathrm{H}_{2}$ observations are from Fouchet et al. (2000), Moses et al. (2005), and Kim et al. (2010), $\mathrm{C}_{2} \mathrm{H}_{4}$ observations are from Romani et al. (2008) and Moses et al. (2005), $\mathrm{C}_{2} \mathrm{H}_{6}$ observations are from Fouchet et al. (2000), Moses et al.
(2005), Yelle et al. (2001) and Kim et al. (2010), and the $\mathrm{C}_{4} \mathrm{H}_{2}$ observations are from Fouchet et al. (2000) and Moses et al. (2005). We also incorporate observations for $\mathrm{C}_{2} \mathrm{H}_{2}, \mathrm{C}_{2} \mathrm{H}_{4}$, and $\mathrm{C}_{2} \mathrm{H}_{6}$ from Gladstone et al. (1996) and references therein.

Many of the published observations do not include error bars in atmospheric pressure. Additionally, there may seasonal in the pressure-temperature structure and the location of the homopause, which adds uncertainty to our predictions as a function of pressure. To account for these sources of uncertainty, we place error bars for the pressure at a factor of two above and below the published observations when errors in pressure were not given. These errors in pressure are of the same order as observations where errors in pressure are given. We do not compare our results for oxygen-bearing species, because the abundances of these species are expected to be greatly enhanced in the stratosphere by the addition of an external source of oxygen, such as Shoemaker-Levy 9.

The differences between our results and those of other models arise primarily because of different photochemistries and different rate constants, especially for the re-formation of methane after its photodissociation,

$$
\begin{aligned}
& \mathrm{CH}_{3}+\mathrm{H}_{2} \rightarrow \mathrm{CH}_{4}+\mathrm{H} \text {, and } \\
& \mathrm{CH}_{3}+\mathrm{H}+\mathrm{M} \rightarrow \mathrm{CH}_{4}+\mathrm{M} .
\end{aligned}
$$

Differences between Jovian photochemical models can result in very large discrepancies between stratospheric abundances of complex hydrocarbons. The differences between Gladstone et al. (1996) and Moses et al. (2005) span several orders of magnitude in some cases (see Moses et al. 2005, their Figure 14).

Both ethane and acetylene agree reasonably well between our model and the observations, and the results for $\mathrm{C}_{4} \mathrm{H}_{2}$ lie more than a factor of five below the observational upper limits. Our predictions for the location of the methane homopause do not agree very well with observations. We use the eddy diffusion coefficient from Model C in Moses et al. (2005), and either this or the use of the Chapman-Enskog diffusion coefficient for Methane may be the source of the discrepancy. Our results are similar to the Model $\mathrm{C}$ results of Moses et al. (2005, their Figure 14). The molecule with the largest discrepancy between the two models is ethylene $\left(\mathrm{C}_{2} \mathrm{H}_{4}\right)$, with the largest discrepancy between our predictions and the 1 millibar observations (ignoring the observation from Gladstone et al. 1996 that predicts a mixing ratio of $\sim 10^{-8}$ ). In our model, the primary path of formation for ethylene follows from the photodissociation of ethane (Reaction 2679 in the network),

$$
\mathrm{C}_{2} \mathrm{H}_{6}+\gamma \rightarrow \mathrm{C}_{2} \mathrm{H}_{4}+\mathrm{H}_{2} \text {, }
$$

and ethane is formed from $\mathrm{CH}_{4}$ following paths to formation like this one:

$$
\begin{aligned}
2\left(\mathrm{CH}_{4}+\gamma\right. & \left.\rightarrow{ }^{1} \mathrm{CH}_{2}+\mathrm{H}_{2}\right), \\
2\left({ }^{1} \mathrm{CH}_{2}+\mathrm{H}_{2}\right. & \left.\rightarrow \mathrm{CH}_{3}+\mathrm{H}\right), \\
\mathrm{CH}_{3}+\mathrm{CH}_{3}+\mathrm{M} & \rightarrow \mathrm{C}_{2} \mathrm{H}_{6}+\mathrm{M} ;
\end{aligned}
$$$$
2 \mathrm{CH}_{4}+2 \gamma \rightarrow \mathrm{C}_{2} \mathrm{H}_{6}+2 \mathrm{H} \text {. }
$$

These differences may be resolved by a more careful accounting of pressure-dependent branching ratios, such as those of

$$
\mathrm{H}+\mathrm{C}_{2} \mathrm{H}_{5} \rightarrow \mathrm{CH}_{3}+\mathrm{CH}_{3}
$$




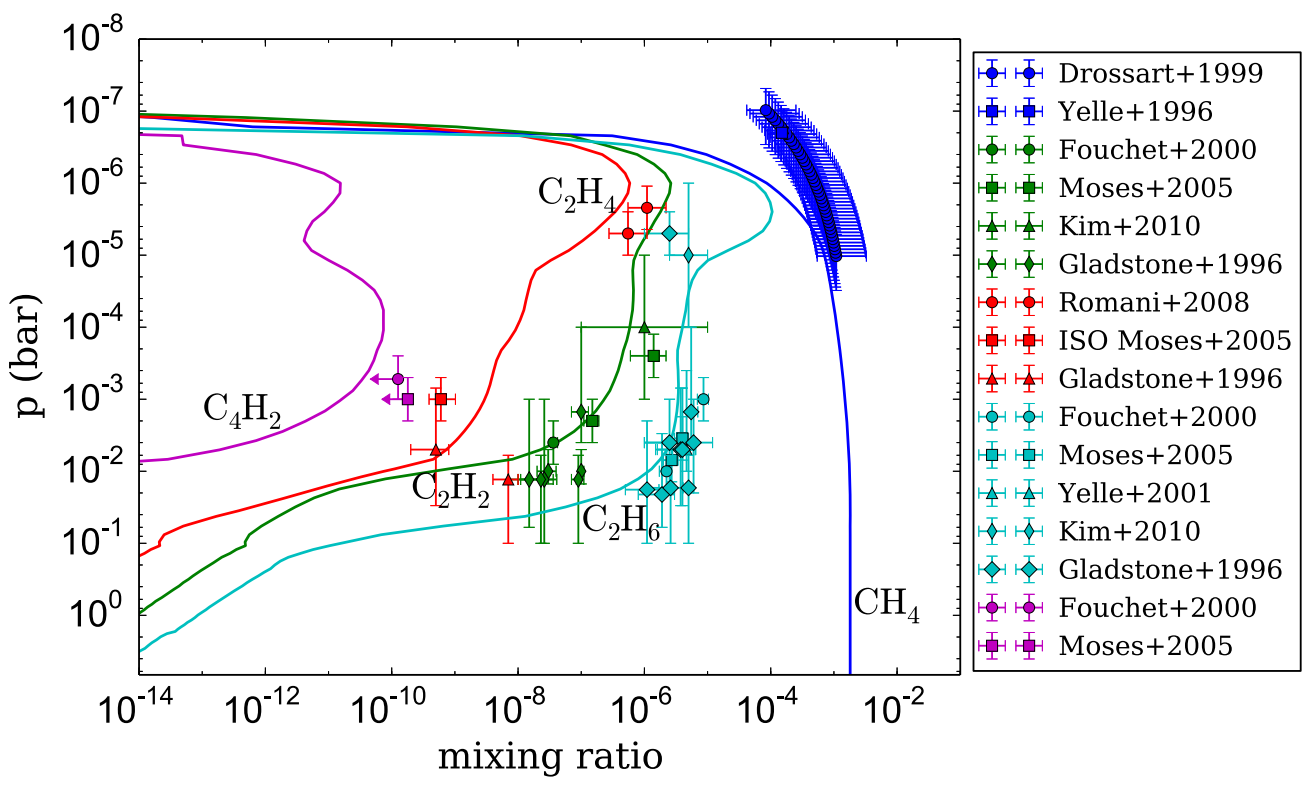

Figure 12. Mixing ratios for various chemical species as a function of pressure, $p$ [bar]. A comparison between our model (solid lines) and that of various observations is shown for complex hydrocarbons in the stratosphere of Jupiter.

from Loison et al. (2015). We use the Kooij form for these reactions (Section 2.1), which does not account for the effect that pressure has on the rate constant.

Ion-neutral chemistry also makes a contribution, via the formation of $\mathrm{C}_{2} \mathrm{H}_{4}$ from the reaction

$$
\begin{aligned}
\mathrm{CH}_{5}^{+}+\mathrm{C}_{2} \mathrm{H}_{2} & \rightarrow \mathrm{C}_{2} \mathrm{H}_{3}^{+}+\mathrm{CH}_{4} \\
\mathrm{C}_{2} \mathrm{H}_{3}^{+}+e^{-}+\mathrm{M} & \rightarrow \mathrm{C}_{2} \mathrm{H}_{3}+\mathrm{M} \\
\mathrm{C}_{2} \mathrm{H}_{3}+\mathrm{CH}_{4} & \rightarrow \mathrm{C}_{2} \mathrm{H}_{4}+\mathrm{CH}_{3},
\end{aligned}
$$

and $\mathrm{CH}_{5}^{+}$forms from a series of reactions starting with the photoionization of $\mathrm{CH}_{3}$ and then a series of hydrogen abstractions, $\mathrm{CH}_{x}^{+}+\mathrm{H}_{2} \rightarrow \mathrm{CH}_{x+1}^{+}+\mathrm{H}$. It should be emphasized that this is not the primary formation pathway for ethylene, but it is an important path of formation in our chemistry and makes some contribution to the mixing ratios at 1 millibar.

Finally, there is a large discrepancy for $\mathrm{CO}$, but this is not due to differences in the chemistry. Rather, this results from Moses et al. (2005) injecting $\mathrm{CO}, \mathrm{CO}_{2}$, and $\mathrm{H}_{2} \mathrm{O}$ into Jupiter's stratosphere. The inclusion of this external source of oxygenbearing species is justified by a number of data model comparisons mentioned at the beginning of this section. We neglected to include these external sources, and therefore oxygen-bearing species, especially $\mathrm{H}_{2} \mathrm{O}$ and $\mathrm{CO}_{2}$ (not shown), fail to agree with observations. Our results therefore suggest that some external source of oxygen-bearing species is necessary to explain the $\mathrm{H}_{2} \mathrm{O}$ and $\mathrm{CO}_{2}$ observations in Jupiter's stratosphere.

\subsection{The Earth}

The Earth's atmosphere is well studied, and the profiles of trace species are well constrained, and the formation and destruction of these species is controlled by photochemistry and deposition. Comparing our results to the present-day Earth atmosphere therefore provides a comprehensive test of our

\footnotetext{
8 Referring primarily to $\mathrm{NO}$ and $\mathrm{NO}_{2}$ chemistry.
}

chemical network (Section 4.4.1). Additionally, the connection between lightning-driven and $\mathrm{NO}_{x}$ chemistry ${ }^{8}$ has been extensively studied with experiments, observations, and models, and provides a useful regime in which to compare the results of STAND2015 applied to a lightning shock model (Section 4.4.2). It is important to find out what our model predicts in habitable environments before the onset of life, and so we apply our model to the early Earth (Section 4.4.3).

\subsubsection{Present-day Earth Atmosphere}

The best understood planetary atmosphere, in terms of both models and observations, is the atmosphere of the present-day Earth. Earth's atmosphere has been studied in situ, with the use of countless balloon experiments used to measure various trace elements, and remotely, with satellite measurements. Models of Earth's atmosphere range from simple to complex, both dynamically (1D diffusion to 3D global circulation models) and chemically (from treating only oxygen and hydrogen chemistry to modeling the transport and chemistry of chlorofluorocarbons and biological aerosols). Seinfeld \& Pandis (2006) provide a useful introduction and review to the subject.

Our interest is in validating our photochemical network to the present-day Earth, and not in coupling Earth's geochemistry to its atmospheric chemistry. We therefore make some simplifying assumptions when we set our boundary conditions. We compare our model to the contemporary Earth by setting the lower boundary conditions, temperature profile, and external UV field as given in Section 4.1. We present these comparisons for $\mathrm{O}_{3}, \mathrm{CH}_{4}$, and $\mathrm{N}_{2} \mathrm{O}$ (Figure 14), $\mathrm{NO}$ and $\mathrm{NO}_{2}$ (Figure 15), and $\mathrm{OH}$ and $\mathrm{H}_{2} \mathrm{O}$ (Figure 16).

The data for $\mathrm{O}_{3}, \mathrm{CH}_{4}$, and $\mathrm{N}_{2} \mathrm{O}$ is taken from the globally averaged mixing ratios from Massie \& Hunten (1981). Following Hu et al. (2012), we apply error bars spanning an order of magnitude in mixing ratio to reflect the temporal and spatial variations. Our model fits the measured $\mathrm{CH}_{4}$ to within the error bars throughout the atmosphere. The $\mathrm{O}_{3}$ predicted by the model deviates from the data with errors at $15 \mathrm{~km}$, and the 


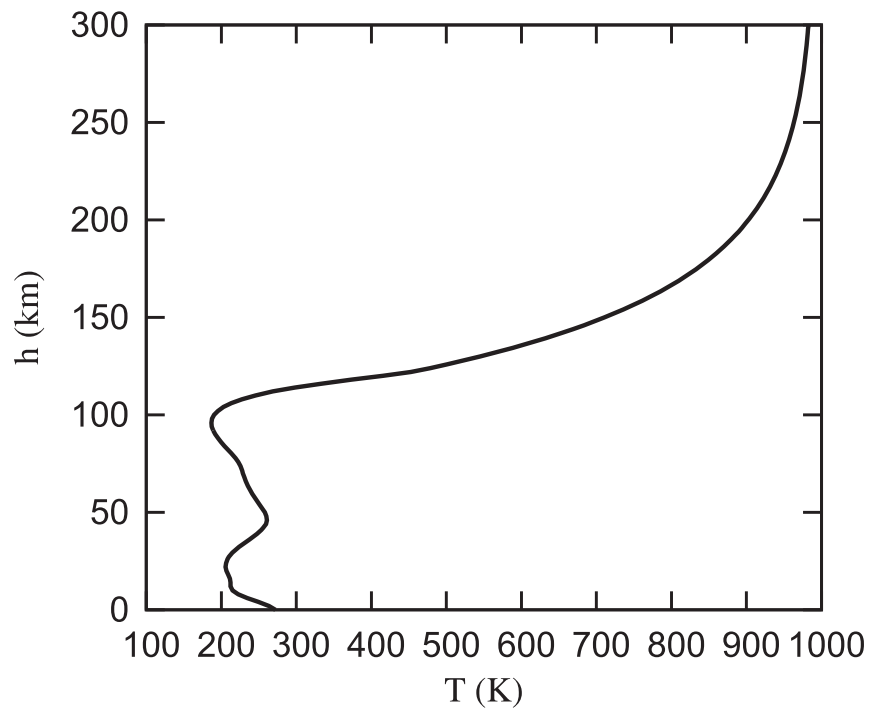

Figure 13. Temperature profile used for the early Earth chemistry, temperature $[\mathrm{K}]$ vs. height $[\mathrm{km}]$. This profile is a synthetic profile for the Earth's atmosphere generated with the MSIS-E-90 model for the date $2000 / 1 / 1$ (Hedin 1987, 1991).

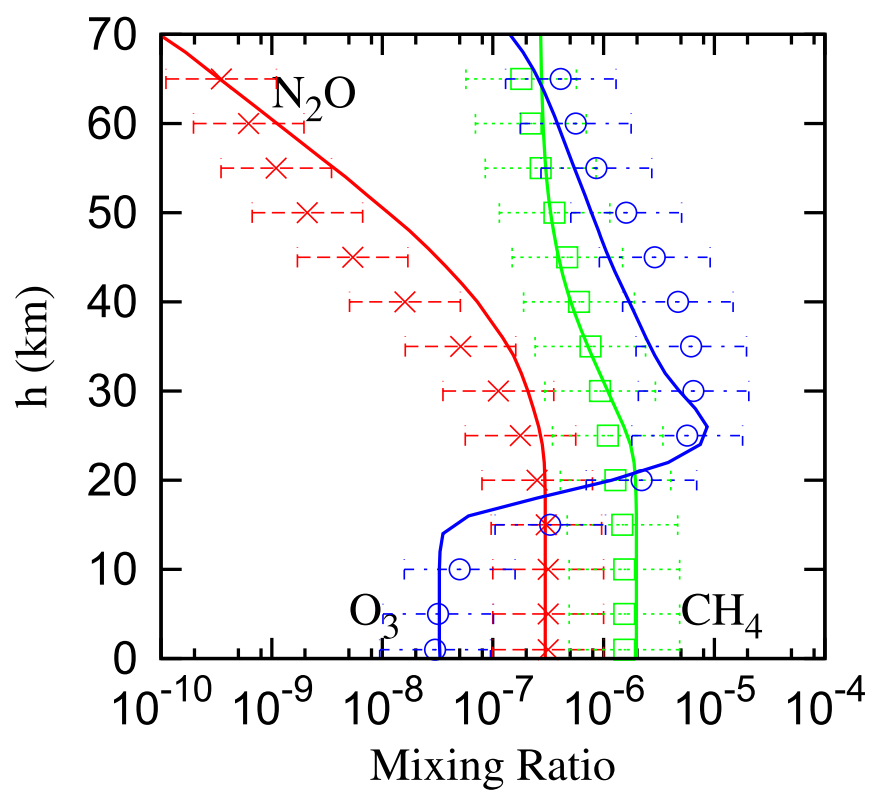

Figure 14. Mixing ratios of ozone, methane, and nitrous oxide as a function of atmospheric height $[\mathrm{km}]$ for the atmosphere of the present-day Earth. The lines are produced by our model and the points are taken from globally averaged measurements (Massie \& Hunten 1981). Errors are set to an order of magnitude to account for diurnal and latitudinal variations.

$\mathrm{N}_{2} \mathrm{O}$ deviates from the data with errors between 40 and $55 \mathrm{~km}$. This may be due to an overestimation of the optical depth. If more UV photons in the model penetrated through to $\sim 10 \mathrm{~km}$, the $\mathrm{O}_{3}$ mixing ratios would be enhanced at $15 \mathrm{~km}$, and the $\mathrm{N}_{2} \mathrm{O}$ mixing ratios would be destroyed more efficiently deeper in the atmosphere.

The data for $\mathrm{NO}$ and $\mathrm{NO}_{2}$ is taken from balloon observations at $35 \mathrm{deg} \mathrm{N}$ in 1993 (Sen et al. 1998), and here also we apply error bars spanning an order of magnitude to reflect spatial and temporal variations. As with $\mathrm{Hu}$ et al. (2012), we seem to overpredict the abundance of NO in the upper atmosphere $(30-40 \mathrm{~km})$. We find that this overprediction is due to Reaction

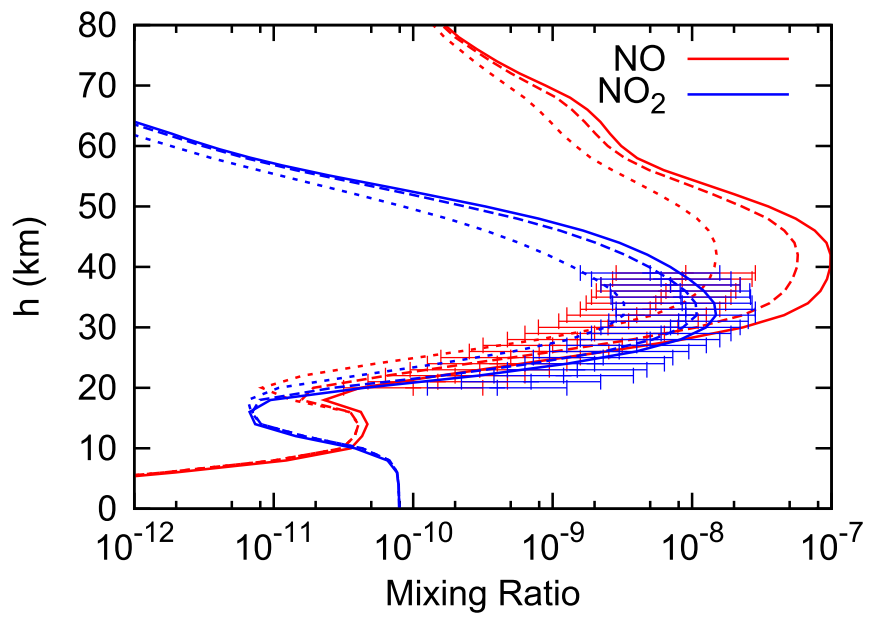

Figure 15. Mixing ratios of $\mathrm{NO}$ and $\mathrm{NO}_{2}$ as a function of atmospheric height $[\mathrm{km}]$ for the atmosphere of the present-day Earth. The lines are produced by our model and the points are taken from balloon measurements (Sen et al. 1998). Errors are set to an order of magnitude to account for diurnal and latitudinal variations. We also show the results from suppressing the rate constant for Reaction 1300 in the network by a factor of 2 (dashed) and a factor of 10 (dotted).

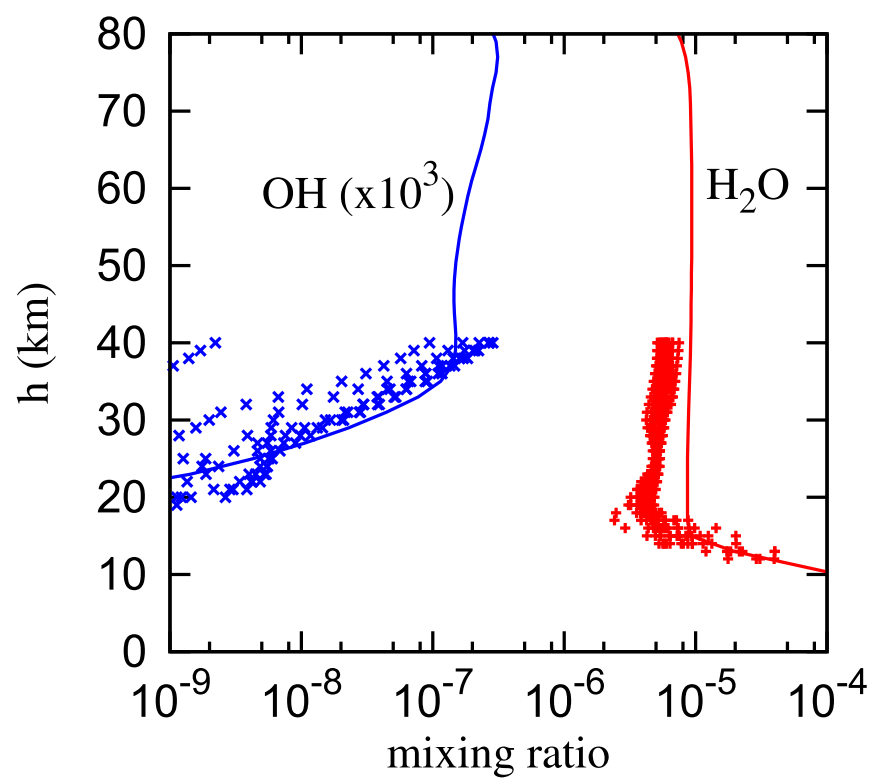

Figure 16. Mixing ratios of $\mathrm{OH}$ and $\mathrm{H}_{2} \mathrm{O}$ as a function of atmospheric height $[\mathrm{km}]$ for the atmosphere of the present-day Earth. The lines are produced by our model and the points are taken from balloon measurements at various latitudes, heights, and times (Kovalenko et al. 2007).

1300 in the network:

$$
\begin{aligned}
& \mathrm{N}_{2} \mathrm{O}+\mathrm{O}\left({ }^{1} \mathrm{D}\right) \rightarrow \mathrm{NO}+\mathrm{NO} ; \\
& k=7.25 \times 10^{-11} \mathrm{~cm}^{3} \mathrm{~s}^{-1} .
\end{aligned}
$$

We use the rate suggested by the JPL Chemical Kinetics and Photochemical Data for Use in Atmospheric Studies (Sander et al. 2011). If the rate constant for this reaction is decreased by a factor somewhere between 2 and 10, we come into much better agreement at $30-40 \mathrm{~km}$, and worse agreement between 20-30 km (see Figure 15).

Finally, the data from $\mathrm{OH}$ and $\mathrm{H}_{2} \mathrm{O}$ was taken from balloon measurements at various latitudes and heights in 2005 (Kovalenko et al. 2007). We plot each individual data point 


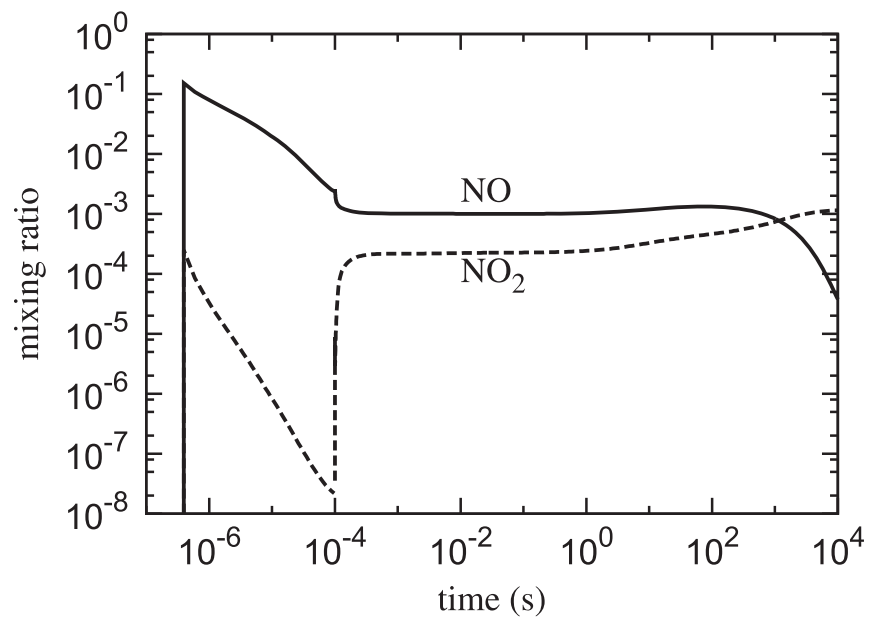

Figure 17. Mixing ratios of $\mathrm{NO}$ (solid) and $\mathrm{NO}_{2}$ (dashed) vs. time [s] in a simulation of a lightning shock on a parcel of gas with an Earth-like atmospheric composition, initially at $300 \mathrm{~K}$ and 1 bar. The temperature and pressure vary as a function of time as described by Orville (1968), until $10^{-4} \mathrm{~s}$, at which time conditions are returned to $300 \mathrm{~K}$ and 1 bar, and the system is allowed to further evolve.

without error bars in order to represent the observed variations; changes at other points of the globe or at other times of the year or day may lead to more significant variations in the abundances. The $\mathrm{H}_{2} \mathrm{O}$ predictions are within a factor of five of the observed water abundance, and our $\mathrm{OH}$ predictions lie within the measurements, indicating that the model correctly reproduces the water and $\mathrm{OH}$ mixing ratios.

\subsubsection{Lightning Shock Model and $N O_{x}$ Chemistry}

It is also useful to the model's $\mathrm{NO}_{x}$ lightning-driven chemistry in the present-day atmosphere. For this purpose, we apply a simple shock model in order to explore the formation of $\mathrm{NO}_{x}$ species due to lightning at a single small region in the atmosphere. We employ the temperature and pressure calculations of Orville (1968, his Figures 1 and 3) and the timescaled results of Jebens et al. (1992, their Figures 2 and 3 ), fitting these to an exponential function. We use the following functions of temperature and pressure:

$$
\begin{gathered}
T(t)=300 \mathrm{~K}+(29800.0 \mathrm{~K}) e^{-t /(55.56 \mu \mathrm{s})} ; \\
P(t)=1.0 \mathrm{bar}+(7.0 \mathrm{bar}) e^{-t /(5.88 \mu \mathrm{s})} .
\end{gathered}
$$

We start with present-day atmospheric chemistry at the base of the troposphere, except without the $\mathrm{N}_{2} \mathrm{O}, \mathrm{NO}$, and $\mathrm{NO}_{2}$ species, and with $T=300 \mathrm{~K}$ and $p=1 \mathrm{bar}$. The shock occurs at $1 \mathrm{~ns}$, and is allowed to evolve until $0.1 \mathrm{~ms}$. At this point the calculation is terminated, and another calculation initiated using for its initial conditions the final conditions of the shock model, except with temperature and pressure returned to $300 \mathrm{~K}$ and 1 bar, respectively. This model is run until $10^{4} \mathrm{~s}$ and results are shown in Figure 17.

We find that the $\mathrm{NO}_{x}$ species are formed in our model thermally by the Zel'dovich mechanism (Zel'dovich \& Raizer 1996):

$$
\begin{gathered}
\mathrm{O}_{2}+\mathrm{M} \rightleftharpoons \mathrm{O}+\mathrm{O}+\mathrm{M}, \\
\mathrm{N}_{2}+\mathrm{M} \rightleftharpoons \mathrm{N}+\mathrm{N}+\mathrm{M}, \\
\mathrm{O}+\mathrm{N}_{2} \rightarrow \mathrm{NO}+\mathrm{N}, \\
\mathrm{N}+\mathrm{O}_{2} \rightarrow \mathrm{NO}+\mathrm{O},
\end{gathered}
$$

$$
\mathrm{O}_{2}+\mathrm{N}_{2} \rightarrow 2 \mathrm{NO} \text {. }
$$

We compare our NO yield to the lightning discharge experiments performed by Navarro-González et al. (2001). We use for our NO mixing ratio the values found before the end of the shock $\left(10^{-4} \mathrm{~s}\right.$ in Figure 17$)$, between $10^{-2}$ and $10^{-3}$, to (Navarro-González et al. 2001, their Equation (4)). We find that

$$
\begin{aligned}
P(\mathrm{NO}) & \approx\left(2.4 \times 10^{22} \mathrm{~K} / \mathrm{J}\right) \frac{X(\mathrm{NO})}{T_{f}} \\
& \approx 2-20 \times 10^{16} \text { molecules } \mathrm{J}^{-1},
\end{aligned}
$$

where $T_{f}[\mathrm{~K}]$ is the "freeze-out" temperature after which the NO mixing ratio does not change appreciably over the timescale of the experiment, which we set to $1000 \mathrm{~K}$ (the approximate temperature of our model at $t \approx 10^{-4} \mathrm{~s}$ ). This is consistent with the production of $\mathrm{NO}$ in the "hot core" region of the experiment. This is also roughly consistent with the literature values for NO production of $10^{17}$ molecules $\mathrm{J}^{-1}$ (Borucki et al. 1984; Price et al. 1997).

This is an order of magnitude comparison between the code and lightning experiments and models, and for a more complete comparison will need to be applied to a model atmosphere, where diffusion and photochemistry together will further process the $\mathrm{NO}_{x}$ species. We plan to do this in a future paper.

\subsubsection{The Early Earth}

The presence of life and the evolution of the Sun both have radically altered Earth's atmospheric chemistry. Oparin (1957) and Miller \& Urey (1959) thought that the atmosphere of the early Earth ${ }^{9}$ was largely reducing, dominated by methane, ammonia, and molecular hydrogen. Kasting (1993) made a compelling case that prebiotic formation of hydrogen would be too slow to allow for much molecular hydrogen in the atmosphere of the early Earth. Furthermore, a major constituent in the early Earth atmosphere needs to be a strong greenhouse gas, in order to compensate for the cooler young Sun. The atmospheric chemistry of the early Earth is difficult to determine, and a severe lack of data results in many possible early Earth chemistries. As an illustrative example, Tian et al. (2005) argue that hydrogen escape was less efficient during the first 1 Gyr as was previously thought. ${ }^{10}$ If Tian et al. (2005) are correct, then Earth's early atmospheric composition could have been reducing.

We present a model of the atmosphere of the early Earth, using the same lower boundary conditions as shown in Kasting (1993, his Figure 1), and a temperature profile for the present Earth (Hedin 1987, 1991) ${ }^{11}$, shown in Figure 13. The lower boundary conditions used for the early Earth are given in Section 4.1. We treat outgassing using the deposition method (Appendix C).

We compare our results to those of Kasting (1993, see his Figure 1). Our results are presented in Figure 18. The results compare reasonably well for $\mathrm{CO}$ and $\mathrm{O}_{2}$, but not for $\mathrm{H}_{2} \mathrm{O}$ and $\mathrm{O}$. The $\mathrm{CO}$ abundance begins to increase at $30 \mathrm{~km}, 10 \mathrm{~km}$ higher than for Kasting (1993), and achieves a mixing ratio of $\approx 5 \times 10^{-3}$ at $60 \mathrm{~km}$, which is within a factor of 2 of Kasting (1993). The $\mathrm{O}_{2}$ likewise begins to rise above a mixing ratio of

\footnotetext{
9 "Early Earth" in this context means the Earth in its first $1 \mathrm{Gyr}$

${ }^{10}$ The debate is ongoing (Catling 2006; Claire et al. 2006).

${ }^{11} \mathrm{http}$ // omniweb.sci.gsfc.nasa.gov/vitmo/
} 


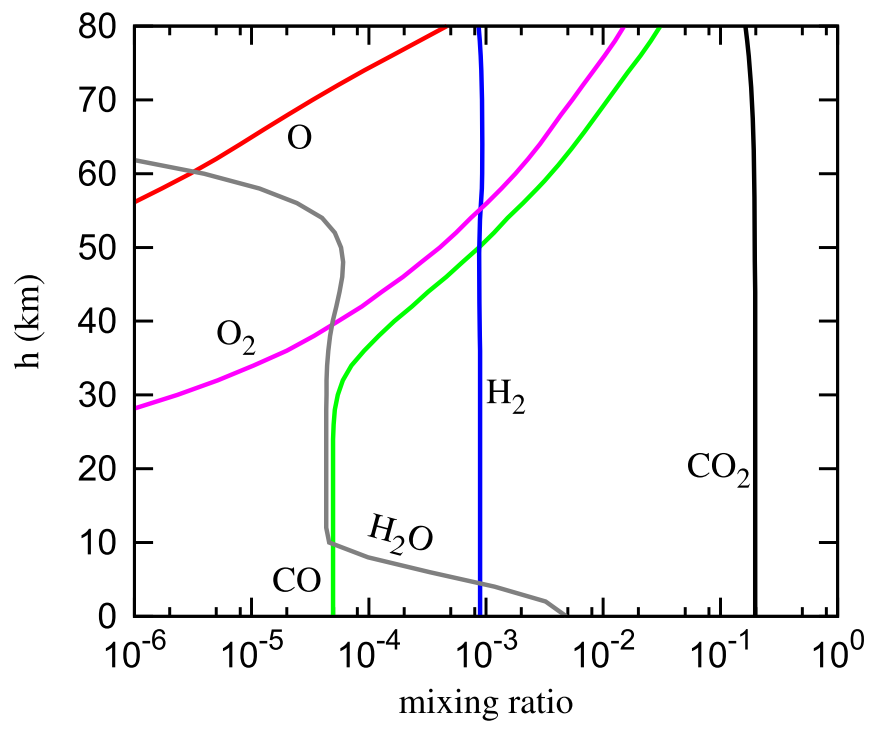

Figure 18. Mixing ratios for $\mathrm{O}, \mathrm{H}_{2}, \mathrm{CO}, \mathrm{O}_{2}, \mathrm{H}_{2} \mathrm{O}$, and $\mathrm{CO}_{2}$, as a function of height $[\mathrm{km}]$, for early Earth photochemistry. These results can be compared to the results of Kasting (1993, his Figure 1).

$10^{-6} 10 \mathrm{~km}$ higher in the atmosphere, and also achieves a mixing ratio of $\approx 2.5 \times 10^{-3}$, again within a factor of 2 of Kasting (1993). The water vapor profile is quite different, however. Instead of falling below a mixing ratio of $10^{-6}$ at $10 \mathrm{~km}$, the $\mathrm{H}_{2} \mathrm{O}$ mixing ratio in our model levels out at $5 \times 10^{-4}$, increasing slightly at $\sim 50 \mathrm{~km}$ before plummeting. Also, the oxygen mixing ratio only reaches $\approx 3 \times 10^{-6}$, approximately two orders of magnitude below the mixing ratio predicted by Kasting (1993). These differences may be due to the different young solar UV fields assumed between ourselves and Kasting (1993), but we suspect that the differences are more likely due either to differences in the water condensation or the temperature profiles used. This seems especially likely for atomic oxygen, which is primarily destroyed by the reaction

$$
\mathrm{O}+\mathrm{H}_{2} \mathrm{O} \rightarrow \mathrm{OH}+\mathrm{OH}
$$

in spite of the sizeable $7640 \mathrm{~K}$ barrier. When the water vapor drops off at $\sim 55 \mathrm{~km}$, this destruction route becomes unviable, and the atomic oxygen mixing ratio rapidly increases.

\section{GLYCINE FORMATION IN A LABORATORY ENVIRONMENT}

The formation of glycine, among several other amino acids, amines, and nucleotides, has been investigated for a variety of chemical compositions, from reducing (Miller 1953) to oxidizing (Schlesinger \& Miller 1983; Miyakawa et al. 2002; Cleaves et al. 2008), and exploring various energy sources (see Miller \& Urey 1959, and references therein). In a recent experiment, $\mathrm{HCN}$ and $\mathrm{H}_{2} \mathrm{~S}$ were exposed to UV light (peak frequency $2540 \AA$ ), resulting in the formation of numerous complex prebiotic compounds (Patel et al. 2015). The techniques used in this experiment afforded the experimenters to track the pathways of formation for these various species.

Prebiotic species are produced in smaller concentrations within a more oxidizing environments (Miller \& Urey 1959). Methane has been found to be important for the formation of prebiotic compounds (Schlesinger \& Miller 1983; Miyakawa et al. 2002). The correlation between reducing chemistry and the efficient production of prebiotic molecules, combined with compelling evidence that the atmosphere of the early Earth was oxidizing (Kasting 1993), would suggest that other processes were responsible for producing the prebiotic chemical inventory on Earth. This process is hypothesized to have taken place within hydrothermal vents (e.g., Ferris 1992), on the surfaces of crystals (Vijayan 1980), or possibly within the interstellar medium (e.g., Greenberg et al. 1995).

Cleaves et al. (2008) have repeated Miller's experiment in a reducing environment, and discovered that amino acids can be efficiently produced in such environments, but that nitrites (e.g., HONO) destroy these species as quickly as they are produced. Adding ferrous iron, in the form of $\mathrm{FeO}$ or $\mathrm{FeS}_{2}$ (in the form of pyrite surfaces) effectively removes the nitrites and allows the amino acids to survive.

We explore the formation of glycine in the context of a weak radiating source. An unattenuated monochromatic beam of light at $\lambda_{0}=1000 \AA$ is applied with an intensity of $\approx 2 \times 10^{-3} \mathrm{erg} \mathrm{cm}^{-2} \mathrm{~s}^{-1}$, corresponding to a flux of $F_{0}=10^{8}$ photons $\mathrm{cm}^{-2} \mathrm{~s}^{-1}$. This flux is applied to Equation (18) such that

$$
\begin{aligned}
k_{\mathrm{ph}, i}(z) & =\int_{1 \AA}^{10^{4} \AA} \sigma_{i}(\lambda) F_{0} \delta\left(\lambda-\lambda_{0}\right) d \lambda ; \\
& =F_{0} \sigma_{i}\left(\lambda_{0}\right),
\end{aligned}
$$

where $\delta$ is the Dirac delta function.

The formation pathways for glycine have not been rigorously determined, although there are some proposed pathways. We include four possible pathways to glycine formation in our network. First, we include glycine formation via the three-body interaction of various species. These reactions have significant barriers, and so will only occur efficiently at rather high temperatures. The reactions are

$$
\begin{gathered}
\mathrm{C}_{2} \mathrm{H}_{4}+\mathrm{HNO}_{2} \rightarrow \mathrm{NH}_{2} \mathrm{CH}_{2} \mathrm{COOH}, \\
\mathrm{C}_{2} \mathrm{H}_{5}+\mathrm{NO}_{2} \rightarrow \mathrm{NH}_{2} \mathrm{CH}_{2} \mathrm{COOH}, \\
\mathrm{CH}_{3} \mathrm{NO}+\mathrm{H}_{2} \mathrm{CO} \rightarrow \mathrm{NH}_{2} \mathrm{CH}_{2} \mathrm{COOH},
\end{gathered}
$$

with rate constants set equal to the three-body formation for analogous chemical species (e.g., $\mathrm{CH}_{2} \mathrm{COOH}$ ). Also included is the ion-neutral pathway proposed for interstellar formation for glycine from Charnley (1997),

$$
\begin{gathered}
\mathrm{CH}_{6} \mathrm{NO}^{+}+\mathrm{HCOOH} \rightarrow \mathrm{C}_{2} \mathrm{H}_{6} \mathrm{NO}_{2}^{+}+\mathrm{H}_{2} \mathrm{O}, \\
\mathrm{C}_{2} \mathrm{H}_{6} \mathrm{NO}_{2}^{+}+e^{-} \rightarrow \mathrm{NH}_{2} \mathrm{CH}_{2} \mathrm{COOH}+\mathrm{H} .
\end{gathered}
$$

Finally, the formation of glycine by a possible pathway similar to that suggested by Patel et al. (2015),

$$
\mathrm{CH}_{3} \mathrm{NO}+\mathrm{CH}_{3} \mathrm{O} \rightarrow \mathrm{NH}_{2} \mathrm{CH}_{2} \mathrm{COOH}+\mathrm{H}
$$

is included.

Additionally, we include $\mathrm{FeO}$ and reactions between $\mathrm{FeO}$ and nitrites. We also inject our gas with $\mathrm{HCOOH}$ in order to facilitate the ion-neutral formation pathway; it is likely that there are other presently unknown paths of formation for formic acid. We run this network for a set of five different initial compositions given in Table 2, labeled Model A-E. Model A is a strongly reducing environment, with only the gases $\mathrm{NH}_{3}, \mathrm{CH}_{4}, \mathrm{H}_{2}$ and $\mathrm{H}_{2} \mathrm{O}, \mathrm{FeO}$, and $\mathrm{HCOOH}$ (Model A). We transition to a more reducing environment in the successive models (Models B, C, D). Finally, for Model E, we run the experiment starting solely from $\mathrm{CO}_{2}, \mathrm{~N}_{2}, \mathrm{H}_{2} \mathrm{O}, \mathrm{FeO}$, and $\mathrm{HCOOH}$. We run all models using the unattenuated UV flux, at 
Table 2

Mixing Ratios for Laboratory Simulations ${ }^{\mathrm{a}}$

\begin{tabular}{lllllll}
\hline \hline Model & $\mathrm{H}_{2} \mathrm{O}$ & $\mathrm{CH}_{4}$ & $\mathrm{NH}_{3}$ & $\mathrm{H}_{2}$ & $\mathrm{CO}_{2}$ & $\mathrm{~N}_{2}$ \\
\hline $\mathrm{A}$ & 0.80 & 0.08 & 0.08 & 0.04 & 0.0 & 0.0 \\
$\mathrm{~B}$ & 0.80 & 0.06 & 0.06 & 0.04 & 0.02 & 0.02 \\
$\mathrm{C}$ & 0.80 & 0.04 & 0.04 & 0.04 & 0.04 & 0.04 \\
D & 0.80 & 0.02 & 0.02 & 0.04 & 0.06 & 0.06 \\
E & 0.84 & 0.00 & 0.00 & 0.00 & 0.08 & 0.08 \\
\hline
\end{tabular}

Note.

${ }^{\mathrm{a}}$ Not including the injected $\mathrm{FeO}$ and $\mathrm{HCOOH}$.

1 bar pressure and $300 \mathrm{~K}$ temperature. The model is run to $t \approx$ 1 week. Our results are plotted in Figure 19.

Moving from Model B to E, less and less glycine is formed, falling from a mixing ratio of $10^{-6}$ for Model $\mathrm{B}$ to $10^{-8}$ for Model E. This is what is expected from the Miller-Urey experiments performed for various chemical compositions: as the chemistry becomes less reducing, it becomes more difficult to form prebiotic molecules.

More interesting is Model A. If all $\mathrm{N}_{2}$ and $\mathrm{CO}_{2}$ are removed, certain formation pathways to $\mathrm{NO}_{2}, \mathrm{HNO}_{2}$, and especially $\mathrm{H}_{2} \mathrm{CO}$ are inhibited. Additionally, $\mathrm{HCNO}$ forms more slowly from $\mathrm{HCN}$, and especially the ionic form, $\mathrm{CHNO}^{+}$(in its various permutations) is difficult to form without some excess unbonded atomic nitrogen or oxygen present in the gas. Model A produces virtually no glycine. We traced this back to the key reactions:

$$
\begin{aligned}
\mathrm{N}_{2}+\gamma & \rightarrow \mathrm{N}_{2}^{+}+e^{-}, \\
\mathrm{N}_{2}^{+}+e^{-} & \rightarrow \mathrm{N}+\mathrm{N}, \\
\mathrm{CO}_{2}+\gamma & \rightarrow \mathrm{CO}+\mathrm{O},
\end{aligned}
$$

which is the same formation pathway for amines in the early Earth as suggested by Zahnle (1986). In our case, however, the atomic nitrogen and oxygen are both important in completing the formation of $\mathrm{HCNO}$ and its isomers.

\section{CONCLUSION}

In this paper, we have presented a gas-phase chemical network, STAND2015. The photochemistry/diffusion code, ArGo, was used to test the network. We have shown that the predictions from STAND2015 converge to chemical equilibrium under the appropriate conditions and also that the molecular diffusion modeled by ARGO makes a reasonable approximation to analytical calculations of molecular diffusion for an isothermal gas in hydrostatic equilibrium. We have compared our model results (STAND2015+ARGO) to chemical kinetics models for HD 209458b, Jupiter, and the Earth. For Jupiter, we found that ion-neutral chemistry may provide significant alternative pathways to formation of various hydrocarbons, especially ethylene $\left(\mathrm{C}_{2} \mathrm{H}_{4}\right)$.

Finally, we numerically simulate a Urey-Miller-like experiment $^{12}$ under various initial chemistries. We found that, in an artificial environment, when derivatives of $\mathrm{FeO}$ and pyrite $\left(\mathrm{FeS}_{2}\right)$ can destroy nitrites in the presence of a reservoir of formic acid, the formation of glycine is considerable also in reducing environments, approaching a mixing ratio of $\sim 10^{-6}$. For an environment more similar to the atmosphere of the early

$\overline{12}$ The experiment we simulate is more like that of Patel et al. (2015).

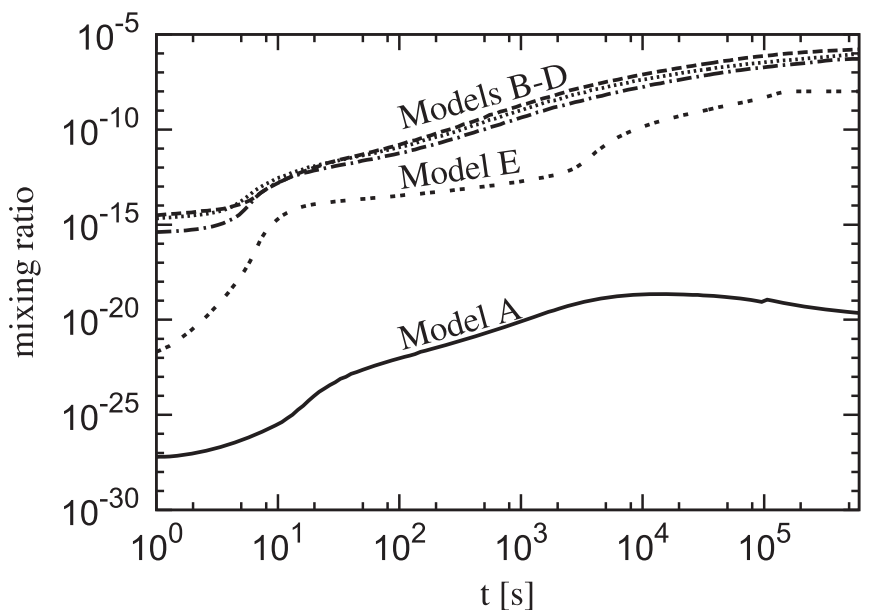

Figure 19. Mixing ratio of glycine as a function of time, for five lab simulations, labeled Models A-E, with parameters given in Table 2 and described in Section 5.

Earth, the mixing ratio drops to $\sim 10^{-8}$. Surprisingly, for a gas without any $\mathrm{CO}_{2}, \mathrm{O}_{2}$, or $\mathrm{N}_{2}$, virtually no glycine is formed. If this result is robust for various other energy sources (shocks, thermal energy, etc.) and for other prebiotic species, this would suggest that the early Earth chemistry should not be too strongly reducing, or else the formation of glycine and other prebiotic species would be severely inhibited.

This network has limitations. It has only been tested for 1D atmosphere models, with non-self-consistent temperature profiles. Using this network within a global circulation model is presently unrealistic, but a reduced version of this network, constructed specifically for given atmospheres, could in principle be employed in 2D or 3D atmosphere simulations. Sulfur chemistry has been shown to play an important role in the formation of prebiotics, and is an essential constituent in volcano plumes. The inclusion of sulfur chemistry will be a natural next step to take the model. Additionally, the models of prebiotic chemistry should consider the formation of species other than glycine. The formation of ribose $\left(\mathrm{C}_{5} \mathrm{H}_{10} \mathrm{O}_{5}\right)$ of nucleotides, such as adenine $\left(\mathrm{C}_{5} \mathrm{H}_{5} \mathrm{~N}_{5}\right)$, and of phosphorusbearing species should also be included to more fully encapsulate the formation of the prebiotic chemical reservoir.

One serious problem with this network, and indeed with any chemical kinetics network, is the uncertainty in rate coefficients. The effects of this uncertainty can be estimated using sensitivity analysis (e.g., within Venot et al. 2012), but can ultimately only be resolved slowly as better experimental and theoretical determinations of the reaction rates are made available. More accurate determinations, especially of the reaction rates for the nitrogen chemistry, would be extremely helpful. This network and model provide a window into a detailed analysis of prebiotic chemistry, but much work must still be done in order to accurately predict the full budget of prebiotic molecules in the variety of environments in which they may occur.

Both authors gratefully acknowledge the support of the ERC Starting Grant \#257431. P.B.R. is grateful to J.I. Moses for several helpful discussions about the network and model comparisons, to G. Laibe for his help with the Lagrangian numerical methods, and to C.R. Stark for his help understanding prebiotic formation in plasma environments. Both 
Table 3

Bond Constants for Benson Additivity

\begin{tabular}{|c|c|c|c|c|c|c|c|}
\hline Species & $a_{1}$ & $a_{2}$ & $a_{3}$ & $a_{4}$ & $a_{5}$ & $a_{6}$ & $a_{7}$ \\
\hline \multicolumn{8}{|l|}{$\mathrm{C}-\mathrm{H}$} \\
\hline $300-1000 \mathrm{~K}$ & $1.1 \mathrm{E} 0$ & $-3.0 \mathrm{E}-3$ & 1.2E-5 & $5.8 \mathrm{E}-8$ & 4.8E-12 & $-2.5 \mathrm{E} 3$ & $-2.5 \mathrm{E}-2$ \\
\hline $1000-6000 \mathrm{~K}$ & $4.0 \mathrm{E}-1$ & $2.3 \mathrm{E}-3$ & $-1.9 \mathrm{E}-6$ & $1.4 \mathrm{E}-10$ & $-8.3 \mathrm{E}-15$ & $-2.0 \mathrm{E} 3$ & $2.8 \mathrm{E} 0$ \\
\hline \multicolumn{8}{|l|}{$\mathrm{C}-\mathrm{C}$} \\
\hline $300-1000 \mathrm{~K}$ & $-2.4 \mathrm{E} 0$ & $1.3 \mathrm{E}-3$ & $-1.4 \mathrm{E}-5$ & $-2.8 \mathrm{E}-7$ & $-5.0 \mathrm{E}-13$ & $3.0 \mathrm{E} 3$ & $3.0 \mathrm{E} 0$ \\
\hline $1000-6000 \mathrm{~K}$ & $1.8 \mathrm{E} 0$ & $1.5 \mathrm{E}-3$ & $5.7 \mathrm{E}-7$ & $4.0 \mathrm{E}-11$ & $-2.5 \mathrm{E}-15$ & $2.5 \mathrm{E} 2$ & $-1.8 \mathrm{E} 1$ \\
\hline \multicolumn{8}{|l|}{$\mathrm{C}-\mathrm{O}$} \\
\hline $300-1000 \mathrm{~K}$ & $-6.8 \mathrm{E}-1$ & $8.3 \mathrm{E}-3$ & $-1.0 \mathrm{E}-5$ & $-2.0 \mathrm{E}-7$ & $-2.3 \mathrm{E}-12$ & $9.0 \mathrm{E} 2$ & 4.8E-1 \\
\hline $1000-6000 \mathrm{~K}$ & $1.7 \mathrm{E} 0$ & $1.3 \mathrm{E}-3$ & 8.3E-6 & 5.5E-11 & $-3.8 \mathrm{E}-15$ & $-6.5 \mathrm{E} 2$ & $-1.1 \mathrm{E} 1$ \\
\hline \multicolumn{8}{|l|}{$\mathrm{O}-\mathrm{H}$} \\
\hline $300-1000 \mathrm{~K}$ & $5.0 \mathrm{E}-2$ & $-7.3 \mathrm{E}-3$ & $1.8 \mathrm{E}-5$ & $1.2 \mathrm{E}-7$ & 8.5E-12 & $-9.0 \mathrm{E} 3$ & $-4.2 \mathrm{E} 0$ \\
\hline $1000-6000 \mathrm{~K}$ & $-4.5 \mathrm{E}-1$ & $-3.1 \mathrm{E}-3$ & $-6.7 \mathrm{E}-6$ & $-1.6 \mathrm{E} 10$ & $-5.4 \mathrm{E}-14$ & $-7.5 \mathrm{E} 3$ & $5.2 \mathrm{E} 0$ \\
\hline
\end{tabular}

authors are grateful for the anonymous referee whose report has helped significantly improve this paper. They also express thanks to Ian Taylor at St. Andrews for his help with computational resources. Finally, they acknowledge the National Institute of Standards and Technology, the databases of which were essential to the completion of this project.

\section{APPENDIX A}

\section{LIST OF SPECIES, REACTIONS, AND RATES}

The purpose of this appendix is to explicitly lay out the content of the chemical network itself. We list the species considered in the network and the reactions.

The species include the elements $\mathrm{H} / \mathrm{C} / \mathrm{N} / \mathrm{O}$, and the network includes a complete chemistry for molecules and ions of up to two carbon, six hydrogen, two nitrogen, and three oxygen atoms. The different chemical kinetics for various neutral molecular isomers is included as completely as possible, although much about branching ratios for reactions is presently not well understood. A list of all the neutral species is given in Table 4. This table lists the species considered and includes the formula as used in the network, the standard formula, the name of the molecule, and the source we used for the thermochemical data. In some cases, the chemical formula in the network is different from the standard chemical formula. This is because we incorporated our own method for distinguishing isomers in order to make sure that we did not incorporate the same molecule under two different formulas.

This list also includes some species with the elements $\mathrm{Na}$, $\mathrm{Mg}, \mathrm{Si}, \mathrm{Cl}, \mathrm{K}, \mathrm{Ti}$, and $\mathrm{Fe}$. The chemistry attempts to include only the dominant species with these elements, in which they would be present in the gas phase. These species are generally only present in the gas phase for very high temperatures (generally $>1000 \mathrm{~K}$ ). For cooler objects, these species are typically ignored. The noble gases $\mathrm{He}$ and $\mathrm{Ar}$ are included, both for the sake of completeness and because they can play an important role in organic ion-neutral chemistry through charge-exchange reactions.

Ions are also included, and a list of the ionic species is given in Table 5. In this case, the uncertainty in reaction rates and branching ratios is much more severe, and so we made no attempt at present to distinguish isomers of ionic species.
It is difficult to determine which rate constants to use for a specific reaction, since there are often many to choose from, and they do not always agree well with each other. We employed the following method for determining which rate constant to include in our network, after plotting all the rate constants versus temperature over a range of $100-30,000 \mathrm{~K}$.

1. If there exists only one published rate constant for a given reaction, we use that value.

2. Reject all rate constants that become unrealistically large at extreme temperature.

3. Choose rate constants that agree with each other over the range of validity.

4. If the most recent published rate constant disagrees with (3), and the authors give convincing arguments for why the previous rates were mistaken, we use the most recently published rate.

The full list of forward reactions and rate constants determined by this method comprise the STAND2015 network and are given in Table 6. Reverse reactions are not explicitly shown; when reactions are reversible, bidirectional arrows are shown. When they are irreversible, or simply not reversed in the network, only unidirectional arrows are shown. Table 6 additionally includes a full list of the references for the rate constants used for each given reaction.

\section{APPENDIX B REVERSING REACTIONS}

For reverse reactions, we follow the prescription given by Burcat \& Ruscic (2005). For the reaction

$$
\mathrm{A}+\mathrm{B} \rightarrow \mathrm{C}+\mathrm{D}+\mathrm{E},
$$

there is a rate constant, $k_{f}$. We resolve to determine the reverse rate constant, $k_{r}$, for the reaction

$$
\mathrm{C}+\mathrm{D}+\mathrm{E} \rightarrow \mathrm{A}+\mathrm{B} .
$$

Note that the number of species is different between the righthand side and left-hand side of Equation (60). We denote this difference in number of reactants and products $\left(n_{\text {react }}\right.$ and $n_{\text {prod }}$, respectively) by $\Delta \nu$, which in our case 
Table 4

Neutral Species Included in the STAND2015 Network

\begin{tabular}{|c|c|c|c|}
\hline $\begin{array}{l}\text { Network } \\
\text { Formula } \\
\end{array}$ & Standard Formula & Name & $\begin{array}{c}\text { Thermochem } \\
\text { Data }\end{array}$ \\
\hline $\mathrm{H}$ & $\mathrm{H}$ & Atomic hydrogen & Burcat \\
\hline $\mathrm{C}$ & $\mathrm{C}$ & Atomic carbon & Burcat \\
\hline$C\left({ }^{1} \mathrm{D}\right)$ & $\mathrm{C}\left({ }^{1} \mathrm{D}\right)$ & Singlet D carbon & Burcat \\
\hline$C\left({ }^{1} S\right)$ & $\mathrm{C}\left({ }^{1} \mathrm{~S}\right)$ & Singlet $\mathrm{S}$ carbon & Burcat \\
\hline $\mathrm{N}$ & $\mathrm{N}$ & Atomic nitrogen & Burcat \\
\hline $\mathrm{O}$ & $\mathrm{O}$ & Atomic oxygen & Burcat \\
\hline $\mathrm{O}\left({ }^{1} \mathrm{D}\right)$ & $\mathrm{O}\left({ }^{1} \mathrm{D}\right)$ & Singlet D oxygen & Burcat \\
\hline $\mathrm{O}\left({ }^{1} \mathrm{~S}\right)$ & $\mathrm{O}\left({ }^{1} \mathrm{~S}\right)$ & Singlet $S$ oxygen & Burcat \\
\hline $\mathrm{He}$ & $\mathrm{He}$ & Helium & Burcat \\
\hline $\mathrm{Na}$ & $\mathrm{Na}$ & Atomic sodium & Burcat \\
\hline $\mathrm{Mg}$ & $\mathrm{Mg}$ & Atomic magnesium & Burcat \\
\hline $\mathrm{Si}$ & $\mathrm{Si}$ & Atomic silicon & Burcat \\
\hline $\mathrm{Cl}$ & $\mathrm{Cl}$ & Atomic chlorine & Burcat \\
\hline $\mathrm{Ar}$ & $\mathrm{Ar}$ & Argon & Burcat \\
\hline K & K & Atomic potassium & Burcat \\
\hline $\mathrm{Ti}$ & $\mathrm{Ti}$ & Atomic titanium & Burcat \\
\hline $\mathrm{Fe}$ & $\mathrm{Fe}$ & Atomic iron & Burcat \\
\hline $\mathrm{H}_{2}$ & $\mathrm{H}_{2}$ & Molecular hydrogen & Burcat \\
\hline $\mathrm{C}_{2}$ & $\mathrm{C}_{2}$ & Dicarbon & Burcat \\
\hline $\mathrm{N}_{2}$ & $\mathrm{~N}_{2}$ & Molecular nitrogen & Burcat \\
\hline $\mathrm{O}_{2}$ & $\mathrm{O}_{2}$ & Molecular oxygen & Burcat \\
\hline $\mathrm{O}_{2}\left(\mathrm{a}^{1} \Delta\right)$ & $\mathrm{O}_{2}\left(\mathrm{a}^{1} \Delta\right)$ & Singlet oxygen & Burcat \\
\hline $\mathrm{CH}$ & $\mathrm{CH}$ & Methylidyne radical & Burcat \\
\hline $\mathrm{HN}$ & $\mathrm{NH}$ & $\begin{array}{l}\text { Nitrogen } \\
\text { monohydride }\end{array}$ & Burcat \\
\hline $\mathrm{HN}\left(\mathrm{a}^{1} \Delta\right)$ & $\mathrm{NH}\left(\mathrm{a}^{1} \Delta\right)$ & $\begin{array}{c}\text { Singlet nitrogen } \\
\text { monohydride }\end{array}$ & Burcat \\
\hline $\mathrm{HO}$ & $\mathrm{OH}$ & Hydroxyl radical & Burcat \\
\hline $\mathrm{CN}$ & $\mathrm{CN}$ & Cyano radical & Burcat \\
\hline $\mathrm{CO}$ & $\mathrm{CO}$ & Carbon monoxide & Burcat \\
\hline KH & $\mathrm{KH}$ & Potassium hydride & Burcat \\
\hline NO & NO & Nitric oxide & Burcat \\
\hline $\mathrm{HCl}$ & $\mathrm{HCl}$ & Hydrogen chloride & Burcat \\
\hline $\mathrm{NaH}$ & $\mathrm{NaH}$ & Sodium hydride & Burcat \\
\hline $\mathrm{MgO}$ & $\mathrm{MgO}$ & Magnesium oxide & Burcat \\
\hline $\mathrm{SiH}$ & $\mathrm{SiH}$ & Silylidyne & NASA-CEA \\
\hline $\mathrm{SiO}$ & $\mathrm{SiO}$ & Silicon monoxide & NASA-CEA \\
\hline $\mathrm{KCl}$ & $\mathrm{KCl}$ & Potassium chloride & Burcat \\
\hline $\mathrm{TiO}$ & $\mathrm{TiO}$ & Titanium(II) oxide & NASA-CEA \\
\hline $\mathrm{FeO}$ & $\mathrm{FeO}$ & Iron(II) oxide & Burcat \\
\hline $\mathrm{O}_{3}$ & $\mathrm{O}_{3}$ & Ozone & Burcat \\
\hline${ }^{3} \mathrm{CH}_{2}$ & $\mathrm{CH}_{2}\left(\mathrm{X}^{3} \mathrm{~B}_{1}\right)$ & Triplet methylene & Burcat \\
\hline${ }^{1} \mathrm{CH}_{2}$ & $\mathrm{CH}_{2}\left(\mathrm{a}^{1} \mathrm{~A}_{1}\right)$ & Singlet methylene & Burcat \\
\hline${ }^{1} \mathrm{CH}_{2}$ & $\mathrm{CH}_{2}\left(\mathrm{a}^{1} \mathrm{~A}_{1}\right)$ & Singlet methylene & Burcat \\
\hline $\mathrm{C}_{2} \mathrm{H}$ & $\mathrm{CCH}$ & Ethynyl radical & Burcat \\
\hline $\mathrm{H}_{2} \mathrm{~N}$ & $\mathrm{NH}_{2}$ & Amidogen & Burcat \\
\hline $\mathrm{HN}_{2}$ & $\mathrm{~N}_{2} \mathrm{H}$ & Amino radical & Burcat \\
\hline $\mathrm{H}_{2} \mathrm{O}$ & $\mathrm{H}_{2} \mathrm{O}$ & Water & Burcat \\
\hline $\mathrm{HO}_{2}$ & $\mathrm{HO}_{2}$ & Hydroperoxyl & Burcat \\
\hline $\mathrm{C}_{2} \mathrm{~N}$ & $\mathrm{CCN}$ & Cyano-methylidyne & Burcat \\
\hline $\mathrm{CNC}$ & $\mathrm{CNC}$ & $\mathrm{CNC}$ radical & Burcat \\
\hline $\mathrm{CN}_{2}$ & $\mathrm{CNN}$ & $\mathrm{CNN}$ radical & Burcat \\
\hline $\mathrm{C}_{2} \mathrm{O}$ & $\mathrm{C}_{2} \mathrm{O}$ & Dicarbon monoxide & Burcat \\
\hline $\mathrm{CO}_{2}$ & $\mathrm{CO}_{2}$ & Carbon dioxide & Burcat \\
\hline $\mathrm{N}_{2} \mathrm{O}$ & $\mathrm{N}_{2} \mathrm{O}$ & Nitrous oxide & Burcat \\
\hline $\mathrm{NO}_{2}$ & $\mathrm{NO}_{2}$ & Nitrogen dioxide & Burcat \\
\hline $\mathrm{HCN}$ & $\mathrm{HCN}$ & Hydrogen cyanide & Burcat \\
\hline $\mathrm{HNC}$ & $\mathrm{HNC}$ & Hydrogen isocyanide & Burcat \\
\hline HNO & $\mathrm{HNO}$ & Nitroxyl & Burcat \\
\hline $\mathrm{NCO}$ & $\mathrm{NCO}$ & Isocyanato radical & Burcat \\
\hline $\mathrm{NaOH}$ & $\mathrm{NaOH}$ & Sodium hydroxide & Burcat \\
\hline $\mathrm{MgHO}$ & $\mathrm{MgOH}$ & $\begin{array}{l}\text { Magnesium } \\
\text { monohydroxide }\end{array}$ & NASA-CEA \\
\hline
\end{tabular}

Table 4

(Continued)

\begin{tabular}{|c|c|c|c|}
\hline $\begin{array}{l}\text { Network } \\
\text { Formula }\end{array}$ & Standard Formula & Name & $\begin{array}{c}\text { Thermochem } \\
\text { Data }\end{array}$ \\
\hline $\mathrm{NaCl}$ & $\mathrm{NaCl}$ & Sodium chloride & Burcat \\
\hline $\mathrm{SiH}_{2}$ & $\mathrm{SiH}_{2}$ & Silylene & NASA-CEA \\
\hline $\mathrm{KOH}$ & $\mathrm{KOH}$ & Potassium hydroxide & Burcat \\
\hline $\mathrm{FeO}_{2}$ & $\mathrm{FeO}_{2}$ & Iron oxide & Burcat \\
\hline $\mathrm{CH}_{3}$ & $\mathrm{CH}_{3}$ & Methyl radical & Burcat \\
\hline $\mathrm{C}_{2} \mathrm{H}_{2}$ & $\mathrm{C}_{2} \mathrm{H}_{2}$ & Acetylene & Burcat \\
\hline $\mathrm{H}_{3} \mathrm{~N}$ & $\mathrm{NH}_{3}$ & Ammonia & Burcat \\
\hline $\mathrm{H}_{2} \mathrm{~N}_{2}$ & $\mathrm{~N}_{2} \mathrm{H}_{2}$ & Diimide & Burcat \\
\hline HNNH & HNNH & (Z)-Diazene & Burcat \\
\hline $\mathrm{H}_{2} \mathrm{O}_{2}$ & $\mathrm{H}_{2} \mathrm{O}_{2}$ & Hydrogen peroxide & Burcat \\
\hline $\mathrm{NCCN}$ & $(\mathrm{CN})_{2}$ & Cyanogen & Burcat \\
\hline $\mathrm{H}_{2} \mathrm{CN}$ & $\mathrm{H}_{2} \mathrm{CN}$ & Dihydrogen cyanide & Burcat \\
\hline $\mathrm{HCCN}$ & $\mathrm{HCCN}$ & $\mathrm{HCCN}$ radical & Burcat \\
\hline $\mathrm{CHN}_{2}$ & $\mathrm{HCNN}$ & $\mathrm{HCNN}$ & Burcat \\
\hline $\mathrm{CH}_{2} \mathrm{O}$ & $\mathrm{H}_{2} \mathrm{CO}$ & Formaldehyde & Burcat \\
\hline $\mathrm{HOCH}$ & $\mathrm{HCOH}$ & Hydroxymethylene & Burcat \\
\hline $\mathrm{HCCO}$ & $\mathrm{HCCO}$ & Ethynyloxy radical & Burcat \\
\hline $\mathrm{COOH}$ & $\mathrm{COOH}$ & $\begin{array}{l}\text { Hydrocarboxyl } \\
\text { radical }\end{array}$ & Burcat \\
\hline $\mathrm{NH}_{2} \mathrm{O}$ & $\mathrm{NHOH}$ & $\mathrm{NHOH}$ & Burcat \\
\hline $\mathrm{HNO}_{2}$ & $\mathrm{HNO}_{2}$ & Nitrous acid & Burcat \\
\hline OCCN & $\mathrm{NCCO}$ & $\mathrm{NCCO}$ & Burcat \\
\hline $\mathrm{HCNO}$ & $\mathrm{HCNO}$ & Fulminic acid & Burcat \\
\hline $\mathrm{HNCO}$ & $\mathrm{HNCO}$ & Isocyanic acid & Burcat \\
\hline CHNO & $\mathrm{CHNO}$ & Cyanic acid & Burcat \\
\hline $\mathrm{HCNO}$ & HCNO & $\mathrm{HCNO}$ & Burcat \\
\hline $\mathrm{SiH}_{3}$ & $\mathrm{SiH}_{3}$ & Silyl radical & Burcat \\
\hline $\mathrm{CH}_{4}$ & $\mathrm{CH}_{4}$ & Methane & Burcat \\
\hline $\mathrm{C}_{2} \mathrm{H}_{3}$ & $\mathrm{C}_{2} \mathrm{H}_{3}$ & Vinyl radical & Burcat \\
\hline $\mathrm{NH}_{2} \mathrm{NH}$ & $\mathrm{NH}_{2} \mathrm{NH}$ & Hydrazinyl radical & Burcat \\
\hline $\mathrm{N}_{2} \mathrm{O}_{3}$ & $\mathrm{~N}_{2} \mathrm{O}_{3}$ & Nitrogen trioxide & Burcat \\
\hline $\mathrm{CH}_{3} \mathrm{~N}$ & $\mathrm{CH}_{2} \mathrm{NH}$ & Methanimine & Burcat \\
\hline $\mathrm{CH}_{2} \mathrm{CN}$ & $\mathrm{CH}_{2} \mathrm{CN}$ & Cyanomethyl radical & Burcat \\
\hline $\mathrm{CH}_{2} \mathrm{~N}_{2}$ & $\mathrm{CH}_{2} \mathrm{~N}_{2}$ & Diazomethane & Burcat \\
\hline $\mathrm{HC}_{3} \mathrm{~N}$ & $\ldots$ & Propiolonitrile & Burcat \\
\hline $\mathrm{CH}_{2} \mathrm{OH}$ & $\mathrm{CH}_{2} \mathrm{OH}$ & $\begin{array}{l}\text { Hydroxymethyl } \\
\text { radical }\end{array}$ & Burcat \\
\hline $\mathrm{CH}_{3} \mathrm{O}$ & $\mathrm{CH}_{3} \mathrm{O}$ & Methoxy radical & Burcat \\
\hline $\mathrm{C}_{2} \mathrm{H}_{2} \mathrm{O}$ & $\mathrm{H}_{2} \mathrm{CCO}$ & Ethenone & Burcat \\
\hline $\mathrm{HCOOH}$ & $\mathrm{HCOOH}$ & Formic acid & Burcat \\
\hline $\mathrm{CH}_{2} \mathrm{O}_{2}$ & $\mathrm{CH}_{2} \mathrm{OO}$ & $\mathrm{CH} 2 \mathrm{OO}$ & Burcat \\
\hline $\mathrm{HNO}_{3}$ & $\mathrm{HNO}_{3}$ & Nitric acid & Burcat \\
\hline $\mathrm{NH}_{2} \mathrm{OH}$ & $\mathrm{NH}_{2} \mathrm{OH}$ & Hydroxylamine & Burcat \\
\hline $\mathrm{HCOCN}$ & $\mathrm{HCOCN}$ & $\mathrm{HCOCN}$ & Benson \\
\hline $\mathrm{MgO}_{2} \mathrm{H}_{2}$ & $\mathrm{H}_{2} \mathrm{MgO}_{2}$ & $\begin{array}{l}\text { Magnesium } \\
\text { hydroxide }\end{array}$ & NASA-CEA \\
\hline $\mathrm{SiH}_{4}$ & $\mathrm{SiH}_{4}$ & Silane & Burcat \\
\hline $\mathrm{C}_{2} \mathrm{H}_{4}$ & $\mathrm{C}_{2} \mathrm{H}_{4}$ & Ethylene & Burcat \\
\hline $\mathrm{C}_{3} \mathrm{H}_{3}$ & $\ldots$ & Propargyl radical & Burcat \\
\hline $\mathrm{H}_{4} \mathrm{~N}_{2}$ & $\mathrm{~N}_{2} \mathrm{H}_{4}$ & Hydrazine & Burcat \\
\hline $\mathrm{H}_{4} \mathrm{O}_{2}$ & $\mathrm{H}_{2} \mathrm{O} \cdot \mathrm{H}_{2} \mathrm{O}$ & Water dimer & Burcat \\
\hline $\mathrm{CH}_{3} \mathrm{CN}$ & $\mathrm{CH}_{3} \mathrm{CN}$ & Acetonitrile & Burcat \\
\hline $\mathrm{C}_{2} \mathrm{H}_{3} \mathrm{~N}$ & $\mathrm{CH}_{2} \mathrm{CNH}$ & $\mathrm{CH} 2=\mathrm{C}=\mathrm{NH}$ & Burcat \\
\hline $\mathrm{CH}_{3} \mathrm{~N}_{2} \mathrm{H}$ & $\mathrm{CH}_{3} \mathrm{~N}_{2} \mathrm{H}$ & Methyl diazene & Burcat \\
\hline $\mathrm{CH}_{3} \mathrm{OH}$ & $\mathrm{CH}_{3} \mathrm{OH}$ & Methanol & Burcat \\
\hline $\mathrm{CH}_{3} \mathrm{O}_{2}$ & $\mathrm{CH}_{3} \mathrm{O}_{2}$ & $\mathrm{CH} 3 \mathrm{O} 2$ & Burcat \\
\hline $\mathrm{C}_{2} \mathrm{H}_{3} \mathrm{O}$ & $\mathrm{CH}_{3} \mathrm{CO}$ & Acetyl radical & Burcat \\
\hline cyc- $\mathrm{C}_{2} \mathrm{H}_{3} \mathrm{O}$ & Oxyranyl & Oxiranyl radical & Burcat \\
\hline $\mathrm{CH}_{2} \mathrm{CHO}$ & $\mathrm{CH}_{2} \mathrm{CHO}$ & $\mathrm{CH} 2 \mathrm{CHO}$ & Burcat \\
\hline $\mathrm{C}_{3} \mathrm{H}_{2} \mathrm{O}$ & $\ldots$ & 2-Propynal & Benson \\
\hline $\mathrm{C}_{2} \mathrm{H}_{2} \mathrm{O}_{2}$ & $(\mathrm{CHO})_{2}$ & Glyoxal & Burcat \\
\hline $\mathrm{H}_{2} \mathrm{NNO}_{2}$ & $\mathrm{H}_{2} \mathrm{~N}-\mathrm{NO}_{2}$ & $\mathrm{H} 2 \mathrm{~N}-\mathrm{NO} 2$ & Burcat \\
\hline $\mathrm{CH}_{3} \mathrm{NO}$ & $\mathrm{HCONH}_{2}$ & Formamide & Burcat \\
\hline
\end{tabular}


Table 4

(Continued)

\begin{tabular}{|c|c|c|c|}
\hline $\begin{array}{l}\text { Network } \\
\text { Formula }\end{array}$ & Standard Formula & Name & $\begin{array}{c}\text { Thermochem } \\
\text { Data }\end{array}$ \\
\hline $\mathrm{C}_{2} \mathrm{H}_{5}$ & $\mathrm{C}_{2} \mathrm{H}_{5}$ & Ethyl radical & Burcat \\
\hline $\mathrm{C}_{3} \mathrm{H}_{4}$ & $\ldots$ & Propyne & Burcat \\
\hline $\mathrm{CH}_{5} \mathrm{~N}$ & $\mathrm{CH}_{3} \mathrm{NH}_{2}$ & Methylamine & Burcat \\
\hline $\mathrm{C}_{3} \mathrm{H}_{3} \mathrm{~N}$ & $\ldots$ & Acrylonitrile & Burcat \\
\hline $\mathrm{C}_{2} \mathrm{H}_{4} \mathrm{O}$ & $\mathrm{CH}_{3} \mathrm{CHO}$ & Acetaldehyde & Burcat \\
\hline $\mathrm{H}_{2} \mathrm{C}_{2} \mathrm{HOH}$ & $\mathrm{CH}_{2} \mathrm{CHOH}$ & Vinyl alcohol & Burcat \\
\hline Oxirane & Oxirane & Oxirane & Burcat \\
\hline $\mathrm{C}_{3} \mathrm{H}_{3} \mathrm{O}$ & $\ldots$ & 1-Oxoprop-2-3nyl & Burcat \\
\hline $\mathrm{CH}_{4} \mathrm{O}_{2}$ & $\mathrm{CH}_{3} \mathrm{OOH}$ & Methyl peroxide & Burcat \\
\hline $\mathrm{CH}_{3} \mathrm{OCO}$ & $\mathrm{CH}_{3} \mathrm{OCO}$ & $\mathrm{CH} 3 \mathrm{OC}(\cdot)(\mathrm{O})$ & Burcat \\
\hline $\mathrm{CH}_{3} \mathrm{NO}_{2}$ & $\mathrm{CH}_{3} \mathrm{NO}_{2}$ & Nitromethane & Burcat \\
\hline $\mathrm{CH}_{3} \mathrm{ONO}$ & $\mathrm{CH}_{3} \mathrm{ONO}$ & Methyl nitrite & Burcat \\
\hline $\mathrm{C}_{2} \mathrm{H}_{6}$ & $\mathrm{C}_{2} \mathrm{H}_{6}$ & Ethane & Burcat \\
\hline $\mathrm{C}_{4} \mathrm{H}_{4}$ & $\ldots$ & 1-Buten-3-yne & Burcat \\
\hline $\mathrm{CH}_{2} \mathrm{NCH}_{3}$ & $\mathrm{NH}_{2} \mathrm{NCH}_{3}$ & $\begin{array}{l}\text { N-Methyl } \\
\text { methanimine }\end{array}$ & Benson \\
\hline $\mathrm{CH}_{3} \mathrm{COOH}$ & $\mathrm{CH}_{3} \mathrm{COOH}$ & Acetic acid & Burcat \\
\hline $\mathrm{CH}_{3} \mathrm{OCHO}$ & $\mathrm{CHOOCH}_{3}$ & Methyl formate & Burcat \\
\hline $\mathrm{CH}_{3} \mathrm{CHOH}$ & $\mathrm{CH}_{3} \mathrm{CHOH}$ & $\begin{array}{l}\text { 1-hydroxy Ethyl } \\
\text { radical }\end{array}$ & Burcat \\
\hline $\mathrm{CH}_{3} \mathrm{CH}_{2} \mathrm{O}$ & $\mathrm{CH}_{3} \mathrm{CH}_{2} \mathrm{O}$ & Ethoxy radical & Burcat \\
\hline $\mathrm{CH}_{3} \mathrm{OCH}_{2}$ & $\mathrm{CH}_{3} \mathrm{OCH}_{2}$ & $\begin{array}{l}\text { Methoxymethyl } \\
\text { radical }\end{array}$ & Burcat \\
\hline $\mathrm{CH}_{3} \mathrm{NO}_{3}$ & $\mathrm{CH}_{3} \mathrm{NO}_{3}$ & Methyl nitrate & Burcat \\
\hline $\mathrm{C}_{2} \mathrm{H}_{3} \mathrm{NO}_{2}$ & $\mathrm{C}_{2} \mathrm{H}_{3} \mathrm{NO}_{2}$ & Nitroethylene & Burcat \\
\hline $\mathrm{Si}_{2} \mathrm{H}_{6}$ & $\mathrm{Si}_{2} \mathrm{H}_{6}$ & Disilane & Burcat \\
\hline $\mathrm{C}_{3} \mathrm{H}_{6}$ & $\ldots$ & Propene & Burcat \\
\hline $\mathrm{C}_{2} \mathrm{H}_{6} \mathrm{~N}$ & $\left(\mathrm{CH}_{3}\right)_{2} \mathrm{~N}$ & Dimethyl amidogen & Burcat \\
\hline $\mathrm{C}_{2} \mathrm{H}_{5} \mathrm{OH}$ & $\mathrm{CH}_{3} \mathrm{CH}_{2} \mathrm{OH}$ & Ethanol & Burcat \\
\hline $\mathrm{C}_{2} \mathrm{H}_{5} \mathrm{OO}$ & $\mathrm{C}_{2} \mathrm{H}_{5} \mathrm{OO}$ & C2H5OO & Burcat \\
\hline $\mathrm{C}_{2} \mathrm{H}_{4} \mathrm{O}_{3}$ & $\mathrm{HOCH}_{2} \mathrm{COOH}$ & Glycolic acid & Burcat \\
\hline$\left(\mathrm{CH}_{3}\right)_{2} \mathrm{O}$ & $\left(\mathrm{CH}_{3}\right)_{2} \mathrm{O}$ & Dimethyl ether & Burcat \\
\hline $\mathrm{C}_{2} \mathrm{H}_{5} \mathrm{NO}$ & $\mathrm{C}_{2} \mathrm{H}_{5} \mathrm{NO}$ & Acetaldoxime & Benson \\
\hline $\mathrm{C}_{4} \mathrm{H}_{6}$ & & 1,3-Butadiene & Burcat \\
\hline$\left(\mathrm{CH}_{3} \mathrm{~N}\right)_{2}$ & $\left(\mathrm{CH}_{3} \mathrm{~N}\right)_{2}$ & Dimethyl diazene & Burcat \\
\hline$\left(\mathrm{CH}_{3} \mathrm{O}\right)_{2}$ & $\left(\mathrm{CH}_{3} \mathrm{O}\right)_{2}$ & Dimethyl peroxide & Burcat \\
\hline$\left(\mathrm{CH}_{2} \mathrm{OH}\right)_{2}$ & $\left(\mathrm{CH}_{2} \mathrm{OH}\right)_{2}$ & 1,2-Ethanediol & Burcat \\
\hline$\left(\mathrm{CH}_{3}\right)_{2} \mathrm{CO}$ & $\left(\mathrm{CH}_{3}\right)_{2} \mathrm{CO}$ & Acetone & Burcat \\
\hline $\mathrm{C}_{2} \mathrm{H}_{6} \mathrm{O}_{2}$ & $\mathrm{HOCH}_{2} \mathrm{CH}_{2} \mathrm{OH}$ & Ethylene glycol & Burcat \\
\hline $\mathrm{C}_{2} \mathrm{H}_{5} \mathrm{NO}_{2}$ & $\mathrm{NH}_{2} \mathrm{CH}_{2} \mathrm{COOH}$ & Glycine & Burcat \\
\hline $\mathrm{aC} 2 \mathrm{H} 5 \mathrm{NO} 2$ & $\mathrm{C}_{2} \mathrm{H}_{5} \mathrm{NO}_{2}$ & Nitroethane & Burcat \\
\hline $\mathrm{bC} 2 \mathrm{H} 5 \mathrm{NO} 2$ & $\mathrm{C}_{2} \mathrm{H}_{5} \mathrm{ONO}$ & Ethyl nitrate & Benson \\
\hline $\mathrm{C}_{3} \mathrm{H}_{8}$ & & Propane & Burcat \\
\hline$\left(\mathrm{CH}_{3}\right)_{2} \mathrm{~N}_{2} \mathrm{O}$ & $\left(\mathrm{CH}_{3}\right)_{2} \mathrm{~N}_{2} \mathrm{O}$ & Dimethylnitrosamine & Benson \\
\hline $\mathrm{C}_{4} \mathrm{H}_{10}$ & $\ldots$ & Butane & Burcat \\
\hline
\end{tabular}

(This table is available in machine-readable form.)

$=n_{\text {prod }}-n_{\text {react }}=2-3=-1$. We then solve for the reaction rate constant as (Burcat \& Ruscic 2005, their Equation (6))

$$
\begin{aligned}
K_{c}= & (R T)^{-\Delta \nu} \exp \left(\Delta a_{1}(\log T-1)+\frac{\Delta a_{2} T}{2}+\frac{\Delta a_{3} T^{2}}{6}\right. \\
& \left.+\frac{\Delta a_{4} T^{3}}{12}+\frac{\Delta a_{5} T^{4}}{20}-\frac{\Delta a_{6}}{T}+\Delta a_{7}\right)
\end{aligned}
$$

where $R=8.314472 \mathrm{~J} \mathrm{~mol}^{-1} \mathrm{~K}^{-1}$ is the gas constant, and $\Delta a_{i}=a_{i}(\mathrm{C}+\mathrm{D}+\mathrm{E})-a_{i}(\mathrm{~A}+\mathrm{B})$ for $1 \leqslant i \leqslant 7$ are the NASA thermodynamics coefficients, which Burcat \& Ruscic
(2005) describes and tabulates. It is important to emphasize here, as done by Visscher \& Moses (2011), the multiplicative factor $(R T)^{-\Delta \nu}$, which in our example would be $1.38065 \times 10^{-22} T$.

The Burcat values for the NASA coefficients have been used for all possible species (see Table 4). For some species, however, the coefficients had to be obtained from other sources. For sources with elements $\mathrm{Na}, \mathrm{Mg}, \mathrm{Si}, \mathrm{Cl}, \mathrm{K}, \mathrm{Ti}$, and $\mathrm{Fe}$, the Burcat values were sparse, so we made use instead of the NASA-CEA values (McBride et al. 1993; Gordon \& McBride 1999), which use nine-coefficient polynomials, so we fit them to a series of seven-coefficient polynomials for various temperature ranges. We do the same for the monatomic gases and ions at high temperatures $6000 \mathrm{~K}<T<20,000 \mathrm{~K}$, using fits to the polynomials provided by Gordon \& McBride (1999). For some species, the thermodynamic properties have not been determined. In these cases, for neutral species we use Benson's additivity method as described by Cohen \& Benson (1993).

Benson's additivity method can be naturally combined with the NASA and Burcat polynomial coefficients using the experimental values for the small alkanes listed within Cohen \& Benson (1993). For the arbitrary alcohol from Cohen \& Benson (1993), we use methanol, and for the arbitrary ether, we used dimethyl ether. The Benson coefficients are

$$
\begin{gathered}
P_{i}=\frac{1}{2} a_{i}\left(\mathrm{C}_{2} \mathrm{H}_{6}\right), \\
S_{i}=a_{i}\left(\mathrm{C}_{3} \mathrm{H}_{8}\right)-a_{i}\left(\mathrm{C}_{2} \mathrm{H}_{6}\right), \\
D_{i}=a_{i}\left(\mathrm{C}_{2} \mathrm{H}_{6} \mathrm{O}\right)-a_{i}\left(\mathrm{C}_{2} \mathrm{H}_{6}\right), \\
F_{i}=a_{i}\left(\mathrm{CH}_{3} \mathrm{OH}\right)-a_{i}\left(\mathrm{CH}_{4}\right) .
\end{gathered}
$$

Here, $a_{i}(X)$ denotes the seven coefficients, $i=1, \ldots, 7$ for species $X$. The coefficients for fundamental bonds are calculated using these coefficients as follows:

$$
\begin{gathered}
a_{i}([\mathrm{C}-\mathrm{H}])=\frac{1}{2} P-\frac{1}{4} S, \\
a_{i}([\mathrm{C}-\mathrm{C}])=\frac{3}{2} S-P, \\
a_{i}([\mathrm{C}-\mathrm{O}])=\frac{1}{2} D+\frac{3}{4} S-\frac{1}{2} P, \\
a_{i}([\mathrm{O}-\mathrm{H}])=F-\frac{1}{2} D-\frac{1}{2} S .
\end{gathered}
$$

The values for these bonds are given in Table 3 . The values for $[\mathrm{N}-\mathrm{H}],[\mathrm{N}-\mathrm{C}]$, and $[\mathrm{N}-\mathrm{O}]$ are similarly determined.

It has been suggested by Lias (1988) and Cohen \& Benson (1993) that using Benson's additivity method to determine the thermodynamic properties of ions, or at least strongly of strongly polarizing groups, can lead to large errors, because the thermodynamic properties of ions do not depend linearly on their length, although Hammerum \& Sølling (1999) have had some success applying Benson's method to ions.

We found, by investigating the thermodynamic properties of ionic species tabulated by Burcat \& Ruscic (2005), that the thermodynamic properties of ions do depend nonlinearly but predictably based on size. We therefore placed all the known thermodynamic properties of ions into a database, and have extrapolated to calculate the thermodynamic properties for the undetermined ions. 
Table 5

List of Ions Included the STAND2015 Network

\begin{tabular}{|c|c|c|c|c|c|c|}
\hline $\mathrm{e}^{-}$ & $\mathrm{C}^{+}$ & $\mathrm{C}^{-}$ & $\mathrm{H}^{+}$ & $\overline{\mathrm{H}^{-}}$ & $\mathrm{K}^{+}$ & $\mathrm{N}^{+}$ \\
\hline $\mathrm{O}^{+}$ & $\mathrm{O}^{+}\left({ }^{2} \mathrm{D}\right)$ & $\mathrm{O}^{+}\left({ }^{3} \mathrm{P}\right)$ & $\mathrm{O}^{-}$ & $\mathrm{Ar}^{+}$ & $\mathrm{Cl}^{+}$ & $\mathrm{C}_{2}^{+}$ \\
\hline $\mathrm{C}_{2}^{-}$ & $\mathrm{C}_{3}^{+}$ & $\mathrm{C}_{4}^{+}$ & $\mathrm{CH}^{+}$ & $\mathrm{CN}^{+}$ & $\mathrm{CN}^{-}$ & $\mathrm{CO}^{+}$ \\
\hline $\mathrm{Fe}^{+}$ & $\mathrm{H}_{2}^{+}$ & $\mathrm{H}_{3}^{+}$ & $\mathrm{HN}^{+}$ & $\mathrm{HO}^{+}$ & $\mathrm{HO}^{-}$ & $\mathrm{He}^{+}$ \\
\hline $\mathrm{Mg}^{+}$ & $\mathrm{Na}^{+}$ & $\mathrm{N}_{2}^{+}$ & $\mathrm{N}_{3}^{+}$ & $\mathrm{N}_{3}^{-}$ & $\mathrm{NO}^{+}$ & $\mathrm{NO}^{-}$ \\
\hline $\mathrm{O}_{2}^{+}$ & $\mathrm{O}_{2}^{+}\left(\mathrm{X}^{2} \Pi_{g}\right)$ & $\mathrm{O}_{2}^{-}$ & $\mathrm{O}_{3}^{-}$ & $\mathrm{Si}^{+}$ & $\mathrm{Ti}^{+}$ & $\mathrm{Ar}_{2}^{+}$ \\
\hline $\mathrm{ArH}^{+}$ & $\mathrm{C}_{2} \mathrm{H}^{+}$ & $\mathrm{C}_{2} \mathrm{H}^{-}$ & $\mathrm{C}_{2} \mathrm{~N}^{+}$ & $\mathrm{C}_{2} \mathrm{O}^{+}$ & $\mathrm{C}_{3} \mathrm{H}^{+}$ & $\mathrm{C}_{3} \mathrm{~N}^{+}$ \\
\hline $\mathrm{C}_{3} \mathrm{O}^{+}$ & $\mathrm{C}_{4} \mathrm{H}^{+}$ & $\mathrm{C}_{5} \mathrm{~N}^{+}$ & $\mathrm{CH}_{2}^{+}$ & $\mathrm{CH}_{3}^{+}$ & $\mathrm{CH}_{4}^{+}$ & $\mathrm{CH}_{5}^{+}$ \\
\hline $\mathrm{CHN}^{+}$ & $\mathrm{CHO}^{+}$ & $\mathrm{CN}_{2}^{+}$ & $\mathrm{CNO}^{+}$ & $\mathrm{CNO}^{-}$ & $\mathrm{CO}_{2}^{+}$ & $\mathrm{CO}_{3}^{-}$ \\
\hline $\mathrm{CO}_{4}^{+}$ & $\mathrm{CO}_{4}^{-}$ & $\mathrm{FeO}^{+}$ & $\mathrm{H}_{2} \mathrm{~N}^{+}$ & $\mathrm{H}_{2} \mathrm{~N}^{-}$ & $\mathrm{H}_{2} \mathrm{O}^{+}$ & $\mathrm{H}_{3} \mathrm{~N}^{+}$ \\
\hline $\mathrm{H}_{3} \mathrm{O}^{+}$ & $\mathrm{H}_{4} \mathrm{~N}^{+}$ & $\mathrm{HN}_{2}^{+}$ & $\mathrm{HN}_{3}^{+}$ & $\mathrm{HNO}^{+}$ & $\mathrm{HO}_{2}^{+}$ & $\mathrm{HO}_{2}^{-}$ \\
\hline $\mathrm{HO}_{4}^{+}$ & $\mathrm{HSi}^{+}$ & $\mathrm{He}_{2}^{+}$ & $\mathrm{HeH}^{+}$ & $\mathrm{MgO}^{+}$ & $\mathrm{N}_{2} \mathrm{O}^{+}$ & $\mathrm{NO}_{2}^{+}$ \\
\hline $\mathrm{NO}_{2}^{-}$ & $\mathrm{NO}_{3}^{-}$ & $\mathrm{Si}_{2}^{+}$ & $\mathrm{SiH}^{+}$ & $\mathrm{SiO}^{+}$ & $\mathrm{TiO}^{+}$ & $\mathrm{Ar}_{2} \mathrm{H}^{+}$ \\
\hline $\mathrm{ArH}_{3}^{+}$ & $\mathrm{C}_{2} \mathrm{H}_{2}^{+}$ & $\mathrm{C}_{2} \mathrm{H}_{2}^{-}$ & $\mathrm{C}_{2} \mathrm{H}_{3}^{+}$ & $\mathrm{C}_{2} \mathrm{H}_{3}^{-}$ & $\mathrm{C}_{2} \mathrm{H}_{4}^{+}$ & $\mathrm{C}_{2} \mathrm{H}_{5}^{+}$ \\
\hline $\mathrm{C}_{2} \mathrm{H}_{6}^{+}$ & $\mathrm{C}_{2} \mathrm{H}_{7}^{+}$ & $\mathrm{C}_{2} \mathrm{HN}^{+}$ & $\mathrm{C}_{2} \mathrm{HO}^{+}$ & $\mathrm{C}_{2} \mathrm{HO}^{-}$ & $\mathrm{C}_{2} \mathrm{~N}_{2}^{+}$ & $\mathrm{C}_{3} \mathrm{H}_{2}^{+}$ \\
\hline $\mathrm{C}_{3} \mathrm{H}_{3}^{+}$ & $\mathrm{C}_{3} \mathrm{H}_{4}^{+}$ & $\mathrm{C}_{3} \mathrm{H}_{5}^{+}$ & $\mathrm{C}_{3} \mathrm{H}_{6}^{+}$ & $\mathrm{C}_{3} \mathrm{H}_{7}^{+}$ & $\mathrm{C}_{3} \mathrm{H}_{8}^{+}$ & $\mathrm{C}_{3} \mathrm{H}_{9}^{+}$ \\
\hline $\mathrm{C}_{3} \mathrm{HN}^{+}$ & $\mathrm{C}_{3} \mathrm{~N}_{2}^{+}$ & $\mathrm{C}_{3} \mathrm{~N}_{3}^{+}$ & $\mathrm{C}_{4} \mathrm{H}_{2}^{+}$ & $\mathrm{C}_{4} \mathrm{H}_{3}^{+}$ & $\mathrm{C}_{4} \mathrm{H}_{4}^{+}$ & $\mathrm{C}_{4} \mathrm{H}_{5}^{+}$ \\
\hline $\mathrm{C}_{4} \mathrm{H}_{7}^{+}$ & $\mathrm{C}_{4} \mathrm{H}_{8}^{+}$ & $\mathrm{C}_{4} \mathrm{H}_{9}^{+}$ & $\mathrm{C}_{5} \mathrm{HN}^{+}$ & $\mathrm{CH}_{2} \mathrm{~N}^{+}$ & $\mathrm{CH}_{2} \mathrm{O}^{+}$ & $\mathrm{CH}_{3} \mathrm{~N}^{+}$ \\
\hline $\mathrm{CH}_{3} \mathrm{O}^{+}$ & $\mathrm{CH}_{3} \mathrm{O}^{-}$ & $\mathrm{CH}_{4} \mathrm{~N}^{+}$ & $\mathrm{CH}_{4} \mathrm{~N}^{-}$ & $\mathrm{CH}_{4} \mathrm{O}^{+}$ & $\mathrm{CH}_{5} \mathrm{~N}^{+}$ & $\mathrm{CH}_{5} \mathrm{O}^{+}$ \\
\hline $\mathrm{CH}_{6} \mathrm{~N}^{+}$ & $\mathrm{CHNO}^{+}$ & $\mathrm{CHO}_{2}^{+}$ & $\mathrm{CHO}_{2}^{-}$ & $\mathrm{FeO}_{2}^{+}$ & $\mathrm{H}_{2} \mathrm{NO}^{+}$ & $\mathrm{H}_{2} \mathrm{O}_{2}^{+}$ \\
\hline $\mathrm{H}_{3} \mathrm{O}_{2}^{+}$ & $\mathrm{HN}_{2} \mathrm{O}^{+}$ & $\mathrm{HNO}_{2}^{+}$ & $\mathrm{MgHO}^{+}$ & $\mathrm{MgO}_{2}^{+}$ & $\mathrm{Si}_{2} \mathrm{H}^{+}$ & $\mathrm{SiCH}^{+}$ \\
\hline $\mathrm{SiH}_{2}^{+}$ & $\mathrm{SiH}_{3}^{+}$ & $\mathrm{SiH}_{3}^{-}$ & $\mathrm{SiH}_{4}^{+}$ & $\mathrm{SiH}_{5}^{+}$ & $\mathrm{SiHO}^{+}$ & $\mathrm{C}_{2} \mathrm{H}_{2} \mathrm{~N}^{+}$ \\
\hline $\mathrm{C}_{2} \mathrm{H}_{2} \mathrm{~N}^{-}$ & $\mathrm{C}_{2} \mathrm{H}_{2} \mathrm{O}^{+}$ & $\mathrm{C}_{2} \mathrm{H}_{3} \mathrm{~N}^{+}$ & $\mathrm{C}_{2} \mathrm{H}_{3} \mathrm{O}^{+}$ & $\mathrm{C}_{2} \mathrm{H}_{3} \mathrm{O}^{-}$ & $\mathrm{C}_{2} \mathrm{H}_{4} \mathrm{~N}^{+}$ & $\mathrm{C}_{2} \mathrm{H}_{4} \mathrm{O}^{+}$ \\
\hline $\mathrm{C}_{2} \mathrm{H}_{5} \mathrm{~N}^{+}$ & $\mathrm{C}_{2} \mathrm{H}_{5} \mathrm{O}^{+}$ & $\mathrm{C}_{2} \mathrm{H}_{5} \mathrm{O}^{-}$ & $\mathrm{C}_{2} \mathrm{H}_{6} \mathrm{O}^{+}$ & $\mathrm{C}_{2} \mathrm{H}_{7} \mathrm{O}^{+}$ & $\mathrm{C}_{2} \mathrm{HN}_{2}^{+}$ & $\mathrm{C}_{3} \mathrm{H}_{2} \mathrm{~N}^{+}$ \\
\hline $\mathrm{C}_{3} \mathrm{H}_{4} \mathrm{O}^{+}$ & $\mathrm{C}_{3} \mathrm{H}_{5} \mathrm{O}^{+}$ & $\mathrm{C}_{3} \mathrm{H}_{6} \mathrm{~N}^{+}$ & $\mathrm{C}_{3} \mathrm{H}_{6} \mathrm{O}^{+}$ & $\mathrm{C}_{3} \mathrm{H}_{7} \mathrm{O}^{+}$ & $\mathrm{C}_{3} \mathrm{H}_{9} \mathrm{O}^{+}$ & $\mathrm{C}_{3} \mathrm{HN}_{2}^{+}$ \\
\hline $\mathrm{C}_{4} \mathrm{H}_{2} \mathrm{~N}^{+}$ & $\mathrm{CH}_{2} \mathrm{NO}^{+}$ & $\mathrm{CH}_{3} \mathrm{NO}^{+}$ & $\mathrm{CH}_{4} \mathrm{NO}^{+}$ & $\mathrm{CH}_{5} \mathrm{NO}^{+}$ & $\mathrm{CH}_{6} \mathrm{NO}^{+}$ & $\mathrm{CH}_{2} \mathrm{O}_{2}^{+}$ \\
\hline $\mathrm{CH}_{2} \mathrm{OH}^{+}$ & $\mathrm{CH}_{3} \mathrm{O}_{2}^{+}$ & $\mathrm{H}_{2} \mathrm{NO}_{2}^{+}$ & $\mathrm{H}_{2} \mathrm{NO}_{3}^{+}$ & $\mathrm{Si}_{2} \mathrm{H}_{2}^{+}$ & $\mathrm{Si}_{2} \mathrm{H}_{3}^{+}$ & $\mathrm{Si}_{2} \mathrm{H}_{4}^{+}$ \\
\hline $\mathrm{Si}_{2} \mathrm{H}_{5}^{+}$ & $\mathrm{Si}_{3} \mathrm{H}_{2}^{+}$ & $\mathrm{Si}_{3} \mathrm{H}_{3}^{+}$ & $\mathrm{Si}_{3} \mathrm{H}_{4}^{+}$ & $\mathrm{Si}_{3} \mathrm{H}_{5}^{+}$ & $\mathrm{Si}_{3} \mathrm{H}_{6}^{+}$ & $\mathrm{Si}_{3} \mathrm{H}_{7}^{+}$ \\
\hline $\mathrm{Si}_{4} \mathrm{H}_{2}^{+}$ & $\mathrm{Si}_{4} \mathrm{H}_{3}^{+}$ & $\mathrm{Si}_{4} \mathrm{H}_{4}^{+}$ & $\mathrm{Si}_{4} \mathrm{H}_{5}^{+}$ & $\mathrm{Si}_{4} \mathrm{H}_{6}^{+}$ & $\mathrm{Si}_{4} \mathrm{H}_{7}^{+}$ & $\mathrm{SiCH}_{2}^{+}$ \\
\hline $\mathrm{SiCH}_{3}^{+}$ & $\mathrm{SiCH}_{4}^{+}$ & $\mathrm{SiCH}_{5}^{+}$ & $\mathrm{SiC}_{2} \mathrm{H}^{+}$ & $\mathrm{SiH}_{3} \mathrm{O}^{+}$ & $\mathrm{SiH}_{3} \mathrm{O}^{-}$ & $\mathrm{aCHNO}^{+}$ \\
\hline $\mathrm{C}_{2} \mathrm{H}_{4} \mathrm{NO}^{-}$ & $\mathrm{C}_{2} \mathrm{H}_{5} \mathrm{O}_{2}^{+}$ & $\mathrm{C}_{4} \mathrm{H}_{7} \mathrm{O}_{2}^{+}$ & $\mathrm{CH}_{2} \mathrm{NO}_{2}^{-}$ & $\mathrm{CH}_{3} \mathrm{NO}_{2}^{+}$ & $\mathrm{CH}_{4} \mathrm{NO}_{2}^{+}$ & $\mathrm{MgH}_{2} \mathrm{O}_{2}^{+}$ \\
\hline $\mathrm{SiC}_{2} \mathrm{H}_{3}^{+}$ & $\mathrm{SiC}_{2} \mathrm{H}_{4}^{+}$ & $\mathrm{SiC}_{2} \mathrm{H}_{5}^{+}$ & $\mathrm{SiC}_{2} \mathrm{H}_{6}^{+}$ & $\mathrm{TiC}_{2} \mathrm{H}_{4}^{+}$ & & \\
\hline
\end{tabular}

\section{APPENDIX C \\ OUTGASSING, CONDENSATION, EVAPORATION, AND ESCAPE}

Boundary conditions play a key role in determining the atmospheric compositions of planets. For rocky planets, these boundary conditions are set by outgassing and escape into the exosphere. At temperatures $\lesssim 1500 \mathrm{~K}$, metals such as silicates, iron, and corundum begin to condense out of the atmospheric gas phase. At much lower temperatures, various other species (e.g., water, ammonia, methane) may also condense out. It is important for comparison to previous models to consider both the atmospheric boundary conditions and atmospheric condensation.

As discussed in Section 3.1, there exist, in addition to the STAND2015 reactions, a series of "banking" reactions for all major species, that collect particles and reintroduce them to the fluid parcel at a rate determined by the diffusion timescales. The very bottom banking reaction can be set to act effectively as an outgassing rate. Imagine a particular reservoir for a species, A. This reservoir is outgassing into the atmosphere with a flux, $\Phi(\mathrm{A})\left[\mathrm{cm}^{-2} \mathrm{~s}^{-1}\right]$. This can be accounted by first taking a reservoir concentration of $\mathrm{A}$, which for a large reservoir will be $\gg[\mathrm{A}](z=0)$, the bottom of the atmosphere. For a reservoir that will not be appreciably depleted over the chemical-dynamical timescale of the atmosphere, the rate is simply:

$$
P_{\text {out }}(\mathrm{A})=\frac{\Phi(\mathrm{A})}{\Delta z} .
$$

For a finite reservoir, we can place the reservoir concentration into the bottom "bank" for the species in question, and the $t=0$ flux, $\Phi(\mathrm{A}, 0)$, and concentration ([BA]) can be used to determine the rate of outgassing,

$$
P_{\text {out }}(\mathrm{A})=L(\mathrm{BA})[\mathrm{BA}],
$$

where

$$
L(\mathrm{BA})=\frac{\Phi(\mathrm{A}, 0)}{[\mathrm{BA}(t=0)] \Delta z} .
$$

These approximations are not used anywhere in this paper. For HD 209458b, we simply start with solar elemental abundances, with everything in atomic form at the bottom of the atmosphere. For both Jupiter and Earth, we start with fixed lower boundary conditions.

Condensation or evaporation of species A can be treated by the reactions ("JA" represents "A in condensate form"):

$$
\begin{gathered}
\mathrm{A} \rightarrow \mathrm{JA}, \quad \text { for condensation; } \\
\mathrm{JA} \rightarrow \mathrm{A}, \quad \text { for evaporation. }
\end{gathered}
$$


Table 6

STAND2015 Chemical Kinetics Network

\begin{tabular}{|c|c|c|c|c|c|c|}
\hline \# & Type & Reaction & $\alpha$ & $\beta$ & $\gamma$ & References \\
\hline 1 & $2 \mathrm{~d}$ & $\mathrm{C}_{2} \leftrightharpoons \mathrm{C}+\mathrm{C}$ & $2.49 \mathrm{e}-08$ & 0.00 & 71600 & 1 \\
\hline 2 & $2 \mathrm{~d}$ & $\mathrm{C}_{2} \leftrightharpoons \mathrm{C}+\mathrm{C}$ & $6.01 \mathrm{e}+11$ & -1.00 & 71600 & $\ldots$ \\
\hline 3 & $2 \mathrm{~d}$ & $\mathrm{CH} \leftrightharpoons \mathrm{C}+\mathrm{H}$ & $3.16 \mathrm{e}-10$ & 0.00 & 33700 & 2 \\
\hline 5 & $2 \mathrm{~d}$ & $\mathrm{CN} \leftrightharpoons \mathrm{C}+\mathrm{N}$ & $1.00 \mathrm{e}-09$ & 0.00 & 71000 & 3 \\
\hline 6 & $2 \mathrm{~d}$ & $\mathrm{CN} \leftrightharpoons \mathrm{C}+\mathrm{N}$ & $2.42 \mathrm{e}+10$ & 0.00 & 71000 & $\ldots$ \\
\hline 7 & $2 d$ & $\mathrm{CO} \leftrightharpoons \mathrm{C}+\mathrm{O}$ & $1.52 \mathrm{e}-04$ & -3.10 & 129000 & 4 \\
\hline 10 & $2 d$ & $\mathrm{H}+\mathrm{H} \leftrightharpoons \mathrm{H}_{2}$ & $1.00 \mathrm{e}-11$ & 0.00 & 0 & 5 \\
\hline
\end{tabular}

Note.

References. (1) Kruse \& Roth (1997), (2) Dean \& Hanson (1992), (3) Tsang (1992), (4) Mick et al. (1993), (5) Baulch et al. (1992), (6) Deppe et al. (1998), (7) Tsang \& Hampson (1986), (8) Thielen \& Roth (1986), (9) Myerson (1973), (10) Javoy et al. (2003), (11) De Cobos \& Troe (1984), (12) Bauerle et al. (1995), (13) Husain \& Young (1975), (14) Lin et al. (1992), (15) Wagner \& Bowman (1987), (16) Mertens \& Hanson (1996), (17) Eremin et al. (1997), (18) Tsang \& Herron (1991), (19) Ross et al. (1997), (20) Fulle \& Hippler (1997), (21) Moses et al. (2005), (22) Yumura \& Asaba (1981), (23) Hanson \& Salimian (1984), (24) Graham \& Johnston (1978), (25) Bozzelli \& Dean (1995), (26) Natarajan et al. (1986), (27) Troe (2005), (28) Wu et al. (1990), (29) Lifshitz et al. (1997), (30) Baulch et al. (2005), (31) Vuitton et al. (2012), (32) Atkinson et al. (2004), (33) Baulch et al. (1994), (34) Meyer et al. (1969), (35) Dorko et al. (1979), (36) Klatt et al. (1995), (37) Schulz et al. (1985), (38) Fernandes et al. (2005), (39) Dean (1985), (40) Li et al. (2006), (41) Frank et al. (1988), (42) Kiefer et al. (1988), (43) Kern et al. (1988), (44) Yang et al. (2005), (45) Warnatz (1984, p. 197), (46) Chang \& Yu (1995), (47) Cribb et al. (1992), (48) Setser \& Rabinovitch (1962), (49) Chang et al. (2007), (50) Saito et al. (1984), (51) Ikeda \& Mackie (1996), (52) Wakamatsu \& Hidaka (2008), (53) O'Neal \& Benson (1962), (54) Atkinson et al. (1997), (55) Huynh \& Violi (2008), (56) Dombrowsky et al. (1991), (57) Koike et al. (2000), (58) Ing et al. (2003), (59) Yasunaga et al. (2008), (60) Herron (1999), (61) Lifshitz \& Tamburu (1998), (62) Lifshitz et al. (1993), (63) Oehlschlaeger et al. (2004), (64) Saito et al. (1990), (65) Lee \& Bozzelli (2003), (66) Miller et al. (2004), (67) Friedrichs et al. (2008), (68) Joshi et al. (2005), (69) Almatarneh et al. (2005), (70) Zaslonko et al. (1997), (71) Fernández-Ramos et al. (1998), (72) Zaslonko et al. (1993), (73) Tsang (2004), (74) Cook et al. (2009), (75) Imai \& Toyama (1962), (76) Hinshelwood \& Askey (1927), (77) Hunt et al. (1965), (78) Sheng et al. (2002), (79) DeSain et al. (2003), (80) Chuchani et al. (1993), (81) Petrov et al. (2009), (82) Batt \& Rattray (1979), (83) Blake \& Jackson (1969), (84) Duan \& Page (1995), (85) Spokes \& Benson (1967), (86) Glänzer \& Troe (1973), (87) Levy (1956), (88) Batt et al. (1975), (89) Li et al. (2004), (90) Natarajan \& Bhaskaran (1981), (91) Arenas et al. (2000), (92) Zalotai et al. (1983), (93) Lifshitz \& Tamburu (1994), (94) Sato \& Hidaka (2000), (95) Hoyermann et al. (1999), (96) Zhang et al. (2005), (97) Zhang et al. (2004), (98) Curran (2006), (99) Patrick \& Golden (1984), (100) Lavvas et al. (2014), (101) Baulch et al. (1981), (102) Crosley (1989), (103) Kretschmer \& Petersen (1963), (104) Fehsenfeld et al. (1974a), (105) Smith et al. (1982), (106) Raksit \& Warneck (1979), (107) Adams \& Smith (1977), (108) Ferguson \& Fehsenfeld (1968), (109) Graham et al. (1973), (110) Fehsenfeld et al. (1967a), (111) Burt et al. (1970), (112) Beaty \& Patterson (1965), (113) Märk \& Oskam (1971), (114) Fehsenfeld et al. (1975a), (115) Sieck (1978), (116) See Section 2.3, (117) Wang et al. (2001), (118) Slack \& Fishburne (1970), (119) Dean et al. (1991), (120) Andersson et al. (2003), (121) Mayer et al. (1967), (122) Whyte \& Phillips (1983), (123) Caridade et al. (2005), (124) Adam et al. (2005), (125) Cohen \& Westberg (1991), (126) Miller et al. (2005), (127) Bauer et al. (1985), (128) Sumathi \& Nguyen (1998), (129) Tsuboi \& Hashimoto (1981), (130) Röhrig \& Wagner (1994), (131) Nguyen et al. (2004), (132) Mousavipour \& Saheb (2007), (133) Bozzelli et al. (1994), (134) Su et al. (2002), (135) Shaw (1977), (136) Louge \& Hanson (1984), (137) Miller \& Melius (1992), (138) Szekely et al. (1985), (139) Corchado \& EspinosaGarcia (1997), (140) Linder et al. (1996), (141) Hsu et al. (1997), (142) He et al. (1993), (143) Senosiain et al. (2006), (144) Loison et al. (2015), (145) Tsang (1987), (146) Morris \& Niki (1973), (147) Boughton et al. (1997), (148) Knyazev et al. (1996), (149) Jamieson et al. (1970), (150) Ohmori et al. (1990), (151) Colberg \& Friedrichs (2006), (152) Li \& Williams (1996), (153) Vaghjiani (1995), (154) Sivaramakrishnan et al. (2009), (155) Lambert et al. (1967), (156) Lifshitz \& BenHamou (1983), (157) Zhang \& Bauer (1997), (158) Moortgat et al. (1977), (159) Aders \& Wagner (1973), (160) Mayer et al. (1966), (161) Brownsword et al. (1996), (162) Ibragimova (1986), (163) Harding et al. (1993), (164) Duff \& Sharma (1996), (165) Bose \& Candler (1996), (166) Brunetti \& Liuti (1975), (167) Lifshitz \& Frenklach (1980), (168) Avramenko \& Krasnen'kov (1966), (169) Sander et al. (2011), (170) Barnett et al. (1987), (171) Safrany \& Jaster (1968), (172) Cimas \& Largo (2006), (173) Wagner et al. (1971), (174) Xu \& Sun (1999), (175) Sun et al. (2004), (176) Takahashi (1972), (177) Paraskevopoulos \& Winkler (1967), (178) Forst et al. (1957), (179) Roscoe \& Roscoe (1973), (180) Lambert et al. (1968), (181) Fairbairn (1969), (182) Murrell \& Rodriguez (1986), (183) Frank (1986), (184) Zhu \& Lin (2007), (185) Korovkina (1976), (186) Harding \& Wagner (1989), (187) Karkach \& Osherov (1999), (188) Meagher \& Anderson (2000), (189) Cvetanović (1987), (190) Hack et al. (2005), (191) Dean \& Kistiakowsky (1971), (192) Harding et al. (2005), (193) Corchado et al. (1998), (194) Cobos \& Troe (1985), (195) Sridharan \& Kaufman (1983), (196) Mahmud et al. (1987), (197) Westenberg \& De Haas (1969), (198) Grotheer \& Just (1981), (199) Gehring et al. (1969), (200) Mayer \& Schieler (1968), (201) Bogan \& Hand (1978), (202) Miyoshi et al. (1993), (203) Kato \& Cvetanovic (1967), (204) Wu et al. (2007), (205) Takahashi et al. (2007), (206) Patterson \& Greene (1962), (207) Meaburn \& Gordon (1968), (208) Pshezhetskii et al. (1959), (209) Wilson (1972), (210) Kruse \& Roth (1999), (211) Fontijn et al. (2001), (212) Harding et al. (2008), (213) Matsui \& Nomaguchi (1978), (214) Geiger et al. (1999), (215) Bergeat et al. (1998), (216) Jachimowski (1977), (217) Lichtin et al. (1984), (218) Bergeat et al. (2009), (219) Tao et al. (2001), (220) Blitz et al. (1997), (221) Mulvihill \& Phillips (1975), (222) Rim \& Hershberger (1999), (223) Tzeng et al. (2009), (224) Wang et al. (2002), (225) Park \& Hershberger (1993), (226) Gannon et al. (2007), (227) Sayah et al. (1988), (228) Feng \& Hershberger (2007), (229) Pang et al. (2008), (230) Sun et al. (2006), (231) Sims et al. (1993), (232) You et al. (2007), (233) Tsuboi et al. (1981), (234) Roose et al. (1978), (235) Baldwin et al. (1961), (236) Davidson et al. (1990), (237) Quandt \& Hershberger (1995), (238) Xu \& Sun (1998), (239) Röhrig et al. (1994), (240) Miller \& Melius (1988), (241) Campomanes et al. (2001), (242) Gonzalez et al. (1992), (243) Mebel et al. (1996), (244) Srinivasan et al. (2007), (245) Ju et al. (2007), (246) Miller \& Melius (1989), (247) Breen \& Glass (1971), (248) Jasper et al. (2007), (249) Humpfer et al. (1995), (250) Xu \& Lin (2007), (251) Wooldridge et al. (1996), (252) Corchado et al. (1995), (253) Grussdorf et al. (1994), (254) Faravelli et al. (2000), (255) Vandooren \& Van Tiggelen (1977), (256) Bryukov et al. (2004), (257) Espinosa-Garcia et al. (1993), (258) Anglada (2004), (259) Lamb et al. (1984), (260) Liu et al. (2002), (261) Li \& Wang (2004), (262) Srinivasan et al. (2007), (263) Baldwin et al. (1984), (264) Cohen (1991), (265) Nielsen et al. (1991), (266) Atkinson et al. (2001), (267) Wu et al. (2003), (268) Zabarnick \& Heicklen (1985), (269) Sanders et al. (1987), (270) Thweatt et al. (2004), (271) Dammeier et al. (2007), (272) Lin et al. (1993), (273) Miller \& Glarborg (1999), (274) Park \& Lin (1997), (275) Vandooren et al. (1994), (276) Howard (1979), (277) Opansky \& Leone (1996a, 1996b), (278) Benson (1994), (279) Hennig \& Wagner (1994), (280) Tomeczek \& Gradoń (2003), (281) Mebel \& Lin (1997), (282) Striebel et al. (2004), (283) Laidler \& Wojciechowski (1961), (284) McKenney et al. (1963), (285) Becker et al. (1992b), (286) Williamson \& Bayes (1967), (287) Alvarez \& Moore (1994), (288) Dombrowsky \& Wagner (1992), (289) Nadtochenko et al. (1979), (290) Zhu \& Lin (2005), (291) Schacke et al. (1974), (292) Bozzelli \& Dean (1989), (293) Tang et al. (2008), (294) Reitel'boim et al. (1978), (295) Seery (1969), (296) Michael et al. (1999), (297) Marinov et al. (1998), (298) 
Bogdanchikov et al. (2004), (299) Shaw (1978), (300) Neiman \& Feklisov (1961), (301) Bozzelli \& Dean (1990), (302) Baker et al. (1971), (303) Atkinson et al. (1973), (304) Yang et al. (2008), (305) Hastie et al. (1976), (306) Morrissey \& Schubert (1963), (307) Haworth et al. (2003), (308) Yee Quee \& Thynne (1968), (309) Stothard et al. (1995), (310) Sahetchian et al. (1987), (311) Hidaka et al. (1990), (312) Dong et al. (2005), (313) Baker et al. (1969), (314) Homann \& Wellmann (1983), (315) Frank et al. (1986), (316) Böhland et al. (1985), (317) Monks et al. (1993), (318) Xu \& Lin (2004), (319) Huynh \& Truong (2008), (320) Gao \& Macdonald (2006), (321) Macdonald (2007), (322) Sumathi \& Peyerimhoff (1996), (323) Glarborg et al. (1995), (324) Bulatov et al. (1980), (325) Mertens et al. (1991), (326) Thaxton et al. (1997), (327) Song et al. (2003), (328) Mebel \& Lin (1999), (329) England \& Corcoran (1975), (330) Choi \& Lin (2005), (331) He et al. (1988), (332) Glänzer \& Troe (1975), (333) Lloyd (1974), (334) Vardanyan et al. (1974), (335) Becker et al. (1992a), (336) Carstensen \& Dean (2008), (337) Borisov et al. (1977), (338) Trenwith (1960), (339) Srinivasan et al. (2005), (340) Canosa et al. (1979), (341) Johnston (1951), (342) Chan et al. (2001), (343) Atkinson et al. (1989), (344) Christie \& Voisey (1967), (345) Anastasi \& Hancock (1988), (346) Fifer (1975), (347) Lindley et al. (1979), (348) Hébrard et al. (2013), (349) Laufer \& Fahr (2004), (350) Woods \& Haynes (1994), (351) Skinner \& Ruehrwein (1959), (352) Tabayashi \& Bauer (1979), (353) Metcalfe et al. (1983), (354) Adachi et al. (1981), (355) Hassinen et al. (1990), (356) Ceursters et al. (2001), (357) Baldwin et al. (1971), (358) Saeys et al. (2006), (359) Donovan et al. (1971), (360) Seetula et al. (1986), (361) Gray \& Herod (1968), (362) Hidaka et al. (2000), (363) Thynne \& Gray (1963), (364) Sanders et al. (1980), (365) Musin \& Lin (1998), (366) Bravo-Pérez et al. (2002), (367) Daele et al. (1995), (368) Kukui et al. (1995), (369) Langer \& Ljungström (1995), (370) Biggs et al. (1995), (371) Langer \& Ljungström (1994), (372) Sun et al. (2001), (373) Peeters et al. (1995), (374) Carl et al. (2003), (375) Osborn (2003), (376) Meyer \& Hershberger (2005), (377) Petty et al. (1993), (378) Nizamov \& Dagdigian (2003), (379) Chakraborty \& Lin (1999), (380) Duran et al. (1988), (381) Knyazev et al. (1996b), (382) Levush et al. (1969), (383) Canosa et al. (1988), (384) Tanzawa \& Gardiner (1980), (385) J. I. Moses (2016, private communication), (386) Adamson et al. (1997), (387) Wallington \& Japar (1989), (388) Fahr \& Stein (1989), (389) Scherzer et al. (1987), (390) Kelly \& Heicklen (1978), (391) Thynne \& Gray (1963), (392) Moshkina et al. (1980), (393) Edwards et al. (1966), (394) Hoehlein \& Freeman (1970), (395) Laidler \& McKenney (1964), (396) Carstensen \& Dean (2005), (397) Horne \& Norrish (1970), (398) Herron (1988), (399) Atkinson et al. (1992), (400) Veyret et al. (1982), (401) Young (1958), (402) Gill et al. (1981), (403) Zhu \& Lin (2009), (404) Hassinen et al. (1985), (405) Tuazon et al. (1984), (406) Edelbüttel-Einhaus et al. (1992), (407) Song et al. (2005), (408) Suzaki et al. (2007), (409) Suzaki et al. (2006), (410) Batt et al. (1977), (411) Ray et al. (1996), (412) Natarajan \& Bhaskaran (1981), (413) Klemm (1965), (414) Hartmann et al. (1990), (415) Wijnen (1960), (416) Heicklen \& Johnston (1962), (417) Jensen (1982), (418) Allison et al. (1996), (419) Bryukov et al. (2006), (420) Husain \& Lee (1988), (421) Husain \& Marshall (1986), (422) Bolden et al. (1970), (423) Laudenslager et al. (1974), (424) Raksit \& Warneck (1980a), (425) Robertson et al. (1983), (426) Dotan \& Lindinger (1982), (427) Karpas et al. (1978), (428) Chau \& Bowers (1976), (429) Thomas et al. (1978), (430) Shul et al. (1987), (431) Lindinger et al. (1981), (432) Villinger et al. (1982), (433) Roche et al. (1971), (434) Lindinger (1973), (435) Lindinger et al. (1975f), (436) Raksit (1982), (437) Bohme et al. (1970), (438) Adams et al. (1970), (439) Shul et al. (1987), (440) Raksit \& Warneck (1981), (441) Huntress \& Baldeschwieler (1969), (442) Anicich et al. (1976), (443) Freeman et al. (1978b), (444) Schildcrout \& Franklin (1970), (445) Bohme et al. (1982), (446) Raksit \& Bohme (1985), (447) Cheng et al. (1973), (448) Cermak et al. (1970), (449) Adams \& Smith (1978), (450) Adams et al. (1978), (451) Szabo \& Derrick (1971), (452) Smith \& Adams (1977b), (453) Viggiano et al. (1980), (454) Schiff \& Bohme (1979), (455) Zielinska \& Wincel (1970), (456) McEwan et al. (1981), (457) Liddy et al. (1977a), (458) Wight \& Beauchamp (1980), (459) Wagner-Redeker et al. (1985), (460) Karpas \& Klein (1975), (461) Tanner et al. (1979b), (462) Mackay \& Bohme (1978), (463) Adams et al. (1978), (464) Mackay et al. (1977), (465) Mackay et al. (1976a), (466) Okada et al. (1972), (467) Mackay et al. (1981), (468) Kumakura et al. (1978a), (469) Raksit \& Bohme (1984), (470) Matsumoto et al. (1975), (471) Kasper \& Franklin (1972), (472) Betowski et al. (1975), (473) Anicich et al. (1986), (474) Debrou et al. (1978), (475) Freeman et al. (1978a), (476) Fluegge (1969a), (477) Smith \& Adams (1978), (478) Kumakura et al. (1978b), (479) Bohme \& Raksit (1985), (480) Kim et al. (1975), (481) Huntress et al. (1973), (482) Huntress \& Elleman (1970), (483) Fehsenfeld (1976), (484) Fluegge (1969b), (485) Huntress et al. (1980), (486) Warneck (1972), (487) Sieck \& Futrell (1968), (488) McAllister (1973), (489) Gupta et al. (1967), (490) Tanner et al. (1979a), (491) Mackay et al. (1978), (492) Bohme et al. (1980), (493) Hemsworth et al. (1973), (494) Munson \& Field (1969), (495) Hopkinson et al. (1979), (496) Lindinger et al. (1975c), (497) Hemsworth et al. (1974), (498) Ikezoe et al. (1987), (499) MeotNer et al. (1986), (500) Raksit et al. (1984), (501) McEwan et al. (1983), (502) Jaffe \& Klein (1974), (503) Fehsenfeld et al. (1972), (504) Raksit \& Warneck (1980c), (505) Raksit \& Warneck (1980b), (506) Fehsenfeld et al. (1971), (507) Fehsenfeld et al. (1970), (508) Ikezoe et al. (1987), (509) Miller et al. (1984), (510) Mackay et al. (1980), (511) Field et al. (1957), (512) Jarrold et al. (1983), (513) Mayer \& Lampe (1974a), (514) Vogt et al. (1978), (515) Melton \& Rudolph (1960), (516) Munson et al. (1964), (517) Büttrill et al. (1974), (518) Mayer \& Lampe (1974b), (519) Kumakura et al. (1979), (520) Strausz et al. (1970), (521) Hiraoka \& Kebarle (1980), (522) Ikezoe et al. (1987), (523) Ausloos \& Lias (1981), (524) Tanner et al. (1979a), (525) Dheandhanoo et al. (1984), (526) Dunbar et al. (1972), (527) Sieck \& Searles (1970), (528) Matsuoka \& Ikezoe (1988), (529) Clary et al. (1985), (530) Armentrout et al. (1978), (531) Adams et al. (1980), (532) Smith \& Adams (1980), (533) Herbst et al. (1975), (534) Fehsenfeld et al. (1976), (535) Howorka et al. (1974), (536) Ausloos (1975), (537) Jones et al. (1981a), (538) Lawson et al. (1976), (539) Ikezoe et al. (1987), (540) Fehsenfeld et al. (1975b), (541) Lindinger et al. (1975a), (542) Henis et al. (1973), (543) Cheng et al. (1974), (544) McAllister \& Pitman (1976), (545) Karpas et al. (1979), (546) Bowers et al. (1969), (547) Smith et al. (1976), (548) Stevenson \& Schissler (1955), (549) Barassin et al. (1983), (550) Huntress et al. (1971), (551) Dotan et al. (1980), (552) Durup-Ferguson et al. (1984), (553) Ikezoe et al. (1987), (554) Lindinger et al. (1975d), (555) Liddy et al. (1977b), (556) Adams \& Smith (1976b), (557) Smith \& Adams (1981), (558) Kemper et al. (1983), (559) Fehsenfeld et al. (1978), (560) Mackay et al. (1979), (561) Bohme \& Mackay (1981), (562) Bohme et al. (1979), (563) Smith \& Adams (1977a), (564) Ikezoe et al. (1987), (565) Cheng \& Lampe (1973), (566) Neilson et al. (1978), (567) Kappes \& Staley (1981), (568) Fehsenfeld et al. (1966b), Jones et al. (1979), (569) Adams \& Smith (1976a), (570) Bolden \& Twiddy (1972), Mauclaire et al. (1978), (571) Heimerl et al. (1969), (572) Theard \& Huntress (1974), (573) Rowe et al. (1981), (574) Smith et al. (1978), (575) Tichy' et al. (1979), (576) Williamson \& Beauchamp (1975), (577) Fehsenfeld (1977), (578) Fehsenfeld et al. (1969c), (579) Ferguson (1968), (580) Jaffe et al. (1973), (581) Johnsen et al. (1970), (582) Jones et al. (1981b), (583) Kemper \& Bowers (1984), (584) Lindinger (1976), (585) Glosik et al. (1978), (586) Lindinger et al. (1974), (587) Dunkin et al. (1971), (588) Rowe et al. (1980), (589) Fahey et al. (1981), (590) Fehsenfeld (1969), (591) Lindinger et al. (1975e), (592) Lindinger et al. (1979), (593) Raksit (1986), (594) Tonkyn \& Weisshaar (1986), (595) Johnsen et al. (1974), (596) Tanaka et al. (1976), (597) Fehsenfeld \& Ferguson (1970), (598) Mackay et al. (1982), (599) Moylan et al. (1985), (600) Mackay et al. (1976b), (601) Ausloos (1975), (602) Ikezoe et al. (1987), (603) Fehsenfeld (1975), (604) Albritton et al. (1983), (605) Fehsenfeld et al. (1974b), (606) Ikezoe et al. (1987), (607) Fehsenfeld et al. (1969b), (608) Bohme et al. (1974), (609) Bohme et al. (1971), (610) Lifshitz et al. (1978), (611) Lindinger et al. (1975b), (612) Fehsenfeld et al. (1973), (613) Dunkin et al. (1970), (614) Payzant et al. (1976), (615) Ferguson et al. (1969), (616) Tanner et al. (1981), (617) Bierbaum et al. (1976), (618) Faigle et al. (1976), (619) Howard et al. (1974), (620) Young et al. (1971), (621) Fehsenfeld et al. (1966a), (622) Ikezoe et al. (1987), (623) Bierbaum et al. (1984), (624) Grabowski (1983), (625) Streit (1982), (626) McFarland et al. (1972), (627) Parkes (1972a), (628) Parkes (1972b), (629) Bohme \& Fehsenfeld (1969), (630) Fehsenfeld et al. (1967b), (631) Viggiano \& Paulson (1983), (632) Lifshitz \& Tassa (1973), (633) Marx et al. (1973), (634) McKnight (1970), (635) Fehsenfeld et al. (1969a), (636) Lifshitz et al. (1977), (637) Fahey et al. (1982), (638) Dunkin et al. (1972), (639) 0.1-370 ̊̊: Verner et al.

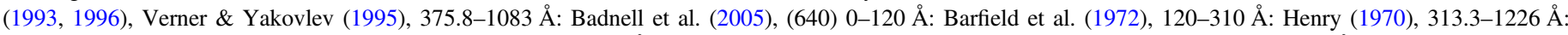
Badnell et al. (2005), (641) Bethe \& Salpeter (1957), (642) 0-20 Å: Verner et al. (1993, 1996), Verner \& Yakovlev (1995), 22.78-504.26 ̊: Badnell et al. (2005),

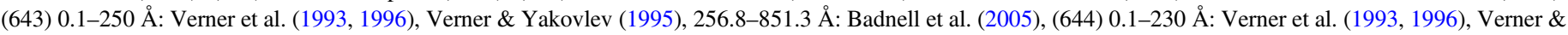

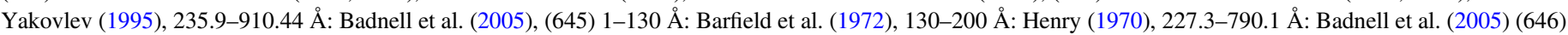
180-16640 Å: Geltman (1962), Broad \& Reinhardt (1976), (647) 0.6-918 ̊̊: Barfield et al. (1972), Padial et al. (1985), 918-1210 Å: Pouilly et al. (1983), Padial et al. (1985), (648) 12-617 Å: Walker \& Kelly (1972), 827-1170 Å: Barsuhn \& Nesbet (1978), van Dishoeck (1987), 1200-3589.9 Å: van Dishoeck (1987), branching ratio: Barsuhn \& Nesbet (1978), (649) 0.61-626.8 Å: Barfield et al. (1972), 905.8-1108 Å: Lavendy et al. (1984, 1987), (650) 89.6-564.5 ̊̊: Masuoka \& Samson 
(1981), 584.3-835.29 ̊: Cairns \& Samson (1965), Kronebusch \& Berkowitz (1976), (651) 89.6-584 Å: Masuoka \& Samson (1981), Kronebusch \& Berkowitz

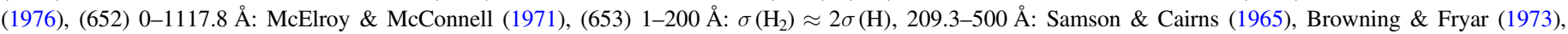
500-844 Å: Cook \& Metzger (1964), Browning \& Fryar (1973), (654) 9.9-247.2 Å: Huffman (1969), 303.8-1037 Å: Samson \& Cairns (1965), Cook \& Metzger (1964), Huffman et al. (1963), Kronebusch \& Berkowitz (1976), (655) 1-180 ̊̊: Huebner \& Mukherjee (2015), 180-580 ̊̊: Lee et al. (1973), Kronebusch \& Berkowitz (1976), 580-1350 Å: Watanabe et al. (1967), Kronebusch \& Berkowitz (1976), 1350-1910 Å: Marmo (1953), (656) 1-1771.2 Å: Barfield et al. (1972), Brion et al. (1979), 1771.2-2000 Å: Ackerman (1971, p. 149), 2000-2200 Å: Herman \& Mentall (1982), 2250-2423.7 A: Shardanand \& Rao (1977), branching ratio: Huffman (1969), Samson \& Cairns (1964), Matsunaga \& Watanabe (1967), Brion et al. (1979), (657) Experimental: 0.61-625.8 Å: Barfield et al. (1972), 1150-1830 Å: Nee \& Lee (1984), Theoretical: van Dishoeck (1984), (658) 2-270 Å: Henry \& McElroy (1968), 303.78-555.26 Å: Cairns \& Samson (1965),

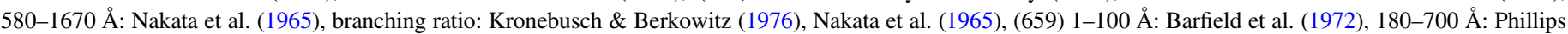
et al. (1977), Dibeler et al. (1966), 700-980.8 Å: Phillips et al. (1977), Katayama et al. (1973), Watanabe \& Jursa (1964), 980.8-1860 ̊̊: Watanabe \& Jursa (1964), Watanabe \& Zelikoff (1953), branching ratio: McNesby et al. (1962), Slanger \& Black (1982), Kronebusch \& Berkowitz (1976), (660) 1-1950 Å: Huebner \& Mukherjee (2015), (661) 1-1850 Å: Huebner \& Mukherjee (2015), (662) 0.61-625 Å: Huebner \& Mukherjee (2015), Barfield et al. (1972), 1080-1700 ̊̊: Zelikoff

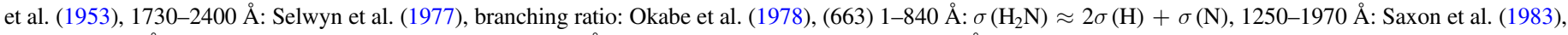
(664) 0.6-940 Å: Huebner \& Mukherjee (2015), 1080-1800 ̊̊: Nakayama et al. (1959), 1850-3978 Å: Bass et al. (1976), branching ratio: Nakayama et al. (1959),

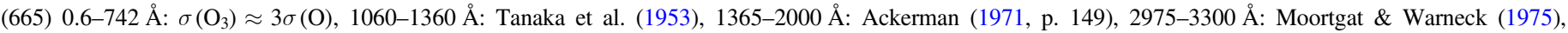

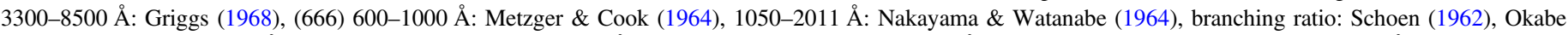

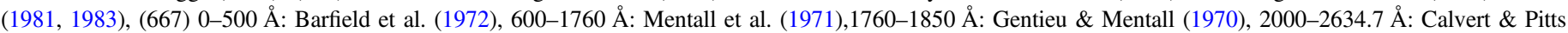
(1966), 2635.7-3531.7 ̊̊: Rogers (1990), 3531.7-3740 Å: Calvert \& Pitts (1966), branching ratio: Clark et al. (1978), Mentall et al. (1971), Guyon et al. (1976), (668) 0.61-627 ̊̊: Barfield et al. (1972), 1200-2000 Å: Okabe (1970), 2100-2550 Å: Dixon \& Kirby (1968), (669) 0.6-940 Å: Barfield et al. (1972), 2000-4000 Å: Cox \&

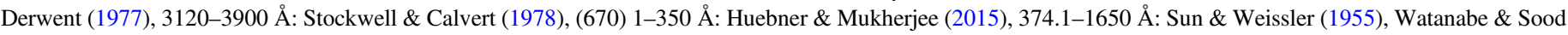
(1965), 1650-2170 Å: Watanabe (1954), 2140-2330 Å: Thompson et al. (1963), branching ratio: McNesby et al. (1962), Schurath et al. (1969), Kronebusch \&

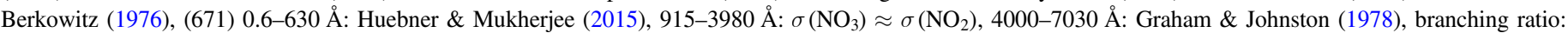
Magnotta \& Johnston (1980), (672) 23.6-1370 Å: Lukirskii et al. (1964),Rustgi (1964), Ditchburn (1955), 1380-1600 Å: Mount \& Moos (1978), branching ratio: Gorden \& Ausloos (1967), Calvert \& Pitts (1966), Stief et al. (1972), Slanger \& Black (1982), Kronebusch \& Berkowitz (1976), (673) 1-1100 Å: Huebner \& Mukherjee (2015), branching ratio: Gorden \& Ausloos (1961), Huebner \& Mukherjee (2015), (674) 0-1100 ̊: $\sigma\left(\mathrm{HNO}_{3}\right) \approx \sigma\left(\mathrm{NO}_{3}\right), 1100-1900 \AA ̊:$ Okabe (1980),

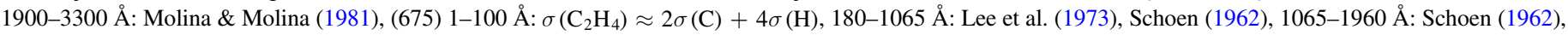
Zelikoff et al. (1953), branching ratio: Lee et al. (1973), McNesby \& Okabe (1964), Back \& Griffiths (1967), (676) $0.61-250 \AA$ : $\sigma\left(\mathrm{C}_{2} \mathrm{H}_{4}\right) \approx 2 \sigma(\mathrm{C})+6 \sigma(\mathrm{H})$, 354-1127 Å: Koch \& Skibowski (1971), 1160-1200 Å: Lombos et al. (1967), 1200-1380 Å: Okabe \& Becker (1963), 1380-1600 Å: Mount \& Moos (1978), branching ratio: Lias et al. (1970), Huebner \& Mukherjee (2015), (677) 2000-3450 Å: Baulch et al. (1982), branching ratio: Weaver et al. (1977), (678) 1200-2053 A: Salahub \& Sandorfy (1971), branching ratio: Porter \& Noyes (1959), Huebner \& Mukherjee (2015), (679) 0.1-2412.63 Å: Verner et al. (1993, 1996), Verner \& Yakovlev (1995), (680) 0.1-2856.34 Å: Verner et al. (1993, 1996), Verner \& Yakovlev (1995), (681) 0.61-877.46 Å: Barfield et al. (1972), 1050-1350 ̊̊: Myer \& Samson (1970), 1400-2200 ̊̊: Inn (1975), (682) Harada et al. (2010), Rimmer \& Helling (2013), (683) Harada et al. (2010), (684) 1-3000 ̊: $\sigma\left(\mathrm{N}_{2} \mathrm{O}_{3}\right) \approx \sigma\left(\mathrm{NO}_{2}\right)+\sigma(\mathrm{NO}), 3000-4000 \AA \AA$ : Stockwell \& Calvert (1978), (685) Pitts et al. (1982), (686) Vakhtin et al. (2001), (687) Fahr \& Nayak (1994), Ferradaz et al. (2009), Friedrichs et al. (2002), Okabe (1981), (688) Fahr \& Nayak (1996), (689) Prasad \& Huntress (1980), (690) Ercolano \& Storey (2006).

(This table is available in its entirety in machine-readable form.)

This physical process is treated in two ways in this paper for Earth and Jupiter. The first method is by considering supersaturation concentrations, above which the species in question condenses out and below which the species in question will evaporate. This method is given by Hamill et al. (1977), Toon \& Farlow (1981), and (Hu et al. 2012), and has the form (for species A)

$$
\begin{gathered}
P=\frac{[\mathrm{A}]}{t_{c}}, \quad L=\frac{[\mathrm{JA}]}{t_{c}} \\
t_{c}=\frac{m_{\mathrm{A}} v_{\mathrm{th}}}{4 \rho_{\mathrm{nuc}}} \frac{n_{\mathrm{gas}}-n_{c}(T, p)}{a},
\end{gathered}
$$

where $m_{\mathrm{A}}[\mathrm{g}]$ is the mass of the condensing species, $v_{\mathrm{th}}$ is the thermal velocity of the gas, $\rho_{\text {nuc }}\left[\mathrm{g} \mathrm{cm}^{-3}\right]$ is the material density of the condensation seed, $n_{\text {gas }}\left[\mathrm{cm}^{-3}\right]$ is the density of the gas, and $n_{c}\left[\mathrm{~cm}^{-3}\right]$ is the saturation number density, at the given temperature and pressure, and $a[\mathrm{~cm}]$ is the average radius of the nucleation site. We consider condensation only for low temperatures, so $n_{c}=p_{v} / k_{B} T$, where $p_{v}\left[\mathrm{dyn} \mathrm{cm}^{-2}\right]$ is the vapor pressure, and is estimated using the relatively simple Antoine equation:

$$
\log p_{v}=A-\frac{B}{C+T}
$$

where $A, B$, and $C$ are all parameters taken from the tabulated NIST chemistry webbook. ${ }^{13}$

Alternatively, one can use the method commonly used in the astrochemical context (Hasegawa et al. 1992; Caselli et al. 1998), where

$$
L\left[\mathrm{~s}^{-1}\right]=\pi a^{2} v_{\mathrm{th}} n_{\mathrm{nuc}}
$$

and

$$
P=\nu_{0}[\mathrm{JA}] e^{-E_{D} / k_{B} T} .
$$

Here, $E_{D}$ is the desorption energy, an empirically determined quantity, taken from Garrod et al. (2008). The frequency,

$$
\nu_{0}[\mathrm{~Hz}]=\left(\frac{2 n_{s} E_{D}}{\pi^{2} m_{\mathrm{A}}}\right)^{1 / 2},
$$

is the characteristic frequency of the surface. The number of sites is estimated, also empirically, by the relation $n_{s}=1.5 \times 10^{15} \mathrm{~cm}^{2}\left(a / a_{0}\right)^{2}$, where $a_{0}=0.1 \mu \mathrm{m}$. The advantage of this approximation is that it is identical to the form generally used for complex surface chemistry in protoplanetary disks. This would allow one to take the results from disk chemistry and utilize them straightforwardly in atmospheric outgassing models.

\footnotetext{
${ }^{13}$ http://webbook.nist.gov/chemistry/
} 
It is worth pointing out that exponentiating Equation (78), dividing by $k_{\mathrm{BT}}$, and then placing the resulting form of $n_{c}$ into Equation (77) yields a form:

$$
\frac{P}{L} \sim \frac{\text { Const. }}{v_{\text {th }}} e^{T_{c} / T}
$$

where $T_{c} / T=B /(C+T)$ from Equation (78). The two forms are therefore analogous parameterizations, with the same temperature dependence, but the saturation approach is dependent on the parameterized vapor pressure, and the deposition approach is parameterized by the number of nucleation sites and the binding energy of the nucleation particle.

Neither the supersaturation method nor the deposition method explain where the condensation seeds first arise. It is assumed that the condensation seeds are already present, and therefore that condensation occurs whenever the supersaturation ratio $S \gtrsim 1$. In some environments like Earth, the condensation seeds come in the form of sand or ash particles, and the supersaturation ratio for water to condense is very small, $S \approx 1.01$. If the seed particles are not already present in the atmosphere, they must form within the gas phase by the growth from small to large, complex clusters. This requires a supersaturation ratio $S \gg 100$, which only occurs when $T \ll T_{c}$ (Helling \& Fomins 2013). Zsom et al. (2012) explore the microphysics of water condensation and cloud formation for Earth and Earth-like planets.

None of these reactions appear in the generic kinetic network, because their inclusion is atmosphere-dependent. Condensation is not considered at all for HD 209458b because it is too hot, but is considered for Earth and Jupiter for water. Ammonia and methane condensation can also be considered for Jupiter and methane and other condensation should be considered for even colder planets, such as Uranus and Neptune.

\section{REFERENCES}

Ackerman, M. 1971, Mesospheric Models and Related Experiments (Berlin: Springer)

Adachi, H., Basco, N., \& James, D. 1981, Int. J. Chem. Kin., 13, 1251

Adam, L., Hack, W., Zhu, H., Qu, Z., \& Schinke, R. 2005, JChPh, 122, 114301

Adams, N., Bohme, D., \& Ferguson, E. 1970, JChPh, 52, 5101

Adams, N., \& Smith, D. 1976a, JPhB, 9, 1439

Adams, N., \& Smith, D. 1976b, IJMIP, 21, 349

Adams, N., \& Smith, D. 1977, CPL, 47, 383

Adams, N., \& Smith, D. 1978, CPL, 54, 530

Adams, N., Smith, D., \& Grief, D. 1978, IJMIP, 26, 405

Adams, N. G., Smith, D., \& Paulson, J. F. 1980, JChPh, 72, 288

Adamson, J., DeSain, J., Curl, R., \& Glass, G. 1997, JPCA, 101, 864

Aders, W.-K., \& Wagner, H. G. 1973, Berich Bunsen Gesell, 77, 712

Agúndez, M., Parmentier, V., Venot, O., Hersant, F., \& Selsis, F. 2014, A\&A, 564, A73

Alam, J. M., \& Lin, J. C. 2008, MWRv, 136, 4653

Albritton, D., Dotan, I., Streit, G., et al. 1983, JChPh, 78, 6614

Allison, T. C., Lynch, G. C., Truhlar, D. G., \& Gordon, M. S. 1996, JPhCh, 100,13575

Almatarneh, M., Flinn, C., \& Poirier, R. 2005, CaJCh, 83, 2082

Alvarez, R. A., \& Moore, C. B. 1994, JPhCh, 98, 174

Anastasi, C., \& Hancock, D. U. 1988, FaTr II, 84, 1697

Andersson, S., Markovic, N., \& Nyman, G. 2003, JPCA, 107, 5439

Anglada, J. M. 2004, JAChS, 126, 9809

Anicich, V. G., Huntress, W. T., \& Futrell, J. H. 1976, CPL, 40, 233

Anicich, V. G., Huntress, W. T., \& McEwan, M. J. 1986, JPhCh, 90, 2446

Aplin, K. L. 2013, Electrifying Atmospheres: Charging, Ionisation and Lightning in the Solar System and Beyond (1st ed.; Berlin: Springer)
Arenas, J. F., Marcos, J. I., López-Tocón, I., Otero, J. C., \& Soto, J. 2000, $\mathrm{JChPh}, 113,2282$

Armentrout, P., Berman, D., \& Beauchamp, J. 1978, CPL, 53, 255

Asplund, M., Grevesse, N., Sauval, A. J., \& Scott, P. 2009, ARA\&A, 47, 481

Atkinson, R., Baulch, D., Cox, R., et al. 1989, JPCRD, 18, 881

Atkinson, R., Baulch, D., Cox, R., et al. 1992, AtmEn A, 26, 1187

Atkinson, R., Baulch, D., Cox, R., et al. 1997, JPCRD, 26, 521

Atkinson, R., Baulch, D. L., Cox, R. A., et al. 2001, IUPAC Subcommittee on Gas Kinetic Data Evaluation for Atmospheric Chemistry Web Version 1

Atkinson, R., Baulch, D., Cox, R., et al. 2004, ACP, 4, 1461

Atkinson, R., Finlayson, B., \& Pitts, J. 1973, JAChS, 95, 7592

Atreya, S. K., Mahaffy, P. R., Niemann, H. B., Wong, M. H., \& Owen, T. C. 2003, P\&SS, 51, 105

Ausloos, P. 1975, in Interactions Between Ions and Molecules, ed. P. Ausloos (New York: Plenum), 489

Ausloos, P., \& Lias, S. 1981, JAChS, 103, 3641

Avramenko, L., \& Krasnen'kov, V. 1966, Russ. Chem. B, 15, 394

Back, R., \& Griffiths, D. 1967, JChPh, 46, 4839

Badnell, N. R., Bautista, M., Butler, K., et al. 2005, MNRAS, 360, 458

Bailey, R. L., Helling, Ch., Hodosán, G., Bilger, C., \& Stark, C. R. 2014, ApJ, 784, 43

Baker, R., Baldwin, R., \& Walker, R. 1971, in Int. Symp. on Combustion, Vol. 16 (Amsterdam: Elsevier), 291

Baker, R., Kerr, J., \& Trotman-Dickenson, A. 1969, J. Chem. Soc. A, 390

Baldwin, R. R., Booth, D., \& Brattan, D. 1961, CaJCh, 39, 2130

Baldwin, R. R., Keen, A., \& Walker, R. W. 1984, FaTr I, 80, 435

Baldwin, R. R., Langford, D., Matchan, M., Walker, R., \& Yorke, D. 1971, in Int. Symp. on Combustion, Vol. 16 (Amsterdam: Elsevier), 251

Banks, P. M., \& Kockarts, G. 1973, Aeronomy (Amsterdam: Elsevier) Bar-Nun, A., Bar-Nun, N., Bauer, S. H., \& Sagan, C. 1970, Sci, 470, 170

Barassin, J., Barassin, A., \& Thomas, R. 1983, IJMIP, 49, 51

Barfield, W., Koontz, G., \& Huebner, W. 1972, JQSRT, 12, 1409

Barnett, A. J., Marston, G., \& Wayne, R. P. 1987, FaTr II, 83, 1453

Barsuhn, J., \& Nesbet, R. 1978, JChPh, 68, 2783

Bass, A. M., Ledford, A. E., \& Laufer, A. H. 1976, JRNBA, 80A, 143

Batt, L., McCulloch, R., \& Milne, R. 1975, Int. J. Chem. Kinet., 7, 1

Batt, L., Milne, R., \& McCulloch, R. 1977, Int. J. Chem. Kin., 9, 567

Batt, L., \& Rattray, G. 1979, Int. J. Chem. Kin., 11, 1183

Bauer, W., Becker, K., \& Meuser, R. 1985, Berich Bunsen Gesell, 89, 340

Bauerle, S., Klatt, M., \& Wagner, H. 1995, Berich Bunsen Gesell, 99, 870

Baulch, D., Bowman, C. T., Cobos, C. J., et al. 2005, JPCRD, 34, 757

Baulch, D., Cobos, C., Cox, R., et al. 1992, JPCRD, 21, 411

Baulch, D., Cobos, C., \& Cox, R. 1994, JPCRD, 23, 847

Baulch, D., Cox, R., Crutzen, P., et al. 1982, JPCRD, 11, 327

Baulch, D., Duxbury, J., Grant, S., \& Montague, D. 1981, Evaluated Kinetic Data for High Temperature Reactions, Homogeneous Gas Phase Reactions of Halogen-and Cyanide-Containing Species, Vol. 4, Tech. Rep., DTIC Document

Beaty, E., \& Patterson, P. 1965, PhRv, 137, A346

Beaulieu, J. P., Kipping, D. M., Batista, V., et al. 2010, MNRAS, 409, 963

Becker, E., Rahman, M., \& Schindler, R. 1992a, Berich Bunsen Gesell, 96, 776

Becker, K., König, R., Meuser, R., Wiesen, P., \& Bayes, K. D. 1992b, J. Photoch. Photobio A, 64, 1

Benneke, B. 2015, arXiv:1504.07655

Benner, S. A., Ricardo, A., \& Carrigan, M. A. 2004, Curr. Opin. Chem. Biol., 8,672

Benson, S. W. 1994, Int. J. Chem. Kin., 26, 997

Bergeat, A., Calvo, T., Daugey, N., Loison, J.-C., \& Dorthe, G. 1998, JCPA, 102,8124

Bergeat, A., Moisan, S., Méreau, R., \& Loison, J.-C. 2009, CPL, 480, 21

Bethe, H. A., \& Salpeter, E. E. 1957, Quantum Mechanics of One-and TwoElectron Atoms, Vol. 63 (Berlin: Springer)

Betowski, D., Payzant, J., Mackay, G. I., \& Bohme, D. 1975, CPL, 31, 321

Bézard, B., Drossart, P., Encrenaz, T., \& Feuchtgruber, H. 2001, Icar, 154, 492

Bierbaum, V. M., DePuy, C., Shapiro, R., \& Stewart, J. H. 1976, JAChS, 98, 4229

Bierbaum, V. M., Grabowski, J. J., \& DePuy, C. H. 1984, JPhCh, 88, 1389

Biggs, P., Canosa-Mass, C. E., Fracheboud, J.-M., Shallcross, D. E., \& Wayne, R. P. 1995, FaTr, 91, 817

Bilger, C., Rimmer, P., \& Helling, Ch. 2013, MNRAS, 435, 1888

Blagojevic, V., Petrie, S., \& Bohme, D. K. 2003, MNRAS, 339, L7

Blake, P., \& Jackson, G. 1969, J Chem Soc B, 94

Blitz, M., Johnson, D., Pilling, M., et al. 1997, JCS(FaTr), 93, 1473

Bogan, D. J., \& Hand, C. W. 1978, JPhCh, 82, 2067

Bogdanchikov, G., Baklanov, A., \& Parker, D. 2004, CPL, 385, 486 
Böhland, T., Dõb, S., Temps, F., \& Wagner, H. G. 1985, Berichte Bunsen Gesell, 89, 1110

Bohme, D., Adams, N., Mosesman, M., Dunkin, D., \& Ferguson, E. 1970, JChPh, 52, 5094

Bohme, D. K., \& Fehsenfeld, F. 1969, CaJCh, 47, 2717

Bohme, D. K., Lee-Ruff, E., \& Young, L. B. 1971, JAChS, 93, 4608

Bohme, D. K., \& Mackay, G. I. 1981, JAChS, 103, 2173

Bohme, D. K., Mackay, G.-I., \& Schiff, H. 1980, JChPh, 73, 4976

Bohme, D. K., Mackay, G., Schiff, H., \& Hemsworth, R. 1974, JChPh, 61, 2175

Bohme, D. K., Mackay, G., \& Tanner, S. 1979, JAChS, 101, 3724

Bohme, D. K., \& Raksit, A. B. 1985, CaJCh, 63, 3007

Bohme, D. K., Raksit, A., \& Schiff, H. 1982, CPL, 93, 592

Bolden, R., Hemsworth, R., Shaw, M., \& Twiddy, N. 1970, JPhB, 3, 45

Bolden, R., \& Twiddy, N. 1972, FaDi, 53, 192

Borisov, A., Zamanskii, V., Potmishil, K., Skachkov, G., \& Foteenkov, V. 1977, Kinet. Catal. (USSR), 18, 307

Borucki, W., Kenzie, R. M., McKay, C., Duong, N., \& Boac, D. 1985, Icar, 64, 221

Borucki, W. J., McKay, C. P., \& Whitten, R. C. 1984, Icar, 60, 260

Bose, D., \& Candler, G. V. 1996, JChPh, 104, 2825

Boughton, J., Kristyan, S., \& Lin, M. 1997, CP, 214, 219

Bowers, M., Elleman, D., \& King, J. 1969, JChPh, 50, 4787

Bozzelli, J. W., Chang, A. Y., \& Dean, A. M. 1994, in Int. Symp. on Combustion, Vol. 25 (Amsterdam: Elsevier), 965

Bozzelli, J. W., \& Dean, A. M. 1989, JPhCh, 93, 1058

Bozzelli, J. W., \& Dean, A. M. 1990, JPhCh, 94, 3313

Bozzelli, J. W., \& Dean, A. M. 1995, Int. J. Chem. Kin., 27, 1097

Bravo-Pérez, G., Alvarez-Idaboy, J. R., Cruz-Torres, A., \& Ruíz, M. E. 2002, JCPA, 106, 4645

Breen, J., \& Glass, G. 1971, Int. J. Chem. Kin., 3, 145

Brion, C., Tan, K., Van der Wiel, M., \& Van der Leeuw, P. E. 1979, JESRP, 17,101

Broad, J. T., \& Reinhardt, W. P. 1976, PhRvA, 14, 2159

Brown, P. N., \& Hindmarsh, A. C. 1989, ApMaC, 31, 40

Browning, R., \& Fryar, J. 1973, JPhB, 6, 364

Brownsword, R., Gatenby, S., Herbert, L., et al. 1996, FaTr, 92, 723

Brunetti, B., \& Liuti, G. 1975, ZPC, 94, 19

Bryukov, M. G., Dellinger, B., \& Knyazev, V. D. 2006, JPCA, 110, 936

Bryukov, M. G., Knyazev, V. D., Lomnicki, S. M., McFerrin, C. A., \& Dellinger, B. 2004, JCPA, 108, 10464

Bulatov, V., Buloyan, A., Cheskis, S., et al. 1980, CPL, 74, 288

Burcat, A., \& Ruscic, B. 2005, Third millenium ideal gas and condensed phase thermochemical database for combustion with updates from active thermochemical tables (Argonne, IL: Argonne National Laboratory)

Burt, J., Dunn, J., McEwan, M., et al. 1970, JChPh, 52, 6062

Büttrill, S., Kim, J., \& Huntress, W. 1974, JChPh, 61, 2122

Cairns, R. B., \& Samson, J. A. R. 1965, JGR, 70, 99

Calvert, J., \& Pitts, J. 1966, Photochemistry (New York: Wiley)

Campomanes, P., Menéndez, I., \& Sordo, T. L. 2001, JPCA, 105, 229

Canosa, C., Penzhorn, R.-D., \& Von Sonntag, C. 1979, Berich Bunsen Gesell, 83,217

Canosa, C., Smith, S. J., Toby, S., \& Wayne, R. P. 1988, FaTr II, 84, 263

Caridade, P., Rodrigues, S., Sousa, F., \& Varandas, A. 2005, JPCA, 109, 2356

Carl, S., Sun, Q., Teugels, L., \& Peeters, J. 2003, PCCP, 5, 5424

Carstensen, H.-H., \& Dean, A. M. 2005, P Combust Inst, 30, 995

Carstensen, H.-H., \& Dean, A. M. 2008, JCPA, 113, 367

Caselli, P., Hasegawa, T. I., \& Herbst, E. 1998, ApJ, 495, 309

Catling, D. C. 2006, Sci, 311, 38

Cavalié, T., Biver, N., Hartogh, P., et al. 2012, P\&SS, 61, 3

Cermak, V., Dalgarno, A., Ferguson, E., Friedman, L., \& McDaniel, E. 1970 Ion Molecule Reactions (New York: Wiley)

Ceursters, B., Nguyen, H. M. T., Nguyen, M. T., Peeters, J., \& Vereecken, L. 2001, PCCP, 3, 3070

Chakraborty, D., \& Lin, M. 1999, JCPA, 103, 601

Chakraborty, D., Park, J., \& Lin, M. 1998, CP, 231, 39

Chan, W.-T., Heck, S. M., \& Pritchard, H. O. 2001, PCCP, 3, 56

Chang, J.-G., Chen, H.-T., Xu, S., \& Lin, M. 2007, JPCA, 111, 6789

Chang, N.-Y., \& Yu, C.-H. 1995, CPL, 242, 232

Chapman, S., \& Cowling, T. G. 1991, The Mathematical Theory of Nonuniform Gases (Cambridge: Cambridge Univ. Press)

Charnley, S. B. 1997, in IAU Coll. 161: Astronomical and Biochemical Origins and the Search for Life in the Universe ed. C. Batalli Cosmovici, S. Bowyer, \& D. Werthimer (Warsaw: Warsaw Technical University), 89

Chau, M., \& Bowers, M. T. 1976, CPL, 44, 490
Cheng, T., \& Lampe, F. 1973, JPhCh, 77, 2841

Cheng, T., Yu, T.-Y., \& Lampe, F. 1973, JPhCh, 77, 2587

Cheng, T., Yu, T.-Y., \& Lampe, F. 1974, JPhCh, 78, 1184

Choi, Y., \& Lin, M. 2005, Int. J. Chem. Kin., 37, 261

Christie, M. I., \& Voisey, M. 1967, TrFa, 63, 2702

Chuchani, G., Martin, I., Rotinov, A., \& Dominguez, R. M. 1993, J Phys Org Chem, 6, 54

Cimas, A., \& Largo, A. 2006, JCPA, 110, 10912

Claire, M. W., Catling, D. C., \& Zahnle, K. J. 2006, Geobiology, 4, 239

Clark, J. H., Moore, C. B., \& Nogar, N. S. 1978, JChPh, 68, 1264

Clary, D., Smith, D., \& Adams, N. 1985, CPL, 119, 320

Cleaves, H. J., Chalmers, J. H., Lazcano, A., Miller, S. L., \& Bada, J. L. 2008, OLEB, 38, 105

Cobos, C., \& Troe, J. 1985, JChPh, 83, 1010

Cohen, N. 1991, Int. J. Chem. Kin., 23, 397

Cohen, N., \& Benson, S. 1993, ChRv, 93, 2419

Cohen, N., \& Westberg, K. 1991, JPCRD, 20, 1211

Colberg, M., \& Friedrichs, G. 2006, JCPA, 110, 160

Cook, G., \& Metzger, P. 1964, JOSA, 54, 968

Cook, R. D., Davidson, D. F., \& Hanson, R. K. 2009, JPCA, 113, 9974

Corchado, J. C., \& Espinosa-Garcia, J. 1997, JChPh, 106, 4013

Corchado, J. C., Espinosa-Garcia, J., Hu, W.-P., Rossi, I., \& Truhlar, D. G. 1995, JPhCh, 99, 687

Corchado, J. C., Espinosa-García, J., Roberto-Neto, O., Chuang, Y.-Y., \& Truhlar, D. G. 1998, JCPA, 102, 4899

Cox, R., \& Derwent, R. 1977, J Photochem, 6, 23

Cribb, P. H., Dove, J. E., \& Yamazaki, S. 1992, CoFl, 88, 169

Crosley, D. R. 1989, JPhCh, 93, 6273

Curran, H. 2006, Int. J. Chem. Kin., 38, 250

Cvetanović, R. J. 1987, JPCRD, 16, 261

Daele, V., Laverdet, G., Le Bras, G., \& Poulet, G. 1995, JPhCh, 99, 1470

Dammeier, J., Colberg, M., \& Friedrichs, G. 2007, PCCP, 9, 4177

Davidson, D. F., Kohse-Höinghaus, K., Chang, A. Y., \& Hanson, R. K. 1990, Int. J. Chem. Kin., 22, 513

De Cobos, A. E. C., \& Troe, J. 1984, Int. J. Chem. Kinet., 16, 1519

Dean, A. J. 1985, JPhCh, 89, 4600

Dean, A. J., Davidson, D., \& Hanson, R. 1991, JPhCh, 95, 183

Dean, A. J., \& Hanson, R. K. 1992, Int. J. Chem. Kin., 24, 517

Dean, A. J., \& Kistiakowsky, G. 1971, JChPh, 54, 1718

Debrou, G. B., Fulford, J. E., Lewars, E. G., \& March, R. E. 1978, IJMIP, 26, 345

Demott, P. J., Cziczo, D. J., Prenni, A. J., et al. 2003, PNAS, 100, 14655

Deppe, J., Friedrichs, G., Ibrahim, A., Römming, H.-J., \& Wagner, H. G. 1998, Berich Bunsen Gesell, 102, 1474

DeSain, J. D., Klippenstein, S. J., Miller, J. A., \& Taatjes, C. A. 2003, JCPA, 107,4415

Désert, J.-M., Vidal-Madjar, A., Lecavelier Des Etangs, A., et al. 2008, A\&A, 492, 585

Dheandhanoo, S., Johnsen, R., \& Biondi, M. A. 1984, P\&SS, 32, 1301

Dibeler, V. H., Walker, J. A., \& Rosenstock, H. M. 1966, JRNBA, 70, 459

Ditchburn, R. 1955, RSPSA, 229, 44

Dixon, R., \& Kirby, G. 1968, TrFa, 64, 2002

Dombrowsky, C., Hoffmann, A., Klatt, M., et al. 1991, Berich Bunsen Gesell, 95,1685

Dombrowsky, C., \& Wagner, H. G. 1992, Berich Bunsen Gesell, 96, 1048

Dong, H., Ding, Y.-h., \& Sun, C.-c. 2005, JChPh, 122, 204321

Donovan, T., Dorko, W., \& Harrison, A. 1971, CaJCh, 49, 828

Dorko, E. A., Pchelkin, N. R., Wert, J. C., \& Mueller, G. W. 1979, JPhCh, 83, 297

Dotan, I., \& Lindinger, W. 1982, JChPh, 76, 4972

Dotan, I., Lindinger, W., Rowe, B., et al. 1980, CPL, 72, 67

Drossart, P., Fouchet, T., Crovisier, J., et al. 1999, in The Universe as Seen by ISO, Vol. 427169

Duan, X., \& Page, M. 1995, JAChS, 117, 5114

Dubrovin, D., Luque, A., Gordillo-Vazquez, F. J., et al. 2014, Icar, 241 , 313

Duff, J., \& Sharma, R. 1996, GeoRL, 23, 2777

Dunbar, R. C., Shen, J., \& Olah, G. A. 1972, JChPh, 56, 3794

Dunkin, D., Fehsenfeld, F., \& Ferguson, E. 1970, JChPh, 53, 987

Dunkin, D., Fehsenfeld, F., \& Ferguson, E. 1972, CPL, 15, 257

Dunkin, D., McFarland, M., Fehsenfeld, F., \& Ferguson, E. 1971, JGR, 76, 3820

Duran, R., Amorebieta, V., \& Colussi, A. 1988, JPhCh, 92, 636

Durup-Ferguson, M., Bohringer, H., Fahey, D. W., \& Ferguson, E. E. 1984, JChPh, 79, 265

Dyudina, U. A., Ingersoll, A. P., Ewald, S. P., et al. 2007, Icar, 190, 545 
Edelbüttel-Einhaus, J., Hoyermann, K., Rohde, G., \& Seeba, J. 1992, in Int. Symp. on Combustion, Vol. 24 (Amsterdam: Elsevier), 661

Edwards, D., Kerr, J., Lloyd, A., \& Trotman-Dickenson, A. 1966, J Chem Soc A, 1500

England, C., \& Corcoran, W. H. 1975, Ind Eng Chem, 14, 55

Enskog, D. 1917, Kinetische Theorie der Vorgaenge in maessig verduennten Gasen. I. Allgemeiner Teil, Dissertation

Ercolano, B., \& Storey, P. J. 2006, MNRAS, 372, 1875

Eremin, A., Ziborov, V., Shumova, V., Voiki, D., \& Roth, P. 1997, Kin Catal, 38,1

Espinosa-Garcia, J., Corchado, J., \& Sana, M. 1993, JCP, 90, 1181

Fahey, D., Böhringer, H., Fehsenfeld, F., \& Ferguson, E. 1982, JChPh, 76, 1799

Fahey, D., Fehsenfeld, F., Ferguson, E., \& Viehland, L. 1981, JChPh, 75, 669

Fahr, A., \& Nayak, A. 1994, CP, 189, 725

Fahr, A., \& Nayak, A. 1996, CP, 203, 351

Fahr, A., \& Stein, S. 1989, in Int. Symp. on Combustion, Vol. 22 (Amsterdam: Elsevier), 1023

Faigle, J. F. G., Isolani, P. C., \& Riveros, J. M. 1976, JAChS, 98, 2049

Fairbairn, A. 1969, RSPSA, 312, 207

Faravelli, T., Goldaniga, A., Zappella, L., et al. 2000, P Combust Inst, 28, 2601

Fegley, B., \& Lodders, K. 1994, Icar, 110, 117

Fehsenfeld, F. 1969, CaJCh, 47, 1808

Fehsenfeld, F. 1975, JChPh, 63, 1686

Fehsenfeld, F. 1976, ApJ, 209, 638

Fehsenfeld, F. 1977, P\&SS, 25, 195

Fehsenfeld, F., Albritton, D., Burt, J., \& Schiff, H. 1969a, CaJCh, 47, 1793

Fehsenfeld, F., Dotan, I., Albritton, D., Howard, C., \& Ferguson, E. 1978, JGRC, 83, 1333

Fehsenfeld, F., Dunkin, D., \& Ferguson, E. 1970, P\&SS, 18, 1267

Fehsenfeld, F., Dunkin, D., \& Ferguson, E. 1971, JGR, 76, 8453

Fehsenfeld, F., Dunkin, D., \& Ferguson, E. 1972, JChPh, 56, 3066

Fehsenfeld, F., Dunkin, D., \& Ferguson, E. 1974a, ApJ, 188, 43

Fehsenfeld, F., Dunkin, D., \& Ferguson, E. 1974b, JChPh, 61, 3181

Fehsenfeld, F., \& Ferguson, E. 1970, JChPh, 53, 2614

Fehsenfeld, F., Ferguson, E., \& Bohme, D. 1969b, P\&SS, 17, 1759

Fehsenfeld, F., Ferguson, E., \& Mosesman, M. 1969c, CPL, 4, 73

Fehsenfeld, F., Ferguson, E., \& Schmeltekopf, A. 1966a, JChPh, 45, 1844

Fehsenfeld, F., Howard, C. J., \& Ferguson, E. 1973, JChPh, 58, 5841

Fehsenfeld, F., Howard, C. J., \& Schmeltekopf, A. 1975a, JChPh, 63, 2835

Fehsenfeld, F., Lindinger, W., \& Albritton, D. 1975b, JChPh, 63, 443

Fehsenfeld, F., Lindinger, W., Schiff, H., Hemsworth, R., \& Bohme, D. 1976, $\mathrm{JChPh}, 64,4887$

Fehsenfeld, F., Schmeltekopf, A., \& Ferguson, E. 1967a, The JChPh, 46, 2802

Fehsenfeld, F., Schmeltekopf, A., Goldan, P., Schiff, H., \& Ferguson, E. 1966b, JChPh, 44, 4087

Fehsenfeld, F., Schmeltekopf, A., Schiff, H., \& Ferguson, E. 1967b, P\&SS, 15, 373

Feng, W., \& Hershberger, J. F. 2007, JCPA, 111, 3831

Ferguson, E. 1968, AEEP, 24, 1

Ferguson, E., \& Fehsenfeld, F. 1968, JGR, 73, 6215

Ferguson, E., Fehsenfeld, F., \& Schmeltekopf, A. L. 1969, Adv Chem Ser, 80, 83

Fernandes, R. X., Giri, B. R., Hippler, H., Kachiani, C., \& Striebel, F. 2005, JCPA, 109, 1063

Fernández-Ramos, A., Martínez-Núñez, E., Ríos, M. A., et al. 1998, JAChS, 120, 7594

Ferradaz, T., Benilan, Y., Fraya, A., et al. 2009, P\&SS, 57, 10

Ferris, J. P. 1992, OLEB, 22, 109

Feuchtgruber, H., Lellouch, E., de Graauw, T., et al. 1997, Natur, 389, 159

Field, F., Franklin, J., \& Lampe, F. 1957, JAChS, 79, 2419

Fifer, R. 1975, Ber Bunsenges Phys Chem, 10, 613

Fluegge, R. A. 1969a, BAPS, 14, 261

Fluegge, R. A. 1969b, JChPh, 50, 4373

Fontijn, A., Fernandez, A., Ristanovic, A., Randall, M. Y., \& Jankowiak, J. T. 2001, JCPA, 105, 3182

Forst, W., Evans, H., \& Winkler, C. 1957, JPhCh, 61, 320

Fouchet, T., Lellouch, E., Bézard, B., et al. 2000, A\&A, 355, L13

Frank, P. 1986, in 15th Int. Symp. on Rarefied Gas Dynamics (Tuebner)

Frank, P., Bhaskaran, K., \& Just, T. 1986, JPhCh, 90, 2226

Frank, P., Bhaskaran, K., \& Just, T. 1988, in The Int. Symp. on Combustion, Vol. 21 (Amsterdam: Elsevier), 885

Freeman, C., Harland, P., \& McEwan, M. 1978a, IJMIP, 28, 19

Freeman, C., Harland, P., \& McEwan, M. 1978b, AJCh, 31, 2157

Friedrichs, G., Colberg, M., Dammeier, J., Bentz, T., \& Olzmann, M. 2008, PCCP, 10, 6520
Friedrichs, G., DAvidson, D. F., \& Hanson, R. K. 2002, Int J Chem Kinet, 37, 374

Fulle, D., \& Hippler, H. 1997, JChPh, 106, 8691

Gannon, K. L., Glowacki, D. R., Blitz, M. A., et al. 2007, JPCA, 111, 6679

Gao, Y., \& Macdonald, R. G. 2006, JCPA, 110, 977

Garrod, R. T., Weaver, S. L. W., \& Herbst, E. 2008, ApJ, 682, 283

Gear, C. W. 1971, Comm ACM, 14, 185

Gehring, M., Hoyermann, K., Wagner, H. G., \& Wolfrum, J. 1969, Berich Bunsen Gesell, 73, 956

Geiger, H., Wiesen, P., \& Becker, K. H. 1999, PCCP, 1, 5601

Geltman, S. 1962, ApJ, 136, 935

Gentieu, E., \& Mentall, J. 1970, Sci, 169, 681

Gill, R., Johnson, W., \& Atkinson, G. 1981, CP, 58, 29

Gladstone, G. R., Allen, M., \& Yung, Y. L. 1996, Icar, 119, 1

Glänzer, K., \& Troe, J. 1973, AcHCh, 56, 577

Glänzer, K., \& Troe, J. 1975, Berich Bunsen Gesell, 79, 465

Glarborg, P., Dam-Johansen, K., \& Miller, J. A. 1995, Int J Chem Kinet, 27, 1207

Glosik, J., Raksit, A., Twiddy, N., Adams, N., \& Smith, D. 1978, JPhB, 11, 3365

Gonzalez, C., Theisen, J., Schlegel, H. B., Hase, W. L., \& Kaiser, E. 1992, JPhCh, 96, 1767

Gorden, R., \& Ausloos, P. 1961, JPhCh, 65, 1033

Gorden, R., \& Ausloos, P. 1967, JChPh, 46, 4823

Gordon, S., \& McBride, B. J. 1999, Thermodynamic Data to $20000 \mathrm{~K}$ for Monatomic Gases (Cleveland: NASA)

Grabowski, J. J. 1983, Doctoral thesis, Univ. Colorado

Graham, R. A., \& Johnston, H. S. 1978, JPhCh, 82, 254

Graham, E., James, D., Keever, W., et al. 1973, JChPh, 59, 4648

Gray, P., \& Herod, A. 1968, Transactions of the Faraday Society, 64, 2723

Greenberg, J. M., Kouchi, A., Niessen, W., et al. 1995, J Biol Phys, 20, 61

Griggs, M. 1968, JChPh, 49, 857

Grotheer, H., \& Just, T. 1981, CPL, 78, 71

Grussdorf, J., Nolte, J., Temps, F., \& Wagner, H. G. 1994, Berich Bunsen Gesell, 98, 546

Gupta, S., Jones, E., Harrison, A. G., \& Myher, J. J. 1967, CaJCh, 45, 3107

Gurnett, D. A., Kurth, W. S., Cairns, I. H., \& Granroth, L. J. 1990, STIN, 91, 11642

Guyon, P. M., Chupka, W. A., \& Berkowitz, J. 1976, JChPh, 64, 1419

Hack, W., Hold, M., Hoyermann, K., Wehmeyer, J., \& Zeuch, T. 2005, PCCP, 7, 1977

Hahn, Y. 1997, PhLA, 231, 82

Haldane, J. B. S. 1928, Ration Annu, 148, 3

Hamill, P., Toon, O. B., \& Kiang, C. S. 1977, JAtS, 34, 1104

Hammerum, S., \& Sølling, T. I. 1999, JAChS, 121, 6002

Hanson, R. K., \& Salimian, S. 1984, in Symp. on Combustion Chemistry (Berlin: Springer), 361

Harada, N., Herbst, E., \& Wakelam, V. 2010, ApJ, 721, 1570

Harding, L. B., Guadagnini, R., \& Schatz, G. C. 1993, JPhCh, 97, 5472

Harding, L. B., Klippenstein, S. J., \& Georgievskii, Y. 2005, P Combust Inst, 30,985

Harding, L. B., Klippenstein, S. J., \& Miller, J. A. 2008, JPCA, 112, 522

Harding, L. B., \& Wagner, A. F. 1989, in Int. Symp. on Combustion, Vol. 22 (Amsterdam: Elsevier), 983

Hartmann, D., Karthäuser, J., Sawerysyn, J., \& Zellner, R. 1990, Berich Bunsen Gesell, 94, 639

Hasegawa, T. I., Herbst, E., \& Leung, C. M. 1992, ApJS, 82, 167

Hassinen, E., Kalliorinne, K., \& Koskikallio, J. 1990, Int. J. Chem. Kin., 22, 741

Hassinen, E., Riepponen, P., Blomqvist, K., et al. 1985, Int. J. Chem. Kin., 17, 1125

Hastie, D., Freeman, C., McEwan, M., \& Schiff, H. 1976, Int. J. Chem. Kin., 8, 307

Haworth, N. L., Mackie, J. C., \& Bacskay, G. B. 2003, JPCA, 107, 6792

He, Y., Liu, X., Lin, M., \& Melius, C. 1993, Int. J. Chem. Kin., 25, 845

He, Y., Sanders, W., \& Lin, M. 1988, JPhCh, 92, 5474

Hébrard, E., Dobrijevic, M., Loison, J. C., et al. 2013, A\&A, 552, A132

Hedin, A. E. 1987, JGRA, 92, 4649

Hedin, A. E. 1991, JGRA, 96, 1159

Heicklen, J., \& Johnston, H. S. 1962, JAChS, 84, 4394

Heimerl, J., Johnsen, R., \& Biondi, M. A. 1969, JChPh, 51, 5041

Helling, Ch., \& Fomins, A. 2013, RSPTA, 371, 20110581

Helling, Ch., Jardine, M., Diver, D., \& Witte, S. 2013, P\&SS, 77, 152

Helling, Ch., Woitke, P., Rimmer, P. B., et al. 2014, Life, 4, 142

Hemsworth, R., Payzant, J., Schiff, H., \& Bohme, D. 1974, CPL, 26, 417

Hemsworth, R., Rundle, H., Bohme, D., et al. 1973, JChPh, 59, 61 
Henis, J., Stewart, G., \& Gaspar, P. 1973, JChPh, 58, 3639

Hennig, G., \& Wagner, H. 1994, Berich Bunsen Gesell, 98, 749

Henry, G. W., Marcy, G. W., Butler, R. P., \& Vogt, S. S. 2000, ApJL, 529, L41

Henry, R. J. 1970, ApJ, 161, 1153

Henry, R. J., \& McElroy, M. B. 1968, AdSpR, 1, 251

Herbst, E., Payzant, J., Schiff, H., \& Bohme, D. 1975, ApJ, 201, 603

Herman, J., \& Mentall, J. 1982, JGRC, 87, 8967

Herron, J. T. 1988, JPCRD, 17, 967

Herron, J. T. 1999, JPCRD, 28, 1453

Hidaka, Y., Nakamura, T., Tanaka, H., Inami, K., \& Kawano, H. 1990, Int. J. Chem. Kin., 22, 701

Hidaka, Y., Oki, T., Kawano, H., \& Higashihara, T. 1989, JPhCh, 93, 7134

Hidaka, Y., Sato, K., \& Yamane, M. 2000, CoFl, 123, 1

Hinshelwood, C., \& Askey, P. 1927, RSPSA, 115, 215

Hiraoka, K., \& Kebarle, P. 1980, CaJCh, 58, 2262

Hoehlein, G., \& Freeman, G. 1970, JAChS, 92, 6118

Homann, K., \& Wellmann, C. 1983, Berich Bunsen Gesell, 87, 609

Hopkinson, A., Mackay, G., \& Bohme, D. 1979, CaJCh, 57, 2996

Horne, D., \& Norrish, R. 1970, RSPSA, 315, 301

Howard, C. J. 1979, JChPh, 71, 2352

Howard, C. J., Fehsenfeld, F., \& McFarland, M. 1974, JChPh, 60, 5086

Howorka, F., Lindinger, W., \& Varney, R. N. 1974, JChPh, 61, 1180

Hoyermann, K., Olzmann, M., Seeba, J., \& Viskolcz, B. 1999, JPCA, 103, 5692

Hsu, C.-C., Lin, M., Mebel, A., \& Melius, C. 1997, JPCA, 101, 60

Hu, R., \& Seager, S. 2014, ApJ, 784, 63

Hu, R., Seager, S., \& Bains, W. 2012, ApJ, 761, 166

Hu, R., Seager, S., \& Bains, W. 2013, ApJ, 769, 6

Hu, R., Seager, S., \& Yung, Y. L. 2015, arXiv:1505.02221

Huebner, W. F., \& Carpenter, C. W. 1979, STIN, 80, 24243

Huebner, W. F., Keady, J. J., \& Lyon, S. P. 1992, Ap\&SS, 195, 1

Huebner, W. F., \& Mukherjee, J. 2015, P\&SS, 106, 11

Huffman, R. E. 1969, CaJCh, 47, 1823

Huffman, R. E., Tanaka, Y., \& Larrabee, J. 1963, JChPh, 39, 910

Humpfer, R., Oser, H., \& Grotheer, H.-H. 1995, Int. J. Chem. Kin., 27, 577

Hunt, M., Kerr, J., \& Trotman-Dickenson, A. 1965, J Chem Soc, 5074

Huntress, W. T., Anicich, V., McEwan, M., \& Karpas, Z. 1980, ApJS, 44, 481

Huntress, W. T., \& Baldeschwieler, J. D. 1969, Natur, 223, 468

Huntress, W. T., \& Elleman, D. 1970, JAChS, 92, 3565

Huntress, W. T., Mosesman, M. M., \& Elleman, D. D. 1971, JChPh, 54, 843

Huntress, W. T., Pinizzotto, R. F., \& Laudenslager, J. B. 1973, JAChS, 95, 4107

Husain, D., \& Lee, Y. 1988, Int. J. Chem. Kin., 20, 223

Husain, D., \& Marshall, P. 1986, Int. J. Chem. Kin., 18, 83

Husain, D., \& Young, A. N. 1975, FaTr II, 71, 525

Huynh, L. K., \& Truong, T. N. 2008, Theoretical Chemistry Accounts, 120, 107

Huynh, L. K., \& Violi, A. 2008, J Org Chem, 73, 94

Ibragimova, L. 1986, Kin Catal, 27, 467

Ikeda, E., \& Mackie, J. C. 1996, in Int. Symp. on Combustion, Vol. 26 (Amsterdam: Elsevier), 597

Ikezoe, Y., Matsuoka, S., \& Takebe, M. 1987, Gas phase ion-molecule reaction rate constants through 1986 (Ion reaction research group of the Mass spectroscopy society of Japan) (Tokyo: Maruzen Company)

Imai, N., \& Toyama, O. 1962, Bulletin of the Chemical Society of Japan, 35 , 860

Indriolo, N., Fields, B. D., \& McCall, B. J. 2009, ApJ, 694, 257

Ing, W.-C., Sheng, C. Y., \& Bozzelli, J. W. 2003, Fuel Process Technol, 83, 111

Inn, E. C. 1975, JAtS, 32, 2375

Jachimowski, C. J. 1977, CoFl, 29, 55

Jaffe, S., Karpas, Z., \& Klein, F. S. 1973, JChPh, 58, 2190

Jaffe, S., \& Klein, F. 1974, IJMIP, 14, 459

Jamieson, J., Brown, G., \& Tanner, J. 1970, CaJCh, 48, 3619

Jarrold, M. F., Bass, L. M., Kemper, P. R., van Koppen, P. A., \& Bowers, M. T. 1983, JChPh, 78, 3756

Jasper, A. W., Klippenstein, S. J., Harding, L. B., \& Ruscic, B. 2007, JCPA, 111,3932

Javoy, S., Naudet, V., Abid, S., \& Paillard, C. 2003, ExTFS, 27, 371

Jebens, D. S., Lakkaraju, H. S., McKay, C. P., \& Borucki, W. J. 1992, GRL, 19,273

Jensen, D. E. 1982, FaTr I, 78, 2835

Johnsen, R., Brown, H., \& Biondi, M. A. 1970, JChPh, 52, 5080

Johnsen, R., Castell, F., \& Biondi, M. A. 1974, JChPh, 61, 5404

Johnson, A. P., Cleaves, H. J., Dworkin, J. P., et al. 2008, Sci, 322, 404

Johnston, H. S. 1951, JAChS, 73, 4542
Jones, J., Birkinshaw, K., \& Twiddy, N. 1981a, CPL, 77, 484

Jones, J., Birkinshaw, K., \& Twiddy, N. 1981b, JPhB, 14, 2705

Jones, J., Lister, D., \& Twiddy, N. 1979, JPhB, 12, 2723

Joshi, A., You, X., Barckholtz, T. A., \& Wang, H. 2005, JPCA, 109, 8016

Ju, L.-P., Han, K.-L., \& Varandas, A. J. 2007, Int. J. Chem. Kin., 39, 148

Kappes, M. M., \& Staley, R. H. 1981, JAChS, 103, 1286

Karkach, S. P., \& Osherov, V. I. 1999, JChPh, 110, 11918

Karpas, Z., Anicich, V., \& Huntress, W. 1978, CPL, 59, 84

Karpas, Z., Anicich, V., \& Huntress, W. 1979, JChPh, 70, 2877

Karpas, Z., \& Klein, F. S. 1975, IJMIP, 16, 289

Kasper, S., \& Franklin, J. 1972, JChPh, 56, 1156

Kasting, J. F. 1993, Sci, 259, 920

Katayama, D., Huffman, R., \& O’Bryan, C. 1973, JChPh, 59, 4309

Kato, A., \& Cvetanovic, R. 1967, CaJCh, 45, 1845

Keller, C., Anicich, V., \& Cravens, T. 1998, P\&SS, 46, 1157

Keller-Rudek, H., Moortgat, G. K., Sander, R., \& Sörensen, R. 2013, ESSD, 5 , 365

Kelly, N., \& Heicklen, J. 1978, J Photochem, 8, 83

Kemper, P. R., \& Bowers, M. 1984, Int. J. Chem. Kin., 16, 707

Kemper, P. R., Bowers, M. T., Parent, D. C., et al. 1983, JChPh, 79, 160

Kern, R., Singh, H., \& Wu, C. 1988, Int. J. Chem. Kin., 20, 731

Kiefer, J., Mitchell, K., Kern, R., \& Yong, J. 1988, JPhCh, 92, 677

Kiefer, J., Santhanam, S., Srinivasan, N. K., et al. 2005, Proc. Combustion Institute, Vol. 30 (Amsterdam: Elsevier), 1129

Kim, J., Theard, L., \& Huntress, W.-T. 1975, JChPh, 62, 45

Kim, S. J., Geballe, T. R., Kim, J., et al. 2010, Icar, 208, 837

Kim, Y. H., \& Fox, J. L. 1994, Icar, 112, 310

Kim, Y. H., Fox, J. L., Black, J. H., \& Moses, J. I. 2014, JGRA, 119, 384

Klatt, M., Spindler, B., \& Wagner, H. G. 1995, ZPC, 191, 241

Klemm, R. 1965, CaJCh, 43, 2633

Knutson, H. A., Charbonneau, D., Allen, L. E., Burrows, A., \& Megeath, S. T. 2008, ApJ, 673, 526

Knyazev, V. D., Benscura, Á, Stoliarov, S. I., et al. 1996, JPhCh, 100, 11346

Knyazev, V. D., Stoliarov, S. I., \& Slagle, I. R. 1996b, in Int. Symp. on Combustion, Vol. 26 (Amsterdam: Elsevier), 513

Koch, E.-E., \& Skibowski, d. M. 1971, CPL, 9, 429

Koike, T., Kudo, M., Maeda, I., \& Yamada, H. 2000, Int. J. Chem. Kin., 32, 1 Kooij, D. M. 1893, ZPC, 12, 155

Korovkina, T. 1976, High Energ Chem, 10, 75

Kovalenko, L. J., Jucks, K. W., Salawitch, R. J., et al. 2007, JGL, 34, 19801

Kretschmer, C., \& Petersen, H. 1963, JChPh, 39, 1772

Kronebusch, P., \& Berkowitz, J. 1976, IJMIP, 22, 283

Kruse, T., \& Roth, P. 1997, JCPA, 101, 2138

Kruse, T., \& Roth, P. 1999, Int. J. Chem. Kin., 31, 11

Kukui, A., Jungkamp, T., \& Schindler, R. 1995, Berich Bunsen Gesell, 99, 1565

Kumakura, M., Arakawa, K., \& Sugiura, T. 1978a, B Chem Soc Jpn, 51, 49

Kumakura, M., Arakawa, K., \& Sugiura, T. 1978b, IJMIP, 26, 303

Kumakura, M., Arakawa, K., \& Sugiura, T. 1979, IJMIP, 29, 21

Laidler, K., \& McKenney, D. 1964, RSPSA, 278, 517

Laidler, K., \& Wojciechowski, B. 1961, RSPSA, 260, 103

Lamb, J. J., Mozurkewich, M., \& Benson, S. W. 1984, JPhCh, 88, 6441

Lambert, R., Christie, M., Golesworthy, R., \& Linnett, J. 1968, RSPSA, 302, 167

Lambert, R., Christie, M., \& Linnett, J. 1967, Chem Commun (London), 8, 388

Langer, S., \& Ljungström, E. 1994, Int J Chem Kin, 26, 367

Langer, S., \& Ljungström, E. 1995, FaTr, 91, 405

Laudenslager, J. B., Huntress, W. T., \& Bowers, M. T. 1974, JChPh, 61, 4600

Laufer, A. H., \& Fahr, A. 2004, ChRv, 104, 2813

Lavendy, H., Gandara, G., \& Robbe, J. 1984, JMoSp, 106, 395

Lavendy, H., Robbe, J., \& Gandara, G. 1987, JPhB, 20, 3067

Lavvas, P., Coustenis, A., \& Vardavas, I. 2008a, P\&SS, 56, 27

Lavvas, P., Coustenis, A., \& Vardavas, I. 2008b, P\&SS, 56, 67

Lavvas, P., Koskinen, T., \& Yelle, R. V. 2014, ApJ, 796, 15

Lawson, G., Bonner, R. F., Mather, R. E., Todd, J. F., \& March, R. E. 1976 , FaTr I, 72, 545

Lee, G., Helling, Ch., Dobbs-Dixon, I., \& Juncher, D. 2015, arXiv:1505.06576 Lee, J., \& Bozzelli, J. W. 2003, Int. J. Chem. Kin., 35, 20

Lee, L., Carlson, R., Judge, D., \& Ogawa, M. 1973, JQSRT, 13, 1023

Lellouch, E., Romani, P. N., \& Rosenqvist, J. 1994, Icar, 108, 112

Levush, S., Abadzhev, S., \& Shevchuk, V. 1969, Neftekhimiya, 9, 215

Levy, J. B. 1956, JAChS, 78, 1780

Li, Q.-S., \& Wang, C. Y. 2004, JCoCh, 25, 251

Li, Q. S., Zhang, Y., \& Zhang, S. 2004, JCPA, 108, 2014

Li, S., \& Williams, F. 1996, in Int. Symp. on Combustion, Vol. 26 (Amsterdam: Elsevier), 1017 
Li, S., Zhang, Q., \& Wang, W. 2006, CPL, 428, 262

Liang, M.-C., Parkinson, C. D., Lee, A. Y.-T., Yung, Y. L., \& Seager, S. 2003, ApJL, 596, L247

Lias, S. 1988, JPCRD, 17, 1

Lias, S., Collin, G., Rebbert, R., \& Ausloos, P. 1970, JChPh, 52, 1841

Lichtin, D., Berman, M., \& Lin, M. 1984, CPL, 108, 18

Liddy, J., Freeman, C., \& McEwan, M. 1977a, MNRAS, 180, 683

Liddy, J., Freeman, C., \& McEwan, M. 1977b, IJMIP, 23, 153

Lifshitz, A., \& Ben-Hamou, H. 1983, JPhCh, 87, 1782

Lifshitz, A., \& Frenklach, M. 1980, Int. J. Chem. Kin., 12, 159

Lifshitz, A., \& Tamburu, C. 1994, JPhCh, 98, 1161

Lifshitz, A., \& Tamburu, C. 1998, Int. J. Chem. Kin., 30, 341

Lifshitz, A., Tamburu, C., \& Carroll, H. F. 1997, Int. J. Chem. Kin., 29, 839

Lifshitz, A., Tamburu, C., Frank, P., \& Just, T. 1993, JPhCh, 97, 4085

Lifshitz, C., \& Tassa, R. 1973, IJMIP, 12, 433

Lifshitz, C., Wu, R., Haartz, J., \& Tiernan, T. 1977, JChPh, 67, 2381

Lifshitz, C., Wu, R., Tiernan, T., \& Terwilliger, D. 1978, JChPh, 68, 247

Lin, M., He, Y., \& Melius, C. 1992, Int. J. Chem. Kin., 24, 1103

Lin, M., He, Y., \& Melius, C. 1993, JPhCh, 97, 9124

Lindemann, F. A., Arrhenius, S., Langmuir, I., et al. 1922, TrFa, 17, 598

Linder, D. P., Duan, X., \& Page, M. 1996, JChPh, 104, 6298

Lindinger, W. 1973, PhRvA, 7, 328

Lindinger, W. 1976, JChPh, 64, 3720

Lindinger, W., Albritton, D., \& Fehsenfeld, F. 1979, JChPh, 70, 2038

Lindinger, W., Albritton, D., Fehsenfeld, F., \& Ferguson, E. 1975a, JGR, 80, 3725

Lindinger, W., Albritton, D., Fehsenfeld, F., \& Ferguson, E. 1975b, JChPh, 63, 3238

Lindinger, W., Albritton, D., Fehsenfeld, F., Schmeltekopf, A., \& Ferguson, E. $1975 \mathrm{c}, \mathrm{JChPh}, 62,3549$

Lindinger, W., Albritton, D., Howard, C. J., Fehsenfeld, F., \& Ferguson, E. 1975d, JChPh, 63, 5220

Lindinger, W., Albritton, D., McFarland, M., et al. 1975e, JChPh, 62, 4101

Lindinger, W., Fehsenfeld, F., Schmeltekopf, A., \& Ferguson, E. 1974, JGR, 79,4753

Lindinger, W., Howorka, F., Lukac, P., et al. 1981, PhRvA, 23, 2319

Lindinger, W., McFarland, M., Fehsenfeld, F., et al. 1975f, JChPh, 63, 2175

Lindley, C. R., Calvert, J. G., \& Shaw, J. H. 1979, CPL, 67, 57

Little, B., Anger, C. D., Ingersoll, A. P., et al. 1999, Icar, 142, 306

Liu, G.-X., Ding, Y.-h., Li, Z.-s., et al. 2002, PCCP, 4, 1021

Lloyd, A. C. 1974, Int. J. Chem. Kin., 6, 169

Loison, J. C., Hébrard, E., Dobrijevic, M., et al. 2015, Icar, 247, 218

Lombos, B., Sauvageau, P., \& Sandorfy, C. 1967, JMoSp, 24, 253

Louge, M. Y., \& Hanson, R. K. 1984, CoFl, 58, 291

Lukirskii, A., Brytov, I., \& Zimkina, T. 1964, OptSp, 17, 234

Luque, A., \& Ebert, U. 2009, NatGe, 2, 757

Macdonald, R. G. 2007, PCCP, 9, 4301

Mackay, G. I., Betowski, L., Payzant, J., Schiff, H., \& Bohme, D. 1976a JPhCh, 80, 2919

Mackay, G. I., \& Bohme, D. K. 1978, IJMIP, 26, 327

Mackay, G. I., Hemsworth, R. S., \& Bohme, D. K. 1976b, CaJCh, 54, 1624

Mackay, G. I., Hopkinson, A., \& Bohme, D. 1978, JAChS, 100, 7460

Mackay, G. I., Rakshit, A. B., \& Bohme, D. K. 1982, CaJCh, 60, 2594

Mackay, G. I., Schiff, H., \& Bohme, D. 1981, CaJCh, 59, 1771

Mackay, G. I., Tanaka, K., \& Bohme, D. K. 1977, IJMIP, 24, 125

Mackay, G. I., Tanner, S. D., Hopkinson, A. C., \& Bohme, D. K. 1979, CaJCh, 57,1518

Mackay, G. I., Vlachos, G., Bohme, D.-K., \& Schiff, H. 1980, IJMIP, 36, 259

Madhusudhan, N., Harrington, J., Stevenson, K. B., et al. 2011, Natur, 469, 64

Madhusudhan, N., Lee, K. K. M., \& Mousis, O. 2012, ApJL, 759, L40

Madhusudhan, N., \& Seager, S. 2009, ApJ, 707, 24

Madronich, S. 1987, JGRD, 92, 9740

Magnotta, F., \& Johnston, H. S. 1980, GeoRL, 7, 769

Mahmud, K., Marshall, P., \& Fontijn, A. 1987, JPhCh, 91, 1568

Manion, J. A., Huie, R. E., Levin, R. D., et al. 2013, NIST Standard Reference Database 17, Version 7.0 (Web Version), Release 1.6.8, Data version 2013.03

Mansergas, A., \& Anglada, J. M. 2006, JCPA, 110, 4001

Marinov, N. M., Pitz, W. J., Westbrook, C. K., et al. 1998, CoFl, 114, 192

Märk, T. D., \& Oskam, H. 1971, PhRvA, 4, 1445

Marmo, F. 1953, JOSA, 43, 1186

Marx, R., Mauclaire, G., Fehsenfeld, F., Dunkin, D., \& Ferguson, E. 1973, $\mathrm{JChPh}, 58,3267$

Massie, S. T., \& Hunten, D. M. 1981, JGR, 86, 9859

Masuoka, T., \& Samson, J. A. 1981, JChPh, 74, 1093

Matsui, Y., \& Nomaguchi, T. 1978, CoFl, 32, 205
Matsumoto, A., Okada, S., Misaki, T., Taniguchi, S., \& Hayakawa, T. 1975, B Chem Soc Jpn, 48, 794

Matsunaga, F., \& Watanabe, K. 1967, Sci Light, 16, 31

Matsuoka, S., \& Ikezoe, Y. 1988, JPhCh, 92, 1126

Mauclaire, G., Derai, R., \& Marx, R. 1978, IJMIP, 26, 289

Mayer, S., \& Schieler, L. 1968, JPhCh, 72, 2628

Mayer, S., Schieler, L., \& Johnston, H. S. 1966, JChPh, 45, 385

Mayer, S., Schieler, L., \& Johnston, H. S. 1967, in Int. Symp. on Combustion, Vol. 11 (Amsterdam: Elsevier), 837

Mayer, T., \& Lampe, F. 1974a, JPhCh, 78, 2645

Mayer, T., \& Lampe, F. 1974b, JPhCh, 78, 2433

McAllister, T. 1973, IJMIP, 10, 419

McAllister, T., \& Pitman, P. 1976, IJMIP, 19, 423

McBride, B. J., Gordon, S., \& Reno, M. A. 1993, NASA Technical Memorandum 4513, Coefficients for Calculating Thermodynamic and Transport Properties of Individual Species (Hampton, VA: NASA STI)

McElroy, M. B., \& McConnell, J. C. 1971, JGR, 76, 6674

McEwan, M., Anicich, V., \& Huntress, W. 1981, IJMIP, 37, 273

McEwan, M., Anicich, V., Huntress, W., Kemper, P., \& Bowers, M. 1983, IJMIP, 50, 179

McFarland, M., Dunkin, D., Fehsenfeld, F., Schmeltekopf, A., \& Ferguson, E. 1972, JChPh, 56, 2358

McKenney, D., Wojciechowski, B., \& Laidler, K. 1963, CaJCh, 41, 1993

McKnight, L. 1970, PhRvA, 2, 762

McNesby, J. R., \& Okabe, H. 1964, Adv Photochem, 3, 157

McNesby, J. R., Tanaka, I., \& Okabe, H. 1962, JChPh, 36, 605

Meaburn, G., \& Gordon, S. 1968, JPhCh, 72, 1592

Meagher, N. E., \& Anderson, W. R. 2000, JCPA, 104, 6013

Mebel, A., \& Lin, M. 1997, IRPC, 16, 249

Mebel, A., \& Lin, M. 1999, JCPA, 103, 2088

Mebel, A., Lin, M., Morokuma, K., \& Melius, C. 1996, Int. J. Chem. Kin., 28, 693

Melton, C., \& Rudolph, P. 1960, JChPh, 32, 1128

Mentall, J., Gentieu, E., Krauss, M., \& Neumann, D. 1971, JChPh, 55, 5471

Meot-Ner, M., Karpas, Z., \& Deakyne, C. A. 1986, JAChS, 108, 3913

Mertens, J. D., \& Hanson, R. K. 1996, in Int. Symp. on Combustion, Vol. 26 (Amsterdam: Elsevier), 551

Mertens, J. D., Kohse-Höinghaus, K., Hanson, R. K., \& Bowman, C. T. 1991, Int J Chem Kin, 23, 655

Metcalfe, E., Booth, D., McAndrew, H., \& Wooley, W. 1983, Fire Mater, 7, 185

Metzger, P., \& Cook, G. 1964, JChPh, 41, 642

Meyer, E., Olschewski, H., Troe, J., \& Wagner, H. G. 1969, in Int. Symp. on Combustion, Vol. 12 (Amsterdam: Elsevier), 345

Meyer, J. P., \& Hershberger, J. F. 2005, JCPA, 109, 4772

Michael, J., Kumaran, S., \& Su, M.-C. 1999, JPhCh A, 103, 5942

Mick, H.-J., Burmeister, M., \& Roth, P. 1993, AIAA, 31, 671

Miller, J. A., \& Glarborg, P. 1999, Int. J. Chem. Kin., 31, 757

Miller, J. A., \& Melius, C. F. 1988, in Int. Symp. on Combustion, Vol. 21 (Amsterdam: Elsevier), 919

Miller, J. A., \& Melius, C. F. 1989, in Int. Symp. on Combustion, Vol. 22 (Amsterdam: Elsevier), 1031

Miller, J. A., \& Melius, C. F. 1992, Int. J. Chem. Kin., 24, 421

Miller, J. A., Pilling, M. J., \& Troe, J. 2005, P Combust Inst, 30, 43

Miller, J. L., McCunn, L. R., Krisch, M. J., Butler, L. J., \& Shu, J. 2004, JChPh, 121, 1830

Miller, S. L. 1953, Sci, 117, 528

Miller, S. L., \& Urey, H. C. 1959, Sci, 130, 245

Miller, T. M., Wetterskog, R. E., \& Paulson, J. F. 1984, JChPh, 80, 4922

Miyakawa, S., Yamanashi, H., Kobayashi, K., Cleaves, H. J., \& Miller, S. L. 2002, PNAS, 99, 14628

Miyoshi, A., Ohmori, K., Tsuchiya, K., \& Matsui, H. 1993, CPL, 204, 241

Molina, L. T., \& Molina, M. J. 1981, J Photochem, 15, 97

Molina-Cuberos, G. J., Lopez-Moreno, J. J., Rodrigo, R., Lara, L. M., \& O'Brien, K. 1999, P\&SS, 47, 1347

Monks, P., Romani, P., Nesbitt, F., Scanlon, M., \& Stief, L. 1993, JGRE, 98, 17115

Moortgat, G., ŠSlemr, F., \& Warneck, P. 1977, Int. J. Chem. Kin., 9, 249

Moortgat, G., \& Warneck, P. 1975, ZNatA, 30, 835

Morris, E., \& Niki, H. 1973, Int. J. Chem. Kin., 5, 47

Morrissey, R. J., \& Schubert, C. 1963, CoFl, 7, 263

Moses, J. I. 2014, RSPTA, 372, 20130073

Moses, J. I., Armstrong, E. S., Fletcher, L. N., et al. 2015, Icar, 261, 149

Moses, J. I., Bézard, B., Lellouch, E., et al. 2000a, Icar, 143, 244

Moses, J. I., Fouchet, T., Bézard, B., et al. 2005, JGRE, 110, 8001

Moses, J. I., Lellouch, E., Bézard, B., et al. 2000b, Icar, 145, 166 
Moses, J. I., Madhusudhan, N., Visscher, C., \& Freedman, R. S. 2013, ApJ, 763,25

Moses, J. I., Visscher, C., Fortney, J. J., et al. 2011, ApJ, 737, 15

Moshkina, R., Polyak, S., Sokolova, N., Masterovoi, I., \& Nalbandyan, A. 1980, Int. J. Chem. Kin., 12, 315

Mount, G., \& Moos, H. 1978, ApJL, 224, L35

Mousavipour, S. H., \& Saheb, V. 2007, B Chem Soc Jpn, 80, 1901

Moylan, C. R., Jasinski, J. M., \& Brauman, J. I. 1985, JAChS, 107, 1934

Mulvihill, J. N., \& Phillips, L. F. 1975, in Int. Symp. on Combustion, Vol. 15 (Amsterdam: Elsevier), 1113

Munson, M. S., \& Field, F. H. 1969, JAChS, 91, 3413

Munson, M. S., Franklin, J., \& Field, F. 1964, JPhCh, 68, 3098

Murrell, J., \& Rodriguez, J. 1986, JMoSt, 139, 267

Musin, R., \& Lin, M. 1998, JCPA, 102, 1808

Myer, J. A., \& Samson, J. A. 1970, JChPh, 52, 266

Myerson, A. L. 1973, In 14th Int. Simp. on Combustion (Amsterdam: Elsevier), 219

Nadtochenko, V., Sarkisov, O., \& Vedeneev, V. 1979, DoSSR, 244, 152

Nakata, R., Watanabe, K., \& Matsunaga, F. 1965, Sci Light, 14, 54 V71

Nakayama, T., Kitamura, M. Y., \& Watanabe, K. 1959, JChPh, 30, 1180

Nakayama, T., \& Watanabe, K. 1964, JChPh, 40, 558

Natarajan, K., \& Bhaskaran, K. 1981, Experimental and Analytical Investigation of High Temperature Ignition of Ethanol, Tech. Rep. (Indian Inst of Tech: Madras Dept of Mechanical Engineering)

Natarajan, K., Thielen, K., Hermanns, H., \& Roth, P. 1986, Berich Bunsen Gesell, 90, 533

Navarro-González, R., Villagrán-Muniz, M., Sobral, H., Molina, L. T., \& Molina, M. J. 2001, GRL, 28, 3867

Nee, J. B., \& Lee, L. 1984, JChPh, 81, 31

Neilson, P. V., Bowers, M. T., Chau, M., Davidson, W. R., \& Aue, D. H. 1978, JAChS, 100, 3649

Neiman, M., \& Feklisov, G. 1961, Zh Fiz Khim, 35, 1064

Nissen, P. E. 2013, A\&A, 552, 10

Nguyen, H. M. T., Zhang, S., Peeters, J., Truong, T. N., \& Nguyen, M. T. 2004, CPL, 388, 94

Nielsen, O. J., Sidebottom, H. W., Donlon, M., \& Treacy, J. 1991, CPL, 178, 163

Nizamov, B., \& Dagdigian, P. J. 2003, JCPA, 107, 2256

Oehlschlaeger, M. A., Davidson, D. F., \& Hanson, R. K. 2004, JPCA, 108, 4247

Ohmori, K., Miyoshi, A., Matsui, H., \& Washida, N. 1990, JPhCh, 94, 3253

Okabe, H. 1970, JChPh, 53, 3507

Okabe, H. 1980, JChPh, 72, 6642

Okabe, H. 1981, JChPh, 75, 2772

Okabe, H. 1983, JChPh, 78, 1312

Okabe, H., \& Becker, D. 1963, JChPh, 39, 2549

Okabe, H., et al. 1978, Photochemistry of Small Molecules, Vol. 431 (New York: Wiley)

Okada, S., Matsumoto, A., Dohmaru, T., Taniguchi, S., \& Hayakawa, T. 1972 , Mass Spectroscopy (Japan), 20, 311

O’Neal, E., \& Benson, S. W. 1962, JChPh, 36, 2196

Opansky, B. J., \& Leone, S. R. 1996a, JPhCh, 100, 4888

Opansky, B. J., \& Leone, S. R. 1996b, JPhCh, 100, 19904

Oparin, A. I. 1957, The Origin of Life on the Earth, (3rd ed.; New York: Academic Press)

Orville, R. E. 1968, JAtS, 25, 852

Osborn, D. L. 2003, JCPA, 107, 3728

Owens, A., Hales, C., Filkin, D., et al. 1985, JGRD, 90, 2283

Padial, N., Collins, L., \& Schneider, B. 1985, ApJ, 298, 369

Pang, J.-L., Xie, H.-B., Zhang, S.-W., Ding, Y.-H., \& Tang, A.-Q. 2008, JCPA, 112,5251

Paraskevopoulos, G., \& Winkler, C. A. 1967, JPhCh, 71, 947

Park, J., \& Hershberger, J. F. 1993, JChPh, 99, 3488

Park, J., \& Lin, M. 1997, JCPA, 101, 5

Parkes, D. A. 1972a, FaTr I, 68, 613

Parkes, D. A. 1972b, FaTr I, 68, 627

Parra-Rojas, F. C., Luque, A., \& Gordillo-VáZquez, F. J. 2013, JGRA, 118 , 5190

Patel, B. H., Percivalle, C., Ritson, D. J., Duffy, C. D., \& Sutherland, J. D. 2015, NatCh, 7, 301

Patrick, R., \& Golden, D. M. 1984, Int. J. Chem. Kin., 16, 1567

Patterson, W., \& Greene, E. 1962, JChPh, 36, 1146

Payzant, J., Tanaka, K., Betowski, L., \& Bohme, D. 1976, JAChS, 98, 894

Peeters, J., Boullart, W., \& Devriendt, K. 1995, JPhCh, 99, 3583

Petrov, Y. P., Turetskii, S., \& Bulgakov, A. 2009, Kin Catal, 50, 344

Petty, J. T., Harrison, J. A., \& Moore, C. B. 1993, JPhCh, 97, 11194
Phillips, E., Lee, L., \& Judge, D. 1977, JQSRT, 18, 309

Pitts, W. M., Pasternack, L., \& McDonald, J. R. 1982, CP, 68, 417

Porter, R. P., \& Noyes, W. A. 1959, JAChS, 81, 2307

Pouilly, B., Robbe, J., Schamps, J., \& Roueff, E. 1983, JPhB, 16, 437

Powner, M. W., Gerland, B., \& Sutherland, J. D. 2009, Natur, 239459.7244

Prasad, S. S., \& Huntress, W. T. 1980, ApJ, 43, 1

Price, C., Penner, J., \& Prather, M. 1997, JGR, 102, 5929

Pshezhetskii, S. Y., Morozov, N., Kamenetskaya, S., Siryatskaya, V., \& Gribova, E. 1959, RJPCA, 33, 402

Quandt, R. W., \& Hershberger, J. F. 1995, JPhCh, 99, 16939

Queloz, D., Eggenberger, A., Mayor, M., et al. 2000, A\&A, 359, L13

Raksit, A. B. 1982, IJMIP, 41, 185

Raksit, A. B. 1986, IJMSI, 69, 45

Raksit, A. B., \& Bohme, D. K. 1984, IJMSI, 57, 211

Raksit, A. B., \& Bohme, D. K. 1985, IJMSI, 63, 217

Raksit, A. B., Schiff, H., \& Bohme, D. 1984, IJMSI, 56, 321

Raksit, A. B., \& Warneck, P. 1979, ZNatA, 34, 1410

Raksit, A. B., \& Warneck, P. 1980a, JChPh, 73, 2673

Raksit, A. B., \& Warneck, P. 1980b, IJMIP, 35, 23

Raksit, A. B., \& Warneck, P. 1980c, FaTr II, 76, 1084

Raksit, A. B., \& Warneck, P. 1981, JChPh, 74, 2853

Ray, A., Daële, V., Vassalli, I., Poulet, G., \& Le Bras, G. 1996, JPhCh, 100, 5737

Reitel'boim, M., Romanovich, L., \& Vedeneev, B. 1978, Kin Catal, 19, 1131

Ribas, I., Guinan, E. F., Güdel, M., \& Audard, M. 2005, ApJ, 622, 680

Ribas, I., Porto de Mello, G. F., Ferreira, L. D., et al. 2010, ApJ, 714, 384

Rim, K. T., \& Hershberger, J. F. 1999, JCPA, 103, 3721

Rimmer, P. B., Herbst, E., Morata, O., \& Roueff, E. 2012, A\&A, 537, A7

Rimmer, P. B., \& Helling, Ch. 2013, ApJ, 774, 108

Rimmer, P. B., Helling, Ch., \& Bilger, C. 2014, IJAsB, 13, 173

Robertson, R., Hils, D., Chatham, H., \& Gallagher, A. 1983, ApPhL, 43, 544

Roble, R., \& Ridley, E. 1994, GeoRL, 21, 417

Roche, A., Sutton, M., Bohme, D., \& Schiff, H. 1971, JChPh, 55, 5480

Rogers, J. D. 1990, JPhCh, 94, 4011

Röhrig, M., Römming, H.-J., \& Wagner, H. G. 1994, Berich Bunsen Gesell, 98, 1332

Röhrig, M., \& Wagner, H. G. 1994, in Int. Symp. on Combustion, Vol. 25 (Amsterdam: Elsevier), 975

Romani, P. N., Jennings, D. E., Bjoraker, P. V., et al. 2008, Icar, 198, 420

Roose, T., Hanson, R., \& Kruger, C. 1978, in 11th Int. Symp. on Shock Tubes and Waves (Seattle, WA: Univ. of Washington), 245

Roscoe, J. M., \& Roscoe, S. G. 1973, CaJCh, 51, 3671

Ross, S. K., Sutherland, J. W., Kuo, S.-C., \& Klemm, R. B. 1997, JPCA, 101, 1104

Rottman, G. J., Woods, T. N., \& McClintock, W. 2006, AdSpR, 37, 201

Rowe, B., Fahey, D., Fehsenfeld, F., \& Albritton, D. 1980, JChPh, 73, 194

Rowe, B., Fahey, D., Ferguson, E., \& Fehsenfeld, F. 1981, JChPh, 75, 3325

Rustgi, O. P. 1964, JOSA, 54, 464

Saeys, M., Reyniers, M.-F., Van Speybroeck, V., Waroquier, M., \& Marin, G. B. 2006, CPPC, 7, 188

Safrany, D. R., \& Jaster, W. 1968, JPhCh, 72, 3305

Sahetchian, K., Heiss, A., \& Rigny, R. 1987, JPhCh, 91, 2382

Saito, K., Kakumoto, T., \& Murakami, I. 1984, CPL, 110, 478

Saito, K., Mochizuki, Y., Yoshinobu, I., \& Imamura, A. 1990, CPL, 167, 347

Salahub, D., \& Sandorfy, C. 1971, CPL, 8, 71

Samson, J. A., \& Cairns, R. 1964, JGR, 69, 4583

Samson, J. A., \& Cairns, R. 1965, JOSA, 55, 1035

Sander, R., Kerkweg, A., Jöckel, P., \& Lelieveld, J. 2005, ACP, 5, 445

Sander, S. P., Friedl, R. R., Barker, J. R., et al. 2011, Chemical Kinetics and Photochemical Data for use in Atmospheric Studies 17 (JPL Publications)

Sanders, N., Butler, J., Pasternack, L., \& McDonald, J. 1980, CP, 48, 203

Sanders, W., Lin, C., \& Lin, M. 1987, CST, 51, 103

Sato, K., \& Hidaka, Y. 2000, CoFl, 122, 291

Saxon, R. P., Lengsfield, B. H., III, \& Liu, B. 1983, JChPh, 78, 312

Sayah, N., Li, X., Caballero, J., \& Jackson, W. M. 1988, J. Photoch. Photobio A, 45, 177

Scattergood, T. W., McKay, C. P., Borucki, W. J., et al. 1989, Icar, 81, 413

Schacke, H., Schmatjko, K., \& Wolfrum, J. 1974, ArPSp, 5, 363

Scherzer, K., Löser, U., \& Stiller, W. 1987, ZCh, 27, 300

Schiff, H., \& Bohme, D. K. 1979, ApJ, 232, 740

Schildcrout, S. M., \& Franklin, J. 1970, JAChS, 92, 251

Schlesinger, G., \& Miller, S. L. 1983, JMolE, 19, 376

Schoen, R. I. 1962, JChPh, 37, 2032

Schulz, G., Klotz, H.-D., \& Spangenberg, H.-J. 1985, ZCh, 25, 88

Schurath, U., Tiedemann, P., \& Schindler, R. N. 1969, JPhCh, 73, 456 
Schwarz, H., Brogi, M., de Kok, R., Birkby, J., \& Snellen, I. 2015, arXiv: 1502.04713

Seager, S., Bains, W., \& Hu, R. 2013a, ApJ, 775, 104

Seager, S., Bains, W., \& Hu, R. 2013b, ApJ, 777, 95

Seery, D. 1969, in Int. Symp. on Combustion, Vol. 12 (Amsterdam: Elsevier), 12

Seetula, J., Blomqvist, K., Kalliorinne, K., \& Koskikallio, J. 1986, Acta Chem Scand, 40, 653

Seinfeld, J. H., \& Pandis, S. N. 2006, Atmospheric Chemistry and Physics: From Air Pollution to Climate Change (2nd ed.; New Jersey: Wiley)

Selwyn, G., Podolske, J., \& Johnston, H. S. 1977, GeoRL, 4, 427

Sen, B., Toon, G. C., \& Osterman, G. B. 1998, JGR, 103, 3571

Senosiain, J. P., Klippenstein, S. J., \& Miller, J. A. 2006, JPCA, 110, 5772

Setser, D., \& Rabinovitch, B. 1962, CaJCh, 40, 1425

Shardanand, \& Rao, A. D. P. 1977, JQSRT, 17, 433

Shaw, R. 1977, Int. J. Chem. Kin., 9, 929

Shaw, R. 1978, JPCRD, 7, 1179

Sheng, C. Y., Bozzelli, J. W., Dean, A. M., \& Chang, A. Y. 2002, JPCA, 106, 7276

Showman, A. P., Cooper, C. S., Fortney, J. J., \& Marley, M. S. 2008, ApJ, 682, 559

Shul, R., Upschulte, B., Passarella, R., Keesee, R., \& Castleman, A. 1987, JPhCh, 91, 2556

Sieck, L. W. 1978, Int. J. Chem. Kin., 10, 335

Sieck, L. W., \& Futrell, J. 1968, JChPh, 48, 1409

Sieck, L. W., \& Searles, S. K. 1970, JChPh, 53, 2601

Sims, I. R., Queffelec, J.-L., Travers, D., et al. 1993, CPL, 211, 461

Sivaramakrishnan, R., Michael, J., \& Klippenstein, S. 2009, JPCA, 114, 755

Skinner, G. B., \& Ruehrwein, R. A. 1959, JPhCh, 63, 1736

Slack, M., \& Fishburne, E. 1970, JChPh, 52, 5830

Slanger, T. G., \& Black, G. 1982, JChPh, 77, 2432

Smith, D. L., \& Adams, N. 1977a, ApJ, 217, 741

Smith, D. L., \& Adams, N. 1977b, CPL, 47, 145

Smith, D. L., \& Adams, N. 1977c, IJMIP, 23, 123

Smith, D. L., \& Adams, N. 1978, CPL, 54, 535

Smith, D. L., \& Adams, N. 1980, CPL, 76, 418

Smith, D. L., \& Adams, N. 1981, MNRAS, 197, 377

Smith, D. L., Adams, N. G., \& Alge, E. 1982, JChPh, 77, 1261

Smith, D. L., Adams, N. G., \& Miller, T. 1978, JChPh, 69, 308

Smith, R. D., Smith, D. L., \& Futrell, J. H. 1976, IJMIP, 19, 369

Song, S., Golden, D. M., Hanson, R. K., et al. 2003, Int. J. Chem. Kin., 35, 304

Song, X., Hou, H., \& Wang, B. 2005, PCCP, 7, 3980

Spokes, G. N., \& Benson, S. W. 1967, JAChS, 89, 6030

Sridharan, U., \& Kaufman, F. 1983, CPL, 102, 45

Srinivasan, N., Su, M.-C., \& Michael, J. 2007, JPCA, 111, 3951

Srinivasan, N., Su, M.-C., Sutherland, J., \& Michael, J. 2005, JPCA, 109, 1857

Stevenson, D. P., \& Schissler, D. O. 1955, JChPh, 23, 1353

Stief, L., Donn, B., Glicker, S., Gentieu, E., \& Mentall, J. 1972, ApJ, 171, 21

Stockwell, W. R., \& Calvert, J. G. 1978, J Photochem, 8, 193

Stothard, N., Humpfer, R., \& Grotheer, H.-H. 1995, CPL, 240, 474

Strausz, O. P., Duholke, W., \& Gunning, H. E. 1970, JAChS, 92, 4128

Streit, G. E. 1982, JPhCh, 86, 2321

Striebel, F., Jusinski, L. E., Fahr, A., et al. 2004, PCCP, 6, 2216

Strobel, D. F. 1983, IRPC, 3, 145

Su, M.-C., Kumaran, S., Lim, K., et al. 2002, JPCA, 106, 8261

Sumathi, R., \& Nguyen, M. T. 1998, JCPA, 102, 8013

Sumathi, R., \& Peyerimhoff, S. 1996, CPL, 263, 742

Sun, F., DeSain, J., Scott, G., et al. 2001, JPCA, 105, 6121

Sun, H., He, H.-Q., Hong, B., et al. 2006, IJQC, 106, 894

Sun, H., \& Weissler, G. 1955, JChPh, 23, 1160

Sun, Y., Zhang, Q.-y., Ai, X.-c., Zhang, J.-p., \& Sun, C.-c. 2004, JMoSt, 686, 123

Suzaki, K., Kanno, N., Tonokura, K., et al. 2006, CPL, 425, 179

Suzaki, K., Tsuchiya, K., Koshi, M., \& Tezaki, A. 2007, JPCA, 111, 3776

Swain, M. R., Tinetti, G., Vasisht, G., et al. 2009, ApJ, 704, 1616

Szabo, I., \& Derrick, P. 1971, IJMIP, 7, 55

Szekely, A., Hanson, R. K., \& Bowman, C. T. 1985, in Int. Symp. on Combustion, Vol. 20 (Amsterdam: Elsevier), 647

Tabayashi, K., \& Bauer, S. 1979, CoFl, 34, 63

Takahashi, K., Yamamoto, O., Inomata, T., \& Kogoma, M. 2007, Int. J. Chem. Kin., 39, 97

Takahashi, S. 1972, Mem Def Acad: Phys Chem Eng, 12, 149

Tanaka, K., Betowksi, L., Mackay, G., \& Bohme, D. 1976, JCP, 65, 3203

Tanaka, Y., Inn, E. C., \& Watanabe, K. 1953, JChPh, 21, 1651

Tang, Y., Wang, R., \& Wang, B. 2008, JCPA, 112, 5295

Tanner, S. D., Mackay, G. I., \& Bohme, D. K. 1979a, CaJCh, 57, 2350
Tanner, S. D., Mackay, G. I., \& Bohme, D. K. 1979b, CaJCh, 57, 2996

Tanner, S. D., Mackay, G. I., \& Bohme, D. K. 1981, CaJCh, 59, 1615

Tanner, S. D., Mackay, G. I., Hopkinson, A., \& Bohme, D. K. 1979b, IJMIP, 29, 153

Tanzawa, T., \& Gardiner, W. 1980, JPhCh, 84, 236

Tao, Y.-g., Ding, Y.-h., Li, Z.-s., Huang, X.-r., \& Sun, C.-C. 2001, JCPA, 105 , 9598

Taylor, W. W. L., Scarf, F. L., Russell, C. T., \& Brace, L. H. 1979, Natur, 279, 614

Thaxton, A. G., Hsu, C.-C., \& Lin, M. 1997, Int. J. Chem. Kin., 29, 245

Theard, L. P., \& Huntress, W. T. 1974, JChPh, 60, 2840

Thielen, K., \& Roth, P. 1986, AIAA, 24, 1102

Thomas, R., Barassin, A., \& Burke, R. 1978, IJMSI, 28, 275

Thompson, B., Harteck, P., \& Reeves, R. 1963, JGR, 68, 6431

Thweatt, W. D., Erickson, M. A., \& Hershberger, J. F. 2004, JPCA, 108, 74

Thynne, J., \& Gray, P. 1962, TrFa, 58, 2403

Thynne, J., \& Gray, P. 1963, TrFa, 59, 1149

Tian, F., Toon, O. B., Pavlov, A. A., \& De Sterck, H. 2005, Sci, 308, 1014

Tichy', M., Raksit, A., Lister, D., et al. 1979, IJMIP, 29, 231

Tomeczek, J., \& Gradoń, B. 2003, CoFl, 133, 311

Tonkyn, R., \& Weisshaar, J. C. 1986, JPhCh, 90, 2305

Toon, O. B., \& Farlow, N. H. 1981, AREPS, 9, 19

Toon, O. B., McKay, C. P., Ackerman, T. P., \& Santhanam, K. 1989, JGR, 94, 16287

Trenwith, A. 1960, J Chem Soc, 3722

Troe, J. 1983, Berich Bunsen Gesell, 87, 161

Troe, J. 2005, JCPA, 109, 8320

Tsang, W. 1987, JPCRD, 16, 471

Tsang, W. 1992, JPCRD, 21, 753

Tsang, W. 2004, Int. J. Chem. Kin., 36, 456

Tsang, W., \& Hampson, R. 1986, JPCRD, 15, 1087

Tsang, W., \& Herron, J. T. 1991, JPCRD, 20, 609

Tsuboi, T., \& Hashimoto, K. 1981, CoFl, 42, 61

Tsuboi, T., Katoh, M., Kikuchi, S., \& Hashimoto, K. 1981, JaJAP, 20, 985

Tu, L., Johnstone, C. P., Güdel, M., \& Lammer, H. 2015, arXiv:1504.04546

Tuazon, E. C., Carter, W. P., Atkinson, R., Winer, A. M., \& Pitts, J. N. 1984, EnST, 18, 49

Tzeng, S.-Y., Chen, P.-H., Wang, N. S., et al. 2009, JPCA, 113, 6314

Vaghjiani, G. L. 1995, Int. J. Chem. Kin., 27, 777

Vakhtin, A. B., Hard, D. E., Smith, I. W. M., \& Leone, S. R. 2001, CPL, 344 317

van Dishoeck, E. F. 1984, Dissertation

van Dishoeck, E. F. 1987, JChPh, 86, 196

Vandooren, J., Bian, J., \& Van Tiggelen, P. 1994, CoFl, 98, 402

Vandooren, J., \& Van Tiggelen, P. 1977, (Amsterdam: Elsevier), 1133-44

Vardanyan, I., Sachyan, G., Philiposyan, A., \& Nalbandyan, A. 1974, CoFl, 22,153

Velinov, P. I. Y., \& Mateev, L. N. 2008, JASTP, 70, 574

Venot, O., Hébrard, E., Agúndez, M., et al. 2012, A\&A, 546, A43

Verner, D., Ferland, G., Korista, K., \& Yakovlev, D. 1996, ApJ, 465, 487

Verner, D., \& Yakovlev, D. 1995, A\&AS, 109, 125

Verner, D., Yakovlev, D., Band, I., \& Trzhaskovskaya, M. 1993, ADNDT, 55, 233

Veyret, B., Rayez, J. C., \& Lesclaux, R. 1982, JPhCh, 86, 3424

Viggiano, A., Albritton, D., Fehsenfeld, F., et al. 1980, ApJ, 236, 492

Viggiano, A., \& Paulson, J. F. 1983, JChPh, 79, 2241

Vijayan, M. 1980, FEBS Lett, 112, 135

Villinger, H., Futrell, J., Howorka, F., Duric, N., \& Lindinger, W. 1982, JChPh, 76, 3529

Visscher, C., \& Moses, J. I. 2011, ApJ, 738, 72

Visscher, C., Moses, J. I., \& Saslow, S. A. 2010, Icar, 209, 602

Vogt, J., Williamson, A. D., \& Beauchamp, J. 1978, JAChS, 100, 3478

Vuitton, V., Yelle, R. V., Lavvas, P., \& Klippenstein, S. J. 2012, ApJ, 744, 11

Wagner, A. F., \& Bowman, J. M. 1987, JPhCh, 91, 5314

Wagner, H. G., Warnatz, J., \& Zetzsch, C. 1971, An Asoc Quim Argent, 59, 169

Wagner-Redeker, W., Kemper, P. R., Jarrold, M. F., \& Bowers, M. T. 1985, JChPh, 83, 1121

Waite, J. H., Young, D. T., Cravens, T. E., et al. 2007, Sci, 870 , 316.5826

Wakamatsu, H., \& Hidaka, Y. 2008, Int. J. Chem. Kin., 40, 320

Wakelam, V., Herbst, E., Loison, J.-C., et al. 2012, ApJS, 199, 21

Walker, T., \& Kelly, H. 1972, CPL, 16, 511

Wallington, T. J., \& Japar, S. M. 1989, JAtC, 9, 399

Walsh, C., \& Millar, T. J. 2011, in IAU Symp. 280 ed. J. Cernicharo, \& R. Bachiller, 56

Wang, C. Y., Zhang, S., \& Li, Q. S. 2002, Theor Chem Acc, 108, 341 
Wang, S., Cui, J.-P., He, Y.-Z., Fan, B.-C., \& Wang, J. 2001, ChPhL, 18, 289

Warnatz, J. 1984, Combustion Chemistry (Berlin: Springer)

Warneck, P. 1972, Berich Bunsen Gesell, 76, 421

Watanabe, K. 1954, JChPh, 22, 1564

Watanabe, K., \& Jursa, A. 1964, JChPh, 41, 1650

Watanabe, K., Matsunaga, F. M., \& Sakai, H. 1967, ApOpt, 6, 391

Watanabe, K., \& Sood, S. 1965, Sci Light, 14, 36

Watanabe, K., \& Zelikoff, M. 1953, JOSA, 43, 753

Weaver, J., Meagher, J., \& Heicklen, J. 1977, J Photochem, 6, 111

Westenberg, A. A., \& De Haas, N. 1969, JPhCh, 73, 1181

Whyte, A., \& Phillips, L. 1983, CPL, 98, 590

Wight, C. A., \& Beauchamp, J. 1980, JPhCh, 84, 2503

Wijnen, M. 1960, JAChS, 82, 3034

Williamson, A. D., \& Beauchamp, J. 1975, JAChS, 97, 5714

Williamson, D. G., \& Bayes, K. D. 1967, JAChS, 89, 3390

Wilson, W. E. 1972, JPCRD, 1, 535

Woods, I., \& Haynes, B. 1994, in Int. Symp. on Combustion, Vol. 25 (Amsterdam: Elsevier), 909

Wooldridge, M. S., Hanson, R. K., \& Bowman, C. T. 1996, Int. J. Chem. Kin., 28,361

Wu, C., Wang, H., Lin, M., \& Fifer, R. 1990, JPhCh, 94, 3344

Wu, C.-W., Lee, Y.-P., Xu, S., \& Lin, M. 2007, JPCA, 111, 6693

Wu, J.-Y., Liu, J.-Y., Li, Z.-S., \& Sun, C.-c. 2003, JChPh, 118, 10986

Xu, S., \& Lin, M. 2007, JCPA, 111, 6730

Xu, Z.-F., \& Lin, M. 2004, Int. J. Chem. Kin., 36, 205

Xu, Z.-F., \& Sun, C.-C. 1999, JMoSt, 459, 37

Xu, Z.-F., \& Sun, J.-Z. 1998, JCPA, 102, 1194

Yang, J., Li, Q. S., \& Zhang, S. 2008, JCoCh, 29, 247

Yang, X., Goldsmith, C. F., \& Tranter, R. S. 2009, JPCA, 113, 8307

Yang, Y., Zhang, W., Pei, S., et al. 2005, JMoSt, 725, 133

Yasunaga, K., Kubo, S., Hoshikawa, H., Kamesawa, T., \& Hidaka, Y. 2008, Int. J. Chem. Kin., 40, 73

Yee Quee, M., \& Thynne, J. 1968, Berich Bunsen Gesell, 72, 211

Yelle, R. V., Griffith, C. A., \& Young, L. A. 2001, Icar, 152, 331
Yelle, R. V., Young, L. A., Vervack, R. J., et al. 1996, JGR, 101, 2149

You, X., Wang, H., Goos, E., Sung, C.-J., \& Klippenstein, S. J. 2007, JCPA, 111,4031

Young, J. 1958, J Chem Soc, 2909

Young, L. B., Lee-Ruff, E., \& Bohme, D. 1971, CaJCh, 49, 979

Yumura, M., \& Asaba, T. 1981, in Int. Symp. on Combustion, Vol. 18 (Amsterdam: Elsevier), 863

Yung, Y. L., Allen, M., \& Pinto, J. P. 1984, ApJS, 55, 465

Yung, Y. L., \& Demore, W. B. (ed.) 1999, Photochemistry of Planetary Atmospheres (New York: OUP), 9

Zabarnick, S., \& Heicklen, J. 1985, Int. J. Chem. Kin., 17, 455

Zahnle, K. 1986, JGRD, 91, 2819

Zahnle, K., Claire, M., \& Catling, D. 2006, Geobiology, 4, 271

Zahnle, K., Mac Low, M.-M., Lodders, K., \& Fegley, B. 1995, GeoRL, 22, 1593

Zahnle, K., Marley, M. S., Freedman, R. S., Lodders, K., \& Fortney, J. J. 2009, ApJL, 701, L20

Zalotai, L., Hunyadi-zoltán, Z., Bérces, T., \& Marta, F. 1983, Int J Chem Kin, 15,505

Zarka, P., \& Pedersen, B. M. 1986, Natur, 323, 605

Zaslonko, I., Petrov, Y. P., \& Smirnov, V. 1997, Kinetics and Catalysis, 38, 321

Zaslonko, I., Smirnov, V., \& Tereza, A. 1993, Kin Catal, 34, 531

Zel'dovich, Y. B., \& Raizer, Y. P. 1996, Physics of Shock Waves and High Temperature Hydrodynamic Phenomena (New York, NY: Academic)

Zelikoff, M., Watanabe, K., \& Inn, E. C. 1953, JChPh, 21, 1643

Zhang, Y.-X., \& Bauer, S. 1997, JPCB, 101, 8717

Zhang, Y.-X., Zhang, S., \& Li, Q. S. 2004, CP, 296, 79

Zhang, Y.-X., Zhang, S., \& Li, Q. S. 2005, CP, 308, 109

Zhu, R., \& Lin, M. 2003, JChPh, 119, 10667

Zhu, R., \& Lin, M. 2007, JCPA, 111, 6766

Zhu, R., \& Lin, M. 2009, CPL, 478, 11

Zhu, R., \& Lin, M.-C. 2005, Int. J. Chem. Kin., 37, 593

Zielinska, T. J., \& Wincel, H. 1970, Nukleonika, 15, 343

Zsom, A., Kaltenegger, L., \& Goldblatt, C. 2012, Icar, 221, 603 